\title{
Communication between mycorrhizal fungi and poplar
}

\author{
Dissertation \\ zur Erlangung des mathematisch-naturwissenschaftlichen Doktorgrades \\ "Doctor rerum naturalium" \\ der Georg-August-Universität Göttingen \\ im Promotionsprogramm "Molekulare Grundlagen und Biotechnologie von \\ Nutzpflanzen (BIONUTZ)" \\ der Georg-August-University School of Science (GAUSS) \\ vorgelegt von
Anna Müller
aus Frankfurt/Oder
}

Göttingen, 2014 


\section{Betreuungsausschuss}

Prof. Dr. Andrea Polle, Abteilung Forstbotanik und Baumphysiologie, Universität Göttingen

Prof. Dr. Jörg-Peter Schnitzler, Abteilung Experimentelle Umweltsituation, Helmholtz Zentrum München

Prof. Dr. Reiner Finkeldey, Abteilung Forstgenetik und Forstpflanzenzüchtung, Universität Göttingen

\section{Mitglieder der Prüfungskommission}

Referentin: Prof. Dr. Andrea Polle, Abteilung Forstbotanik und Baumphysiologie, Universität Göttingen

Koreferent: Prof. Dr. Jörg-Peter Schnitzler, Abteilung Experimentelle Umweltsituation, Helmholtz Zentrum München

2. Koreferent: Prof. Dr. Reiner Finkeldey, Abteilung Forstgenetik und Forstpflanzenzüchtung, Universität Göttingen

Weitere Mitglieder der Prüfungskommission:

Prof. Dr. Ivo Feußner, Abteilung Biochemie der Pflanze, Universität Göttingen

PD Dr. Thomas Teichmann, Abteilung Zellbiologie der Pflanze, Universität Göttingen

Prof. Dr. Petr Karlovsky, Abteilung Molekulare Phytopathologie und Mykotoxinforschung, Universität Göttingen

Tag der mündlichen Prüfung: 30.01.2015 


\section{Table of contents}

Summary

Zusammenfassung ………………………………………………………………... VIII

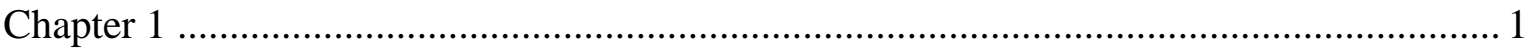

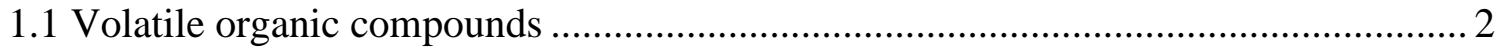

1.2 Role of volatiles in aboveground and belowground communications ......................... 4

1.3 Communication of ectomycorrhizal fungi with plants .......................................... 6

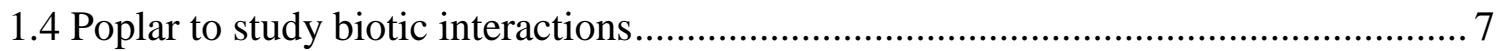

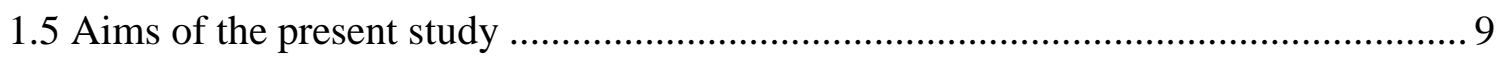

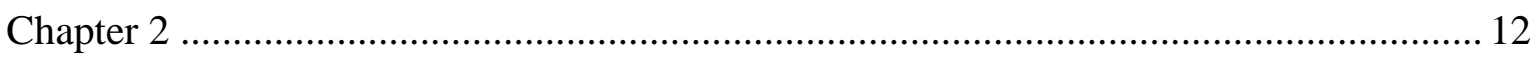

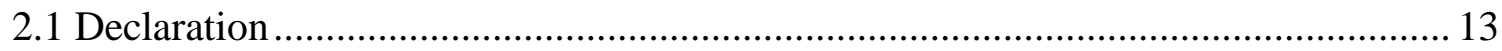

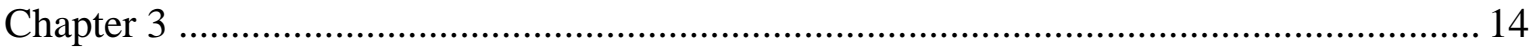

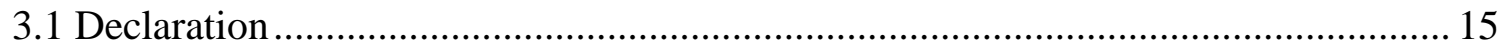

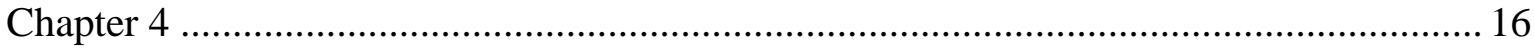

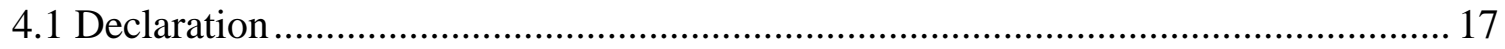

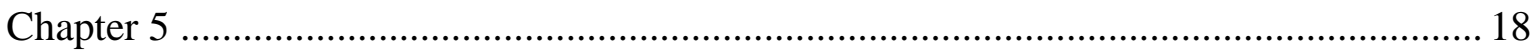

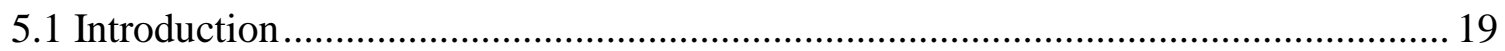

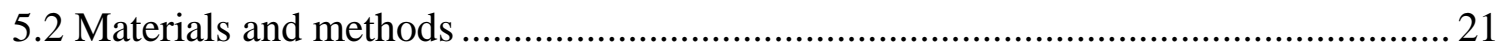

5.2.1 Plant and insect material ............................................................. 21

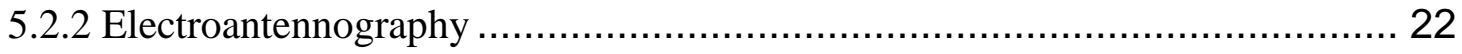

5.2.3 Volatile collection and analysis by gas chromatography-mass spectrometry (GC-

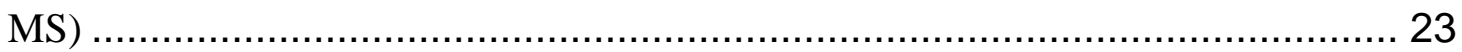

5.2 .3 Olfactometer Bioassays............................................................ 24

5.2.4 C. populi bioassays under greenhouse conditions ............................... 24

5.2.5 C. populi bioassays under close-to-natural conditions............................. 25

5.2.6 Non-targeted metabolome analysis by FT-ICR/MS .............................. 26

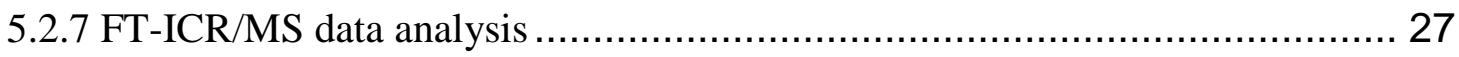

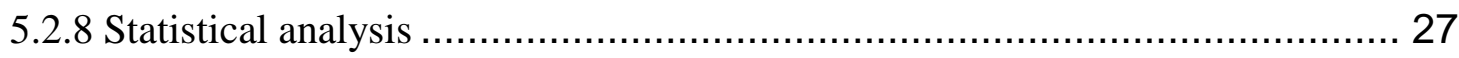

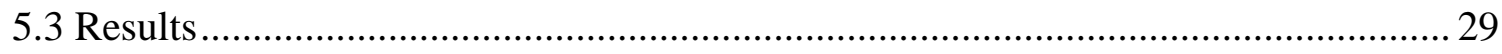

5.3.1 C. populi and $P$. vitellinae detected higher isoprenoids but not isoprene ......... 29 
5.3.2 BVOC emission profiles differed between infested and non-infested IE and NE poplars

5.3.3 C. populi larvae and adults showed no clear preference for NE or IE poplar leaves in Y-tube olfactometer or greenhouse bioassays.....

5.3.4 C. populi preferred to feed on IE in close-to-natural conditions 36

5.3.5 Metabolome-wide changes depended on leaf development, herbivory and isoprene emission capacity

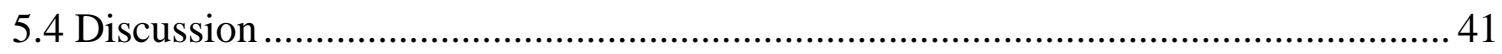

5.4.1 Isoprene does not act as an attractant for C. populi or P. vitellinae ................ 41

5.4.2 C. populi shows a slight preference to isoprene emitting plants

5.4.3 Leaf age, genotype and treatment dependent differences in IE and NE poplar metabolomics under outdoor conditions ................................................ 42

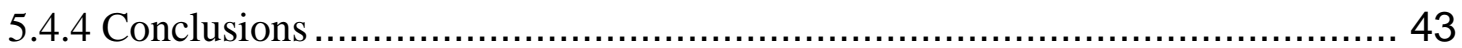

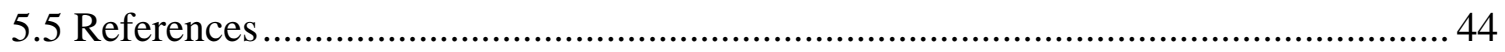

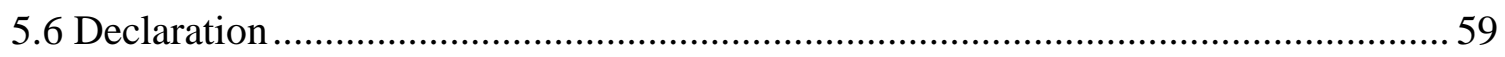

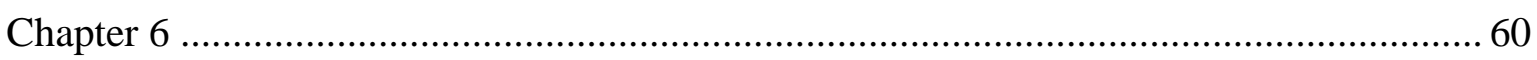

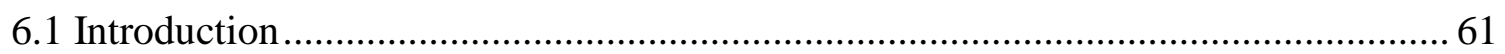

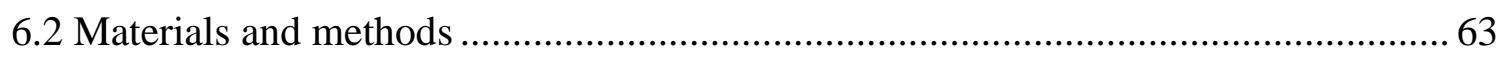

6.2.1 Plant material and inoculation of poplar with the mycorrhizal fungus Laccaria

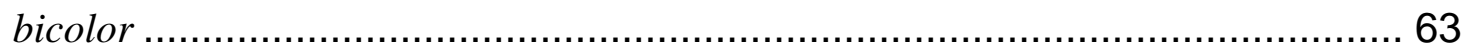

6.2.2 Exposition of poplar to $C$. populi beetles...................................... 64

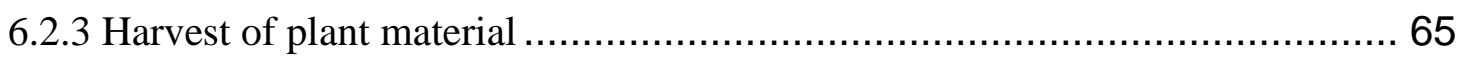

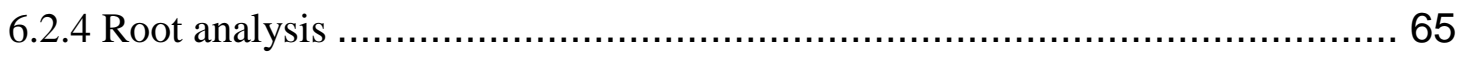

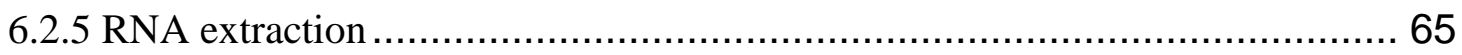

6.2.6 RNA sequencing and bioinformatical analysis................................... 66

6.2.7 Statistical analysis of behavioural, biomass and growth data .................... 67

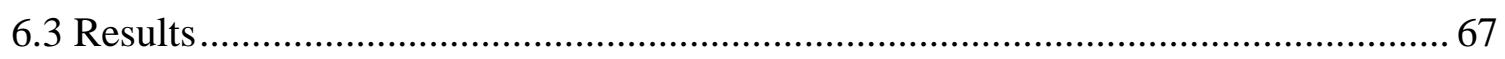

6.3.1 Effect of EMF inoculation on feeding and egg deposition of C. populi .......... 67

6.3.2 Plant performance after EMF inoculation and beetle infestation ..................68 68

6.3.3 Effect of EMF inoculation and beetle infestation on molecular changes at the

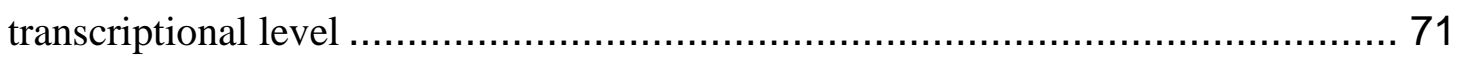

6.3.4 Co-expression network analysis .............................................. 74

6.3.5 Hormone signalling pathways, flavonoid biosynthesis pathways and aldoxime biosynthesis in response to EMF inoculation and beetle infestation ...................... 77

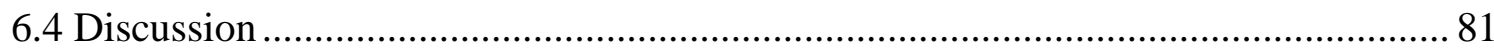


6.4.1 C. populi beetles prefer non-inoculated over inoculated poplars

6.4.2 C. populi beetles induce strong defence reactions in inoculated and noninoculated poplars

6.4.3 EMF inoculated poplars differ from non-inoculated poplars in hormone signalling pathway, flavonoid biosynthesis pathway and aldoxime biosynthesis ...... 82

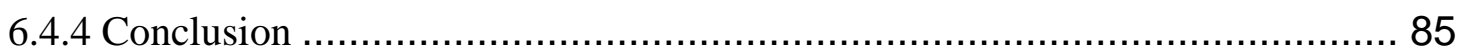

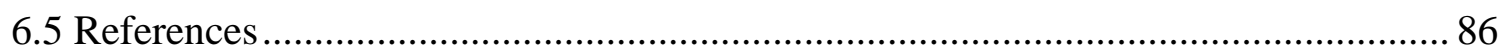

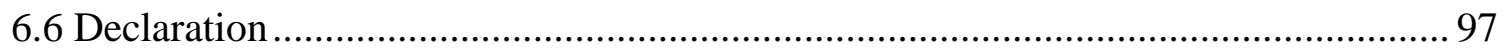

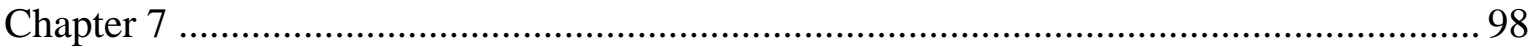

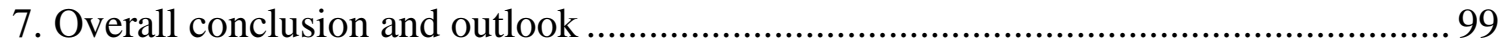

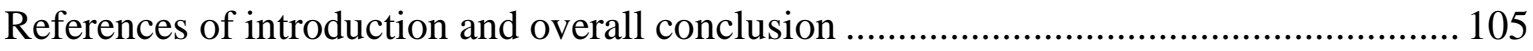

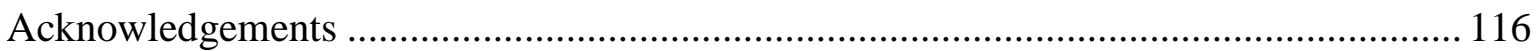

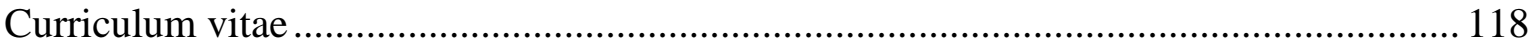




\section{Summary}

Volatile organic compounds (VOCs) have multiple functions in the atmosphere and biosphere. VOCs are involved in above- and belowground biotic interactions. For example, VOCs released by microbes have the potential to influence plant growth and VOCs released by plants modify the performance of pathogens and herbivores. Very little is known on the role of VOCs in the communication of ectomycorrhizal fungi (EMF) with their host. EMF form symbiosis with tree species such as poplars (Populus spp.). Poplars are of high economic value as a resource for biomass, but they release high concentrations of isoprene, a climate-relevant VOC, into the atmosphere. The function of isoprene in biotic interactions of poplars with EMF or herbivores is unclear. Furthermore, it is important to understand how EMF inoculation affects the metabolism of poplars and thereby, their aboveground interactions.

The main aim of this work was to analyse the communication of plants with fungi by VOCs. Towards this goal, Laccaria bicolor and Populus $\times$ canescens were employed as the model species. To investigate the specificity of VOC patterns and plant responses, a number of other EMF and non-mycorrhizal forming fungi were tested and the non-host plant Arabidopsis thaliana was used. To study the significance of isoprene or EMF on aboveground herbivory, the preference of poplar and willow beetles (Chrysomela populi, Phrotara vitellinae) for non-isoprene emitting poplars or non-inoculated poplars were tested. In particular, the following questions were addressed: i) Can EMF and fungi of other lifestyles be distinguished by their VOC emission patterns? ii) Are fungal VOCs involved in the recognition of EMF by poplar and Arabidopsis and if so, which compounds in the volatile blend are involved in the response? iii) Is the isoprene emission of poplars important for the attraction of leaf feeding herbivores? iv) Does the inoculation of poplars with the EMF L. bicolor affect the defence against the poplar leaf beetles $C$. populi and if so, which transcriptional changes in leaves of EMF inoculated compared with noninoculated plants are involved in this response?

Studies on mycorrhizal interactions with poplar require controlled cultivation systems. Therefore, detailed protocols for growth of poplars species with or without EMF under axenic or field conditions were described. To elucidate the interaction between poplar and EMF, bi-compartmented growth systems for the cultivation of plants without direct contact to EMF with low background VOC emission were established.

i) To investigate the specificity and similarities of VOCs from EMF and other, nonmycorrhizal forming fungi, VOC patterns of different fungal lifestyles were compared. In 
the present study the VOC emissions of three EMF species Cenococcum geophilum, L. bicolor and Paxillus involutus (strains MAJ and NAU), three fungal pathogens Armillaria mellea, Pholiota squarrosa and Verticillium longisporum and two saprophytes Stropharia rugosoannulata and Trichoderma viride were collected in the headspace of fungal cultures. The fungi were grown in Petri dishes on a synthetic medium with a low background VOC profile. All VOCs measured in control plates without fungi were excluded from the dataset. After removal of forty compounds that were present in the control plates, fifty-four fungal VOCs were identified. The fungi differed strongly in their VOC profiles. Only fifteen VOCs were common to all lifestyles, among them the typical fungal compound 1octen-3-ol. Fifteen VOCs had not been identified in the VOC profiles of fungi before and some VOCs were unique to a lifestyle or species. Particularly, the emission of sesquiterpenes (SQTs) differed strongly between the species. Multivariate analysis of the VOC profiles clustered the fungal species according to their lifestyle.

ii) To find out whether fungal VOCs are important signalling compounds for plants independent of their ability to form mycorrhizas or not, the host plant $P$. $x$ canescens and the non-host A. thaliana were exposed to VOCs of the EMF L. bicolor and C. geophilum. Plants and fungi were grown in closed systems in two separate compartments with a common headspace. Collection of the VOC emissions in the control cultures with the plants revealed that Arabidopsis emitted only few VOCs whereas in the culture of $L$. bicolor as well as in the co-culture of both fungus and plant mainly SQTs were detected. Lateral root development of Arabidopsis and poplar was promoted by L. bicolor VOCs. $C$. geophilium, which is not able to produce SQTs, did not affect the root architecture by its VOC emission. Suppression of the SQT synthesis in L. bicolor by inhibition of the mevalonate pathway with lovastatin significantly reduced lateral root stimulation. These results suggested that SQTs triggered lateral root formation. We identified the low abundant thujopsen to be able to stimulate lateral root formation in the absence of the fungus or when the fungal SQT biosynthesis was blocked by lovastatin. The sesquiterpene $\beta$-caryophyllene had no influence on the root architecture. This work demonstrated that fungal SQTs, among them the specific compound thujopsen, are important signalling compounds in interaction of EMF with host and non-host plants.

iii) The herbivorous beetles $C$. populi and $P$. vitellinae are commonly found in poplar plantations and can cause significant economic loss. To find out whether isoprene from poplar leaves is detected by $C$. populi and $P$. vitellinae beetles and plays a role in the orientation of the beetles, feeding experiments with the beetles and isoprene-emitting and 
transgenic non-emitting poplar lines were conducted. In greenhouse experiments as well as in olfactometer tests in the laboratory, the beetles and larvae showed no preference for isoprene-emitting or non-emitting poplar lines. Unexpectedly, under outdoor conditions $C$. populi preferred to feed and oviposit on isoprene-emitting over non-isoprene emitting lines. Metabolomic analysis demonstrated alterations in the leaves that were dependent on the poplar line and effects on the terpene patterns. The beetles were able to detect various terpenes, but unable to detect isoprene. Therefore, small changes in the VOC emission in the transgenic non-isoprene emitting poplar lines due to the repression of the isoprene production and/or the resulting changes in the metabolomic profiles may have altered the beetle preference. This finding shows that although the main target - isoprene - did not influence the behaviour of the beetles, subsequent consequences of this modification, affected the performance of the beetles on the poplars. However, the magnitude of this effect was small.

iv) Under natural conditions poplars interact with below- or aboveground organisms at the same time. To investigate whether EMF inoculation of poplars induces molecular changes in leaves and whether these changes have consequences for the performance of leaf beetles, $C$. populi beetles were given the choice between $P . \times$ canescens that were inoculated or non-inoculated with L. bicolor. C. populi preferred non-inoculated over inoculated poplars with regard to feeding and oviposition. RNA-sequencing of the leaf transcriptome indicated that the infestation by $C$. populi beetles induced a strong defence response in poplars. EMF inoculation also affected the leaf transcriptome, but of only few genes. Compared to non-inoculated poplars, the EMF inoculated poplars displayed decreased transcript levels of genes in the ABA signalling pathway and the flavonoid biosynthesis and increased transcript levels in the biosynthesis genes for aldoximes, which have recently been identified as defence compounds. These results suggest that EMF activate defences from herbivores and therefore, improve the natural protection of poplars. However, in young poplars EMF also caused a significant growth trade-off.

In conclusion, the results of this thesis show that EMF VOC profiles differed from those of other fungal lifestyles and that a distinct chemical group, the SQTs, acted as signal molecules in the early interaction with plants. For the first time, a fungal VOC responsible for the induction of lateral root formation in plants, thujopsene, was identified. It was shown that isoprene, the main poplar VOC, has a minor role in aboveground interactions with the herbivore $C$. populi. EMF led to transcript changes in poplar leaves and reduced the attractiveness of the poplars for $C$. populi beetles. The results of this thesis can be used 
for biotechnological improvement of poplars and enhanced protection of poplars in biomass plantations. 


\section{Zusammenfassung}

Flüchtige organische Verbindungen (volatile organic compounds, VOCs) haben vielseitige Funktionen in der Biosphäre und Atmosphäre. VOCs sind an ober- und unterirdischen Interaktionen beteiligt. Zum Beispiel können von Mikroorganismen emittierte VOCs das Pflanzenwachstum beeinflussen und von Pflanzen emittierte VOCs sich auf das Verhalten von Pathogenen und Herbivoren auswirken. Nur wenig ist über die Rolle von VOCs in der Kommunikation von Ektomykorrhizapilzen (EMF) mit ihren Wirtspflanzen bekannt. EMF gehen Symbiosen mit Baumarten wie Pappeln (Populus spp.) ein. Pappeln sind als Biomasseproduzenten von großer ökonomischer Bedeutung, emittieren jedoch eine hohe Konzentration des klima-relevanten VOCs Isopren in die Atmosphäre. Die Rolle von Isopren in biotischen Interaktionen von Pappeln mit Herbivoren ist unklar. Zudem ist es wichtig zu verstehen wie EMF-Inokulation den Metabolismus von Pappeln und dadurch deren oberirdische Interaktion beeinflussen.

Hauptziel dieser Arbeit war es, die Kommunikation durch VOCs zwischen Pflanzen und Pilzen zu untersuchen. $\mathrm{Zu}$ diesem Zweck wurden die Modellarten Laccaria bicolor und Populus $\times$ canescens verwendet. Um die Spezifität von VOC-Mustern sowie PflanzenReaktionen zu untersuchen, wurden einige andere EMF und nicht-Mykorrhiza bildende Pilze getestet sowie die Nicht-Wirtspflanze Arabidopsis verwendet. Um die Bedeutung von Isopren oder EMF auf oberirdische Herbivorie zu untersuchen, wurde die Präferenz des Pappelblattkäfers (Chrysomela populi) und des Weidenblattkäfers (Phrotara vitellinae) für nicht-Isopren emittierende Pappeln überprüft. Insbesondere wurden folgende Fragestellungen untersucht: i) Können EMF und Pilze anderer Lebensweisen aufgrund ihrer VOC-Emissions-Muster voneinander unterschieden werden? ii) Sind pilzliche VOCs an der Erkennung von EMF durch Pappel und Arabidopsis beteiligt und wenn dies zutrifft, welche Verbindungen der Volatilen-Mischung sind an der Reaktion beteiligt? iii) Ist die Isopren-Emission von Pappeln für die Orientierung von Pappelblattkäfern von Bedeutung? iv) Beeinflusst eine Inokulation von Pappeln mit EMF die Abwehr gegen den Pappelblattkäfer C. populi und wenn, welche Transkriptionsveränderungen in den Blättern von EMF-inokulierten im Vergleich zu nicht-inokulierten Pflanzen sind an dieser Reaktion beteiligt?

Untersuchungen über Mykorrhiza-Interaktion mit Pappeln erfordern kontrollierte

Kultivierungs-Systeme. Daher werden detaillierte Protokolle für die Anzucht von Pappelarten mit und ohne EMF unter axenischen und Freiland-Bedingungen angegeben. 
Zur Untersuchung der Interaktion zwischen Pappeln und EMF werden zwei-geteilte Wachstumssysteme für die Kultivierung der Pflanzen ohne direkten Kontakt zu EMF beschrieben.

i) Um die Spezifität und Gemeinsamkeiten von VOCs von EMF und anderen, nichtMykorrhiza bildenden Pilzen zu untersuchen, wurden VOC-Muster von Pilzen verschiedener Lebenssweisen verglichen. In der vorliegenden Arbeit wurden die VOCEmissionen der drei EMF Cenococcum geophilum, L. bicolor und Paxillus involutus (Stämme MAJ und NAU), der drei Pathogene Armillaria mellea, Pholiota squarrosa und Verticillium longisporum sowie der zwei Saprophyten Stropharia rugosoannulata und Trichoderma viride im Gasraum der Kulturen gesammelt. Die Pilze wurden in Petrischalen auf einem synthetischen Medium, welches eine geringe eigene VOC-Emission aufwies, angezogen. Alle VOCs, welche in Kontrollschalen ohne Pilz gemessen wurden, wurden aus dem Datensatz entfernt. Nach Entfernung dieser 40 Hintergrund-VOCs der Kontrollplatten verblieben 54 Pilz-VOCs. Die untersuchten Pilze unterschieden sich stark in ihrem VOC-Emissions-Profil. Nur 15 VOCs wurden bei allen Lebensweisen identifiziert; darunter die typische Pilz-VOC 1-octen-3-ol. Fünfzehn VOCs wurden zuvor noch nicht bei Pilzen gemessen und einige VOCs wurden nur bei einem Pilz oder einer Lebensweise gefunden. Insbesondere die Emission der Sesquiterpene (SQTs) unterschied sich stark zwischen den Pilzen. Multivariate Analysen der VOC-Profile gruppierte die Pilzarten nach ihren Lebensweisen.

ii) Zur Ermittlung, ob Pilz-VOCs wichtige Signalstoffe für Pflanzen sind, unabhängig von ihrer Fähigkeit eine Mykorrhiza bilden zu können, wurden die Wirtspflanze P. $\times$ canescens und die Nicht-Wirtspflanze A. thaliana VOCs der EMF L. bicolor und C. geophilum ausgesetzt. Pflanzen und Pilze wurden in einem geschlossenen System mit zwei separaten Kompartimenten und gemeinsamem Gasraum kultiviert. Sammeln der PilzVOC-Emissionen in den Kontrollplatten mit den Pflanzen zeigte, dass Arabidopsis nur wenige VOCs emittierte, wohingegen sowohl in den Kulturen von L. bicolor als auch in der gemeinsamen Kultur von L. bicolor mit Pflanzen vor allem SQTs detektiert wurden. Die Seitenwurzelbildung von Arabidopsis und Pappel wurde durch L. bicolor-VOCs angeregt. C. geophilum, welcher nicht fähig ist SQTs zu bilden, hatte keine Wirkung auf die Wurzelstruktur. Unterdrückung der SQT-Synthese in L. bicolor durch Inhibierung des Mevalonat-Biosyntheseweges mit Lovastatin verminderte die Stimulierung der Seitenwurzelbildung signifikant. Diese Ergebnisse deuten darauf hin, dass pilzliche SQTs Seitenwurzelbildung auslösen. Das schwach emittierte Thujopsen stimulierte die 
Seitenwurzelbildung sowohl in Abwesenheit des Pilzes als auch bei einer Unterdrückung der SQT-Biosynthese des Pilzes durch Lovastatin. Das SQT $\beta$-Caryophyllene hatte keinen Einfluss auf die Wurzelstruktur. Diese Arbeit zeigt, dass pilzliche SQTs, darunter das spezifische Thujopsen, wichtige Signalstoffe in der Interaktion zwischen EMF und Wirtssowie Nicht-Wirtspflanzen darstellen.

iii) Die Käfer $C$. populi und $P$. vitellinae sind typisch vorkommende Schädlinge in Pappelplantagen und können signifikante ökonomische Verluste verursachen. Zur Ermittlung, ob von Pappelblättern emittiertes Isopren von $C$. populi und $P$. vitellinae Käfern wahrgenommen wird und eine Rolle bei der Orientierung dieser Käfer spielt, wurden verschiedene Fraßversuche mit den Käfern und Isopren-emittierenden und transgenen nicht-Isopren-emittierenden Pappeln durchgeführt. Sowohl in Gewächshausals auch in Laborversuchen zeigten weder die Larven noch die Käfer eine Präferenz für Isopren-emittierende oder nicht-emittierende Linien. Unerwarteter Weise wurden eine verstärkte Eiablage und ein höherer Fraßschaden auf Isopren-emittierenden gegenüber nicht-emittierenden Linien unter Freilandbedingungen festgestellt. Metabolomanalysen wiesen auf Veränderungen in den Blättern, welche von der Pappellinie abhängig waren, und auf Effekte auf Terpen-Muster hin. Die Käfer waren in der Lage verschiedene Terpene wahrzunehmen, waren aber nicht in der Lage Isopren wahrzunehmen. Daher könnten kleine Veränderungen der VOC-Emission in den transgenen nicht-Isopren emittierenden Pappellinien durch Unterdrückung der Isopren-Produktion und/oder ausgelöste Veränderungen im Metabolom-Profil die Käfer-Präferenz verändert haben. Obwohl das Hauptziel der Untersuchung - Isopren - keinen Einfluss auf das Käferverhalten hatte, wurde das Käferverhalten auf den Pappeln durch Konsequenzen der Modifikation beeinflusst. Das Ausmaß dieses Effektes war jedoch marginal.

iv) Unter natürlichen Bedingungen interagieren Pappeln zeitgleich mit unterirdischen und oberirdischen Organismen. Zur Untersuchung, ob eine Inokulation von Pappeln mit EMF in den Blättern molekulare Veränderungen hervorruft und ob diese Veränderungen das Verhalten von Pappelblattkäfern beeinflussen, hatten C. populi-Käfer die Wahl zwischen Pappeln, welche mit L. bicolor inokuliert waren, und solchen, die nicht inokuliert waren. C. populi präferierten die Nicht-inokulierten sowohl als Nahrung als auch zur Eiablage. RNA-Sequenzierung des Blatttranskriptoms deutete an, dass der Käferbefall eine starke Abwehrreaktion in den Pflanzen auslöste. Auch die EMF-Inokulation beeinflusste das Blatt-Transkriptom, jedoch nur von wenigen Genen. Im Vergleich zu den nichtinokulierten Pappeln wiesen die inokulierten Pappeln verringerte Transkript-Abundanzen 
von Genen des Abscisinsäure-Signalweges und der Flavonoid-Biosynthese sowie erhöhte Transkript-Abundanzen der Biosynthesegene von Aldoximen auf, welche kürzlich als Abwehrstoffe identifiziert wurden. Diese Ergebnisse lassen vermuten, dass EMF die Abwehr gegen Herbivore aktivieren und dadurch den natürlichen Schutz von Pappeln verbessern. In jungen Pappeln verursachen EMF jedoch auch ein signifikant geringeres Wachstum.

Zusammenfassend zeigen die Ergebnisse dieser Dissertation, dass EMF-VOC-Profile sich von jenen anderer Pilze oder anderer Lebensweisen unterscheiden und dass eine bestimmte chemische Gruppe, die SQTs, als Signalmoleküle in frühen Interaktionen mit Pflanzen fungieren. Zum ersten Mal konnte eine Pilz-VOCs, Thujopsen, identifiziert werden, welche für die Stimulierung der Seitenwurzelbildung in Pflanzen verantwortlich ist. Es wurde gezeigt, dass die Haupt-Pappel-VOC Isopren nur eine geringe Rolle in oberirdischen Interaktionen mit dem Herbivoren $C$. populi spielt. EMF führten zu Transkriptveränderungen in Pappelblättern und einer reduzierten Attraktivität für C. populi Käfer. Die Ergebnisse dieser Dissertation können für biotechnologische Verbesserungen von Pappeln und verstärkten Schutz von Pappeln in Biomasseplantagen verwendet werden. 
Chapter 1

Introduction 


\section{Introduction}

\subsection{Volatile organic compounds}

Plants release up to one-fifth of the assimilated carbon as a complex mixture of volatile organic compounds (VOCs) (Kesselmeier et al., 2002). VOCs are transported by diffusion through the air and soil, where they have multiple functions in the atmosphere and biosphere (Aochi and Farmer, 2005; Wenke et al., 2010). For example, increased VOC emissions by forests can lead to aerosol formation in the atmosphere that affects the climate (Kulmala et al., 2004). VOCs induce thermotolerance of photosynthesis in plants such as reed (Phragmites australis L.) (Velikova and Loreto, 2005) or Grey poplar (Populus $\times$ canescens) (Behnke et al., 2007) and are involved in plant reproduction as shown for bumblebee (Bombus vosnesenskii) pollinators that were attracted to monkeyflowers (Mimulus lewisii) (Byers et al., 2014). Studies demonstrated an involvement of VOCs in interplant communication such as between sagebrush (Artemisia tridentata) and leaves of nearby tomato (Lycopersicom esculentum) plants (Farmer and Ryan, 1990). Furthermore, VOCs are important for plant defence. For example oviposition of the lepidopteran caterpillars (Manduca quinquemaculat) was decreased by the VOC emission of Coyote tobacco plants (Nicotiana attenuata Torr. ex Wats) (Kessler and Baldwin, 2001).

With more than 30,000 known members, the isoprenoids such as isoprene, monoterpenes and sesquiterpenes are the most prominent group of VOCs (Sacchettini and Poulter, 1997). The precursor of all isoprenoids is the $\mathrm{C}_{5}$-compound isopentenyl diphosphate (IPP), which can be synthesised by the mevalonate (MVA) pathway (Agranoff et al., 1960) and the methylerythritol 4-phosphate (MEP) pathway (Agranoff et al., 1960; Rohmer et al., 1993) (Fig. 1.1). Condensation of IPP and the isomer dimethylallyl pyrophosphate (DMAPP) results in the formation of the isoprenoid precursor units geranyl diphosphate (GPP, $\mathrm{C}_{10}$ ), farneysl diphosphate (FPP, $\mathrm{C}_{15}$ ) and geranyl geranyl diphosphate (GGPP, $\mathrm{C}_{20}$ ). Terpene synthases convert these precursors into isoprene $\left(C_{5}\right)$, monoterpenes $\left(C_{10}\right)$, sesquiterpenes $\left(\mathrm{C}_{15}\right)$ and higher isoprenoids $\left(\mathrm{C}_{20}\right.$, etc. $)$ (Bohlmann et al., 1998).

Fungi, animals and certain bacteria produce isoprenoids exclusively by the MVA pathway (Altincicek et al., 2001; Scalcinati et al., 2012). In plants, sesquiterpenes are generally synthesised via the MVA pathway in the cytosol (Soler et al., 1992; Kesselmeier and Staudt, 1999) whereas isoprene, monoterpenes and higher isoprenoids are synthesized via the MEP pathway in the plastids (Soler et al., 1992). In choloroplasts of wild tomato plants 
(Solanum habrochaites) sesquiterpene synthases were identified which use IPP and DMAPP of the MVA pathway for the biosynthesis of sesquiterpenes (Sallaud et al., 2009).

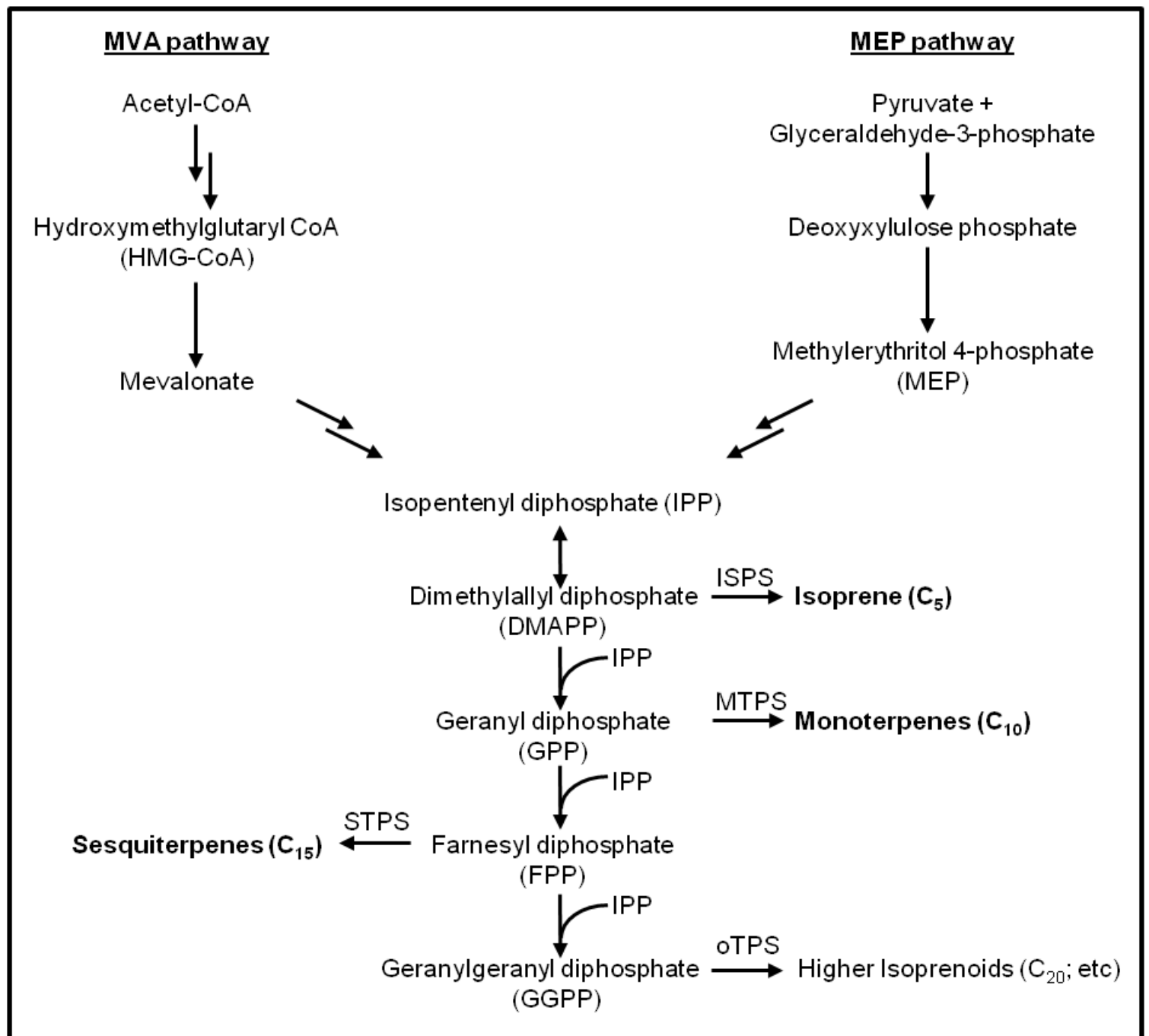

Fig. 1.1 Overview on the mevalonate (MVA) and methylerythritol 4-phosphate (MEP) pathways of terpene biosynthesis (after Phillips and Croteau, 1999; Rodriguez-Concepcion, 2004). In plants, the MVA pathway takes place in the cytosol and the MEP pathway in the plastids. Steps that are common in both pathways are catalysed by separate phenyltransferases in the different compartments. Fungi produce isoprenoids via the MVA pathway. Condensation of isopentenyl diphosphate (IPP) and dimethylallyl diphosphate (DMAPP) results in the formation of the terpene precursors geranyl diphosphate (GPP), farnesyl diphosphate (FPP) and geranylgeranyl diphosphate (GGPP). The formation of terpenes which differ in the number of carbon (C) atoms is catalysed by isoprene synthases (ISPS), monoterpene synthases (MTPS), sesquiterpene synthases (STPS) and other terpene synthases for higher isoprenoids (oTPS).

Terpene synthases catalyse the formation of a high diversity of terpenes. For example, the multiple product $\gamma$-humulene synthase in Grand fir (Abies grandes) synthesizes 52 sesquiterpenes (Steele et al., 1998). Numerous subsequent modification steps lead to the 
diverse structures of terpenes (Sacchettini, 1997; Davis and Croteau, 2000; Agger et al., 2009). The biological functions of VOCs are currently studied in various research areas.

\subsection{Role of volatiles in aboveground and belowground communications}

The VOC emission of plants is influenced by multiple abiotic factors such as temperature, water availability, nutrition and light intensity (Gouinguene and Turlings, 2002; Loivamaki et al., 2007; Vickers et al., 2009). For example, corn plants (Zea mays) release higher VOC concentrations in dry than in wet soil and at temperatures between $22^{\circ} \mathrm{C}$ and $27^{\circ} \mathrm{C}$ than under lower or higher temperatures (Gouinguene and Turlings, 2002). Isoprene emission of Grey poplars (Populus $\times$ canescens) is influenced by circadian rhythm and is regulated by elements in the region of the isoprene synthase promotor (Loivamaki et al., 2007). VOC emissions are also affected by interactions of plants with other organisms (Kessler and Baldwin, 2001; Kessler et al., 2006). In Silver birch (Betula pendula Roth) the isoprenoid emission was induced by Autumn moth (Epirrita autumnata) larvae feeding (Vuorinen et al., 2007). Monoterpene emission was enhanced in herbivore damaged Ponderosa pine (Pinus ponderosa) and Douglas fir (Pseudotsuga menziesii) (Litvak et al., 1999).

VOC emissions play important roles in the recognition, attraction and defence in inter- and intra-species interactions and enable aboveground as well as belowground communication between organisms. Pollinators such as European honeybees (Apis mellifera ligustica) (Farina et al., 2007) and hawkmoths (Manduca sexta) (Riffell et al., 2008) are able to recognise floral odours. In the last decades many studies focused on the attraction of pollinators to floral tissues (Raguso, 2004; Raguso, 2009; Wright and Schiestl, 2009; Kessler et al., 2011; Schiestl and Dötterl, 2012), but also herbivorous insects use VOC blends to localise their host plant. This behaviour was for example shown for Chrysomelidae larvae of Green tortoise beetles (Cassida denticollis) that find their host tansy (Tanacetum vulgare) based on the green leaf volatile (Z)-3-hexen-1-ol (Müller and Hilker, 2000). Both mono- and sesquiterpenes are known to be involved in the communication of plants with insects (Pichersky and Gershenzon, 2002; Degenhardt et al., 2003; Schnee et al., 2006). Feeding and oviposition by herbivores altered the VOC emission and induced the emission of novel VOCs in plants such as corn seedlings (Zea mays) damaged by beet armyworm larva (Spodoptera exigua) (Turlings and Tumlinson, 1992) and Barrel medic plants (Medicago truncatula) damaged by cotton leafworms (Spodoptera littoralis) (Leitner et al., 2009). In poplars (Populus trichocarpa $\times$ deltoides) 
the attack of forest tent caterpillars (Malacosoma disstria) enhanced the VOC emission of terpenoids (Arimura et al., 2004).

Plant VOCs induced by herbivore attack have important functions in indirect plant defence through the attraction of carnivorous insects that prey on the herbivores (Dicke and Loon, 2000; Kessler and Baldwin, 2002; Dicke et al., 2009). For example, the parasitic red-tailed wasp (Cardiochiles nigriceps) was attracted to tobacco (Nicotiana tabacum), cotton (Gossypium hirsutum) and maize (Zea mays) damaged by the tobacco budworm (Heliothis virescens) (De Moraes et al., 1998); spider-mite-(Tetranychus urticae)-infested lima beans (Phaseolus lunatus L. cv. Sieva) were more attractive for the parasitoid White butterfly (Cotesia glomerata) than uninfested plants (Mumm et al., 2008). Furthermore, the gregarious parasitoid (Glyptapanteles flavicoxis) showed a preference for Black poplar trees (Populus nigra) after herbivory by gypsy moth (Lymantria dispar) (Havill and Raffa, 2000; Mccormick et al., 2014).

Belowground, VOCs are released into the rhizosphere by roots (Chamberlain et al., 2001) and by soil-dwelling organisms like bacteria (Vespermann et al., 2007) and fungi (Splivallo et al., 2007a). Rasmann et al. (2005) demonstrated that maize roots emit the sesquiterpene $\beta$-caryophyllene in response to damage by larvae of the Western corn rootworm (Diabrotica virgifera virgifera) to attract entomopathogenic nematodes in the soil. The emission of the sesquiterpene $\beta$-caryophyllene by a Fusarium oxysporum strain with its bacterial consortium enhanced growth of lettuce plants (Minerdi et al., 2011). The saprophyte Trichoderma viride enhanced lateral root formation of Thale cress (Arabidopsis thaliana) when plant und fungus shared the same atmosphere in a growth chamber (Hung et al., 2013). Arabidopsis also showed enhanced root growth before root colonisation with the endophytic fungus Piriformospora indica (Peskan-Berghofer et al., 2004). More than 100 VOCs were detected in the VOC profiles of the ectomycorrhizal fungi (EMF) Tuber borchii, Tuber melanosporum and Tuber indicum (Splivallo et al., 2007a). VOC blends of these EMF inhibited root growth of Arabidopsis; the two VOCs 1-octen-3-ol and trans-2octenal emitted by the truffles induced an oxidative burst in Arabidopsis leaves (Splivallo et al., 2007b). The precise role of EMF VOCs in the communication with other organisms is still unclear. 


\subsection{Communication of ectomycorrhizal fungi with plants}

Symbiotic associations with mycorrhizal fungi are formed by more than $80 \%$ of all terrestrial plants (Smith and Read, 2008). There are different types of mycorrhizal associations: ectomycorrhiza (EM), arbuscular mycorrhiza (AM), ectendomycorrhiza, ericoid mycorrhiza, arbutoid mycorrhiza, monotropoid mycorrhiza and orchid mycorrhiza (Harley and Smith, 1983; Finlay, 2008).

During the formation of EMs an internal network of hyphae is established between the epidermal and cortical cells in roots. This network, called the Hartig net, enhances the exchange of nutrients between the symbiotic partners (Smith and Read, 2008). EM can differ considerably in the mantle structure ensheathing the root and the extramatrical hyphae that grow throughout the soil (Agerer, 2001).

In the ectomycorrhizal symbiosis the ectomycorrhizal fungus (EMF) receives up to $22 \%$ of the photosynthetically assimilated carbon of the host plant (Söderström et al., 1988; Hobbie, 2006). The formation of a strong carbon sink by the fungus can influence plant growth as was demonstrated in Scots pine (Pinus sylvestris) seedlings that had lower carbohydrate concentrations in aboveground plant parts and in parallel a reduced plant growth in mycorrhized compared to non-mycorrhized plants (Wallander and Nylund, 1991). The plant benefits from the mycorrhizal association by an improved nutrient and water supply (Smith and Read, 2008). In varieties of Douglas fir (Pseudotsuga menziesii var. menziesii and var. glauca) the nitrogen use efficiency was positively related to the EM colonization (Dučić et al., 2009). EMF inoculation also reduced plant stress under abiotic stress conditions like for $P$. $\times$ canescens under drought stress (Luo et al., 2009b) and for Scots pine (Pinus sylvestris L.) under heavy metal stress (Schützendübel and Polle, 2002).

Studies promoted the assumption that VOCs play important roles in recognition and growth promotion of the interacting partners. VOCs of lucerne cells (Medicago sativa L. cv. Europ) stimulated the hyphal growth of the arbuscular mycorrhizal fungus (AMF) Glomus calendonium (Carr et al., 1985). Also hyphae of the AMF Gigaspora margarita showed strong branching in response to sesquiterpenes of Birdsfoot trefoil (Lotus japonicus) (Akiyama et al., 2005). Some VOCs are only produced during the interaction of the partners without direct contact and not in pure culture of plant or fungus as shown for P. sylvestris seedlings with the EMF Boletus variegatus (Krupa and Fries, 1971) and American basswood plants (Tilia americana L.) with the EMF Tuber borchii (Menotta et al., 2004). 
Mycorrhizal fungi also affect the interaction of plants with aboveground insects (Manninen et al., 1998). AMF and EMF both increased the abundance of the Burdock leaf miner (Amauromyza maculosa) and the American serpentine leaf miner (Liriomyza trifolii) on Groundsel trees (Baccharis halimifolia) (Younginger et al., 2009). In another study the number of galls of stem galling wasps (Cynipidae) was positively correlated to the AM colonization and negatively correlated to the EM colonization on shrub live oaks (Quercus turbinella Greene) (Mueller et al., 2005). EMF inoculation of Timor mountain gum (Eucalyptus urophylla) decreased leaf herbivory of the Green flower beetle (Anomala cupripes) (Gange et al., 2005). The performance of the leaf chewing generalist (Lymantria dispar) was enhanced on EMF-inoculated Pure American chestnut seedlings (Castanea dentata) compared to non-inoculated seedlings (Rieske et al., 2003). Obviously, the influence of mycorrhizal fungi on plant-herbivore interactions is highly variable and depends on the plant, mycorrhizal and insect species (Gehring and Whitham, 2003).

Buckhorn plantain plants (Plantago lanceolata) that were attacked by cotton leafworm (Spodoptera littoralis Boisd) showed reduced sesquiterpene emissions after AM formation compared to non mycorrhizal plants (Fontana et al., 2009). While first studies with herbaceous plants demonstrated that mycorrhizal fungi induce VOC changes in plants which might affect herbivores, the underlying changes in plant metabolism and VOC emission in interactions between trees, mycorrhizal fungi and herbivores still need to be elucidated.

\subsection{Poplar to study biotic interactions}

The model tree poplar is widely distributed and of high economic value (Dickmann, 2001). They are grown worldwide for biomass, bioenergy, paper and plywood (Polle and Douglas, 2010; Polle et al., 2013). Therefore, studies on poplar are conducted to understand their wood formation (Janz et al. 2011) and stress tolerance (Chen and Polle, 2009; Janz et al., 2012; Danielsen and Polle, 2014). Because plant growth and biomass are influenced by mycorrhizal associations and infestations with beetles (Colpaert et al., 1992; Manninen et al., 1998; Georgi et al., 2012), the interactions of poplar with mycorrhizal fungi (Felten et al., 2009; Luo et al., 2009b; Nehls et al., 2010) and herbivores (Philippe and Bohlmann, 2007; Mccormick et al., 2014) are studied as well. Poplars inoculated with EM displayed differences in the transcript abundance of various genes and hormonal changes compared to non-inoculated poplars (Luo et al., 2009a). 
Poplars emit high concentrations of the $\mathrm{C}_{5}$-VOC isoprene (2-methyl 1,3-butadiene)

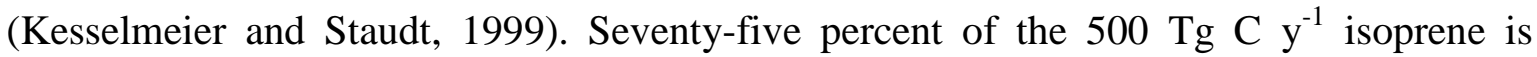
emitted by poplar and oak (Guenther et al., 1995). Isoprene is highly reactive and contributes to various atmospheric reactions. It reacts with OH-radicals (Thompson, 1992) and is involved in the formation of aerosol (Claeys, 2004) and the NOx cycling and thus in the formation or decomposition of ozone in the atmosphere (Williams et al., 1997). Isoprene emission in plants has its optimum at temperatures around $40^{\circ} \mathrm{C}$ (Sharkey et al., 1996). To enable a more environmental-friendly biomass production, transgenic nonisoprene emitting $P . \times$ canescens are produced (Behnke et al., 2010). The reduction of the isoprene emission had no positive effect on the plant biomass (Behnke et al., 2012).

Insects react to the isoprene emission from plants. In Arabidopsis, the parasitic diadegma wasp (Diadegma semiclausum) was repelled by the isoprene emission of transgenic isoprene emitting Arabidopsis plants (Loivamäki et al., 2008). The feeding of the tobacco hornworm (Manduca sexta) was reduced by the isoprene emission in transgenic tobacco plants (Nicotiana tabacum cv. Samsun) (Laothawornkitkul et al., 2008). Behnke et al. (2012) observed a strong infestation of transgenic non-isoprene-emitting and isopreneemitting $P . \times$ canescens under outdoor conditions by the naturally occurring willow leaf beetles (Phratora vitellinae). In that study, the number of beetles was higher on the transgenic non-isoprene-emitting poplars than on the isoprene-emitting plants. This suggests that isoprene emission of poplar might play a role in deterring or attracting other aboveground herbivores, but there is still a lack of data about the function of isoprene in biotic interactions with poplar.

The model EM fungus L. bicolor promoted lateral root development in $P . \times$ canescens when contact to the fungus was prevented by a membrane (Felten et al., 2009). Studies at first indicated that hormones may be involved in the belowground interaction between poplar and mycorrhizal fungi. Mutants of the EMF Hebeloma cylindrosporum Romagnesi producing higher amounts of the auxin IAA than the wildtype fungus formed more mycorrhizas with Cluster pine trees (Pinus pinaster) than with the wildtype EMF (Gay et al., 1994). When seedlings of Douglas fir (Pseudotsuga menziesii (Mirb.) Franco), Lodgepole pine (Pinus contorta Dougl.) and Englemann spruce (Picea englemanii Parry) were cultivated with EMF differing in ethylene production capacity, the number of primary lateral roots was increased in plants inoculated with EMF that produced higher amounts of ethylene (Scagel and Linderman, 1998). The EMF Bohemian truffle (Pisolithus tinctorius) emits the indolic compound hypaphorine (Beguiristain et al., 1995), which reduced hair 
length in Arabidopsis (Reboutier et al., 2002). The small size and short life cycle (Pang and Meyerowitz, 1987) of Arabidopsis makes it an optimal plant to elucidate the signals involved in interactions between mycorrhizal fungi and non-host plants. Splivallo et al. (2009) observed that the EMFs white truffle (Tuber borchii) and black truffle (Tuber melanosporum) induced lateral root formation and stimulated root hair growth of the host plant Hairy rockrose (Cistus incanus) and the non-host plant Arabidopsis in a co-culture system, in which the fungus was grown on medium in the lower part of a Petri dish and the plants were grown without direct contact to the fungus in the upper part of the same Petri dish. The EMFs of that study produced high concentrations of auxin and ethylene. Addition of a mixture of auxin and the ethylene precursor 1-aminocyclopropane-1carboxylic acid triggered the same alterations in root morphology in both plants that were also observed in the co-culture of plants and EMFs. An auxin and ethylene double mutant was less sensitive to the truffle hormones than wildtype plants (Splivallo et al. 2009). These studies suggested that the induced changes of EMF on plant roots are independent of root colonisation, because they were also observed for the non-host plant Arabidopsis, and that auxin and ethylene play a role in signalling between EMF and plants.

However, when the exchange of hormones between Arabidopsis plants and L. bicolor was prevented by growing plants and fungi on different sides in two-compartmented plates, the plants still responded to EMF signals with changes in the root architecture (Felten et al., 2010). The timing of the lateral root stimulation by auxin application differed from the timing in the co-culture with the fungus (Felten et al., 2010). This suggests an involvement of VOCs in belowground interactions of plants such as poplar with EMF, but the responsible compounds have not yet been identified.

\subsection{Aims of the present study}

The main objectives of this study were to gain further knowledge on the belowground communication of poplar with mycorrhizal fungi and the multitrophic interaction of mycorrhizal fungi, poplar and herbivores. These investigations required controlled cultivation of poplar with and without ectomycorrhizal fungi under axenic or outdoor conditions as well as cultivation techniques of ectomycorrhizal fungi. Therefore, in chapter 2, cultivation systems for poplar with or without mycorrhizas are described. Furthermore, a growth system with low VOC emission was developed to avoid disturbance 
of the analysis of plant and fungal VOC blends by background volatiles of the growth medium and Petri dishes.

To investigate the role of VOCs in EMF-host tree interactions, it is necessary to have knowledge on the fungal VOC profiles. In the present study it was therefore hypothesised that EMF differ in their VOC emission patterns from fungi of other lifestyles. In chapter 3, the three EMF Cenococcum geophilum, L. bicolor and Paxillus involutus (strains MAJ and NAU), the three fungal pathogens Armillaria mellea, Pholiota squarrosa and Verticillium longisporum and the two saprophytes Stropharia rugosoannulata and Trichoderma viride were grown in Petri dishes on a synthetic medium with a low VOC emission. Fungal VOC emissions were collected in the headspace of the cultures. The fungi were clustered by multivariate analysis based on their VOC profiles.

A role of VOCs in the interaction of EMF with the host plant poplar as well as the non-host plant Arabidopsis has been suggested, but the key VOCs in these interactions are still unknown. To identify the VOCs that are emitted by poplar, Arabidopsis and EMF, in chapter 4, the VOC blends of $P . x$ canescens, A. thaliana, L. bicolor and C. geophilum were analysed when plants and fungi were grown individually or together. The induction of lateral root formation, an early response of the plant to the presence of EMF, was studied. In the co-cultures, plants were exposed to VOCs of the different EMF in bicompartmented Petri dishes without direct contact of roots and fungi. The VOC pattern was modified by growth of L. bicolor in the presence of the MVA pathway inhibitor, lovastatin. Under these conditions sesquiterpene (SQT) biosynthesis was suppressed. Candidate SQTs were selected based on the results of the lovastatin experiments and the influence of various concentrations of these compounds on lateral root formation was tested.

Poplar leaves emit high isoprene concentrations. The impact of the isoprene emission of poplars on the attraction of typical herbivores present on poplars such as the poplar leaf beetle Chrysomela populi is unknown. In the present study, it was hypothesized that C. populi is able to detect isoprene and uses this signal for the localisation of its food resource. In chapter 5, the ability of $C$. populi to detect isoprene and other terpenes was investigated by electroantennography using pure compounds. To test the relevance of the results for poplars, feeding and oviposition of the beetles on isoprene-emitting and transgenic non-isoprene emitting poplar lines was compared under greenhouse and outdoor 
conditions. VOC and metabolomic profiles of leaves from infested and non-infested isoprene-emitting and non-emitting poplar lines were investigated.

It was hypothesised that the inoculation of poplar with EMF induces changes in the leaves that influence herbivore interaction. In chapter $6, P . \times$ canescens plants were inoculated with L. bicolor. The feeding and oviposition behaviour of $C$. populi beetles on inoculated and non-inoculated poplars was compared under outdoor conditions. RNA-Sequencing of leaf samples was conducted to identify the molecular basis for changes in beetle behaviour and distinct pathways such as hormone signalling pathways, flavonoid biosynthesis pathways and aldoxime biosynthesis were identified to be affected by EMF inoculation or beetle infestation. 


\section{Chapter 2}

\section{Growing poplars for research with and without mycorrhizas}

Müller A*, Volmer K*, Mishra-Knyrim M and Polle A

*These authors have contributed equally to this work.

Published in Frontiers in Plant Science (2013) 4: 332

Link:

http://journal.frontiersin.org/article/10.3389/fpls.2013.00332/ 
Chapter 2: Growing poplars for research with and without mycorrhizas

\subsection{Declaration}

The following data shown in this chapter have been provided by other authors:

- The studies with poplar sand cultures under axenic conditions were conducted by Katharina Volmer ${ }^{1}$.

- The data of the Petri dish system for the cocultivation of poplar with $P$. involutus were provided by Manika Mishra-Knyrim ${ }^{1}$.

The manuscript was written by Anna Müller ${ }^{1}$, Katharina Volmer ${ }^{1}$ and Andrea Polle ${ }^{1}$. All authors commented on the final version.

${ }^{1}$ Büsgen Institute, Forest Botany and Tree Physiology, University of Göttingen, Germany 


\section{Chapter 3}

\section{Volatile profiles of fungi}

- Chemotyping of species and ecological functions

Müller A*, Faubert P*, Hagen M, zu Castell W, Polle A, Schnitzler JP and Rosenkranz M

*These authors have contributed equally to this work.

Published in Fungal Genetics and Biology (2013) 54: 25-33

Link:

http://www.sciencedirect.com/science/article/pii/S1087184513000297 


\subsection{Declaration}

The following data shown in this chapter have been provided by other authors:

- The GC-MS analyses were conducted by Patrick Faubert ${ }^{2,3}$.

- The chemotyping was performed by Michael Hagen ${ }^{4}$.

The manuscript was written by Anna Müller ${ }^{1}$, Patrick Faubert ${ }^{2,3}$, Andrea Polle ${ }^{1}$, Jörg-Peter Schnitzler ${ }^{2}$, Michael Hagen ${ }^{4}$ and Maaria Rosenkranz ${ }^{2}$. All authors commented on the final version.

${ }^{1}$ Büsgen Institute, Forest Botany and Tree Physiology, University of Göttingen, Germany ${ }^{2}$ Research Unit Environmental Simulation, Institute of Biochemical Plant Pathology, Helmholtz Zentrum München, Germany

${ }^{3}$ Present address: Département des Sciences Fondamentales, Chaire en éco-conseil, Université du Québec à Chicoutimi, Canada

${ }^{4}$ Research Unit Scientific Computing, Institute of Biomathematics and Biometry, Helmholtz Zentrum München, Germany 


\section{Chapter 4}

Volatile signalling by sesquiterpenes from ectomycorrhizal fungi reprogrammes root architecture

Ditengou F A*, Müller A*, Rosenkranz M, Felten J, Lasok H, van Doorn MM, Legué V, Palme K, Schnitzler JP and Polle A *These authors have contributed equally to this work.

Published in Nature Communications (2015) 6:6279

Link:

http://www.nature.com/ncomms/2015/150223/ncomms7279/full/ncomms7279.html 


\subsection{Declaration}

The following data shown in this chapter have been provided by other authors:

- Auxin and ROS assays were conducted by Franck A. Ditengou ${ }^{1}$ and Hanna Lasok ${ }^{1}$.

- Poplar root assays with P. tremula $x$ P. alba and L. bicolor were performed by Judith Felten ${ }^{4}$.

- Root assays of poplar with L. bicolor, lovastatin and thujopsen were conducted by Maja Miloradovic van Doorn ${ }^{3}$.

The manuscript was written by Anna Müller ${ }^{2}$, Andrea Polle ${ }^{2}$, Franck A. Ditengou ${ }^{1}$, JörgPeter Schnitzler ${ }^{3}$, Maaria Rosenkranz ${ }^{3}$ and Klaus Palme ${ }^{1,5,6,7}$. All authors commented on the final version.

${ }^{1}$ Institute of Biology II, Faculty of Biology, Albert-Ludwigs-University of Freiburg, Germany

2 Forest Botany und Tree Physiology, Georg-August Universität Göttingen, Germany

${ }^{3}$ Research Unit Environmental Simulation, Institute of Biochemical Plant Pathology, Helmholtz Zentrum München, Germany

${ }^{4}$ Umeå Plant Science Center, Department for Forest Genetics and Plant Physiology, Sweden

${ }^{5}$ BIOSS Centre of Biological Systems Analysis, Albert-Ludwigs-University of Freiburg, Germany

6 Freiburg Institute of Advanced Sciences (FRIAS), Albert-Ludwigs-University of Freiburg, Germany

7 Centre for Biological Signalling Studies (BIOSS), Albert-Ludwigs-University of Freiburg, Germany 


\section{Chapter 5}

Feeding behaviour of poplar leaf beetles and volatile emission and metabolic profiles of transgenic non-isoprene emitting poplars

Müller A*, Kaling M*, Faubert P, Gort G, Smid HM, Van Loon JJA, Dicke M, Kanawati B, Schmitt-Kopplin P, Polle A, Schnitzler JP, Rosenkranz M *These authors have contributed equally to this work. 


\section{Feeding behaviour of poplar leaf beetles and volatile emission and metabolic profiles of transgenic non-isoprene emitting poplars}

Müller $\mathrm{A}^{1 *}$, Kaling $\mathrm{M}^{2,3}$, Faubert $\mathrm{P}^{2,4}$, Gort $\mathrm{G}^{5}$, Smid $\mathrm{HM}^{6}$, Van Loon $\mathrm{JJA}^{6}$, Dicke $\mathrm{M}^{6}$, Kanawati $\mathrm{B}^{3}$, Schmitt-Kopplin $\mathrm{P}^{3}$, Polle $\mathrm{A}^{1}$, Schnitzler JP ${ }^{2}$, Rosenkranz $\mathrm{M}^{2}$

${ }^{1}$ Büsgen Institute, Forest Botany and Tree Physiology, University of Göttingen, Büsgenweg 2, 37077 Göttingen, Germany

${ }^{2}$ Research Unit Environmental Simulation, Institute of Biochemical Plant Pathology, Helmholtz Zentrum München - German Research Center for Environmental Health (GmbH), Ingolstädter Landstraße 1, 85764 Neuherberg, Germany

${ }^{3}$ Research Unit Analytical BioGeoChemistry, Helmholtz Zentrum München, D-85764, Neuherberg, Germany

${ }^{4}$ Present address: Département des Sciences Fondamentales, Chaire en éco-conseil, Université du Québec à Chicoutimi, 555, boul. de 1'Université, Chicoutimi, Qc, G7H 2B1, Canada

${ }^{5}$ Mathematical and Statistical Methods Group, Wageningen University, P.O. Box 100, 6700 AC Wageningen, The Netherlands

${ }^{6}$ Laboratory of Entomology, Wageningen University, NL-6700 EH Wageningen, P.O. Box 8031, The Netherlands

*Anna Müller and Moritz Kaling made equal contributions to the manuscript.

\subsection{Introduction}

Isoprene is a biogenic volatile organic compound (BVOC) emitted in large quantities by fast growing tree species, such as poplar, willow and oil palm (Rosenkranz and Schnitzler, 2013). Isoprene affects the chemistry of the troposphere by contributing to ozone production, methane oxidation and secondary organic aerosol (SOA) formation (Guenther et al. 1995; Lerdau, 2007; Claeys et al. 2004). Considering the growing interest in biomass production by poplar plantations, genetically modified, isoprene non-emitting (NE) poplar trees could help to prevent atmospheric pollution and climate change (Behnke et al. 2007; 2012). 
BVOCs play important roles in the interaction between plants and herbivores. Induced BVOCs are released from plants during and following abiotic or biotic stresses, such as high temperature episodes or insect feeding (Arimura et al. 2005, Behnke et al. 2007; Stam et al. 2014). Plants, insects and microbes can interact with community members by volatile compounds (Baldwin et al. 2006; Gershenzon and Dudareva, 2007; Peñuelas et al. 2014; Dicke and Baldwin 2010). Insects can recognise individual molecules with their olfactory receptor neurons (ORN) (e.g., Bruce et al. 2005); however, a correct mix of volatiles is typically necessary to detect the host odour blend (Bruce and Pickett, 2011). Common insect-induced plant BVOCs are green leaf volatiles (GLVs) and mono- and sesquiterpenes (Arimura et al. 2005).

A previous study demonstrated that isoprene emitted by transgenic Arabidopsis interferes with the attraction of Diadegma semiclausum, a parasitic wasp searching for its herbivorous host (Loivamäki et al. 2008). Moreover, Laothawornkitkul et al. (2008) showed that isoprene-emitting transgenic tobacco plants are less attractive for Manduca sexta than unmodified tobacco plants. A further indication that isoprene may act as a repellent comes from a study with transgenic poplars showing that Brassy willow beetles (Phratora vitellinae; Coleoptera, Chrysomelidae) were more abundant on NE poplars than on isoprene emitting (IE) plants under outdoor conditions (Behnke et al. 2012). Whether the preference of $P$. vitellinae was due to the altered isoprene emission capacity or due to other yet unrevealed biochemical factors, remained unexplored in this study (Behnke et al. 2012).

The poplar leaf beetle (Chrysomela populi; Coleoptera, Chrysomelidae) is a common leaffeeding beetle that is highly abundant in poplar plantations. It is particularly found on young trees where it can cause high economic losses (Urban 2006; Fernandez and Hilker, 2007). Both larvae and adults of this species feed on the plants, particularly on young leaves. Commonly, members of the Chrysomelidae are highly specialised herbivorous beetles (Fernandez and Hilker, 2007). Poplar leaf beetles are specialists using salicyl glucosides from the host plant in their own defence (Rank et al. 1998). In previous olfactometer studies, it was shown that $C$. populi uses monoterpenes and sesquiterpenes to search for young but not fully mature poplar leaves (Brilli et al. 2009) that are rich in salicylic glucosides (Rank et al. 1998).

In the present study, we make use of several biochemically and transcriptionally wellcharacterised NE and IE poplar genotypes (e.g., Behnke et al. 2010; Kaling et al. 2014) 
aiming to clarify the potential bioactive function of isoprene in a widespread, common plant-herbivore interaction. We investigated whether (i) C. populi is able to detect isoprene and other volatile terpenoids typically emitted by poplar leaves following herbivory, (ii) the suppression of isoprene emission in NE poplars affects the plant VOC profile, metabolome or biomass, (iii) the absence of isoprene affects the behaviour and fitness of $C$. populi on NE poplars. We conducted electroantennography (EAG), feeding preference and growth experiments under greenhouse conditions, analysed the VOC emission profile of infested and non-infested genotypes and tested the feeding choice behaviour of leaf beetles and plant metabolomic adjustments and biomass of the IE and NE poplar trees in caged outdoor exposure systems.

\subsection{Materials and methods}

\subsubsection{Plant and insect material}

Transgenic non-isoprene emitting (NE) poplars (genotypes RA1, RA2 and RA22, (for more details on the RA genotypes see Behnke et al. 2007) and isoprene emitting (IE) wild type and $\beta$-glucuronidase (GUS)/green fluorescent (GFP) (both genes in one vector) expressing Grey poplar trees (Populus x canescens; syn. Populus tremula x P. alba) (for more details on the GUS/GFP genotypes see Cinege et al. 2009) were used. In the NE genotypes, the isoprene synthase expression was silenced by the RNA interference (RNAi) technique (Behnke et al. 2007; 2010; 2013). The GUS/GFP genotypes (in which both genes were expressed under the control of the Populus x canescens isoprene synthase (PcISPS) promoter) were used as isoprene emitting controls for the transgenic manipulation (Way et al. 2013). The experiments were conducted in the greenhouse with IE lines: GUS2, GUS26, wild type and NE lines: RA1 and RA2 and in the outdoor conditions with IE lines: GUS26, wild type, and NE: lines RA1 and RA22. When no differences among the IE or the NE genotypes were found, the results of IE or NE genotype were pooled. Cultivation and growth conditions were as previously described for greenhouse (Behnke et al. 2007; Cinege et al. 2009) and outdoor conditions (Müller et al. 2013a). The trees were used when they had reached a height of approximately $60-80 \mathrm{~cm}$ and 20 leaves.

Chrysomela populi were collected in poplar plantations in Southern Germany near Freising, Scheyern and Sigmaringen. For larval bioassays, eggs were collected and larvae allowed to hatch under controlled conditions in a greenhouse. For the bioassays, either $1^{\text {st }}$ 
instar larvae or $3^{\text {rd }}$ instar larvae were used. The $1^{\text {st }}$ instar larvae were allowed to eat the remains of the egg before the initiation of the experiments. The $3^{\text {rd }}$ instar larvae had fed either on IE or NE plants until they reached the $3^{\text {rd }}$ larval stage before the beginning of the experiment to investigate if an effect of feeding experience occurred. The bioassays with adult beetles were performed with overwintered insects except for EAG and cafeteria studies, in which the $1^{\text {st }}$ new generation of the summer was used, and olfactometer experiments, in which the $2^{\text {nd }}$ generation of the summer was used. For cafeteria experiments, the adults were allowed to feed either on IE or on NE plants before the start of the experiment. For BVOC analysis, $C$. populi were allowed to feed on the poplar plants $24 \mathrm{~h}$ before VOC sampling started.

Phratora vitellinae L. (Brassy willow beetle) adults for additional EAG studies were collected outdoors on Grey poplars at Göttingen University.

\subsubsection{Electroantennography}

Electroantennography (EAG) recordings were performed as described in Smid et al. (2002). The responses of $C$. populi and $P$. vitellinae individuals to isoprene, $\alpha$-pinene, $\beta$ pinene, ocimene, linalool, $\beta$-caryophyllene and methyl salicylate were recorded. Ten $\mu \mathrm{L}$ of $0.1 \%, 1 \%$, or $10 \%$ (v:v) of each compound in hexadecane (99\% purity, Sigma-Aldrich) was applied on a strip of filter paper, which was inserted into a Pasteur pipette. Stimulus puffs $\left(0.5 \mathrm{sec}, 120 \mathrm{ml} \mathrm{min}^{-1}\right)$ were injected into a continuous air stream of humidified,

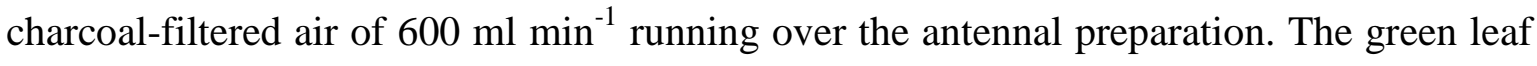
odour (Z)-3-hexen-1-yl acetate ( $\geq 98 \%$ purity, Sigma-Aldrich; $10 \%$ solution in hexadecane) was used as a standard odour. The standard odour was applied in the beginning and end of one series that involved five different volatile compounds in the three different concentrations in ascending order and the control stimulations. Control stimulations were performed with $10 \mu \mathrm{L}$ of hexadecane. Both standard and control odours were applied before and after the series of stimulations of each compound dilution. We also performed EAG studies with P. vitellinae (Brassy willow beetle), another leaf beetle that commonly feeds on Grey poplar (Behnke et al. 2012). 


\subsubsection{Volatile collection and analysis by gas chromatography-mass spectrometry (GC-} MS)

For dynamic headspace collection, two plants of each genotype and treatment ( $C$. populi infested and control plants) were placed in parallel in two glass cuvettes (volume $60 \mathrm{~L}$; air temp. $23^{\circ} \mathrm{C}$; approx. $200 \mu \mathrm{mol}$ photons $\mathrm{m}^{-2} \mathrm{~s}^{-1}$ ). After acclimation, the system was purged for $30 \mathrm{~min}$ with $500 \mathrm{ml} \mathrm{min}{ }^{-1}$ synthetic air mixed with $370 \mathrm{ppm} \mathrm{CO}_{2}$ before BVOC trapping onto the adsorbents started. Air was pumped out of the cuvette with $100 \mathrm{ml} \mathrm{min}^{-1}$ by passing first through a tube filled with polydimethylsiloxane (PDMS) (Gerstel GmbH \& Co. KG, Mülheim an der Ruhr, Germany) and $50 \mathrm{mg}$ of Carbopack B (mesh 60/80; GraceAlltech, Düsseldorf, Germany). Headspace volatiles from non-infested and infested IE and NE genotypes were collected for a period of $2 \mathrm{~h}$ between 9:30 AM and 11:30 AM. Six independent collections were performed with each genotype and treatment. Leaf areas of all trees were determined immediately after the experiments using a portable Area Meter (LI-COR, Walz, Effeltrich, Germany).

The samples were analysed with a thermo-desorption unit (Gerstel) coupled to a gas chromatograph-mass spectrometer (GC-MS; GC model: 7890A; MS model: 5975C; Agilent Technologies, Santa Clara, CA, USA). BVOCs were desorbed from $30^{\circ} \mathrm{C}$ to $270^{\circ} \mathrm{C}$ at a rate of $400^{\circ} \mathrm{C} \mathrm{min}^{-1}$, followed by a holding time of 3 minutes. The compounds were refocused on Tenax (cryo-cooling technique) at $-50^{\circ} \mathrm{C}$ and desorbed to $250^{\circ} \mathrm{C}$ at a rate of $10^{\circ} \mathrm{C} \mathrm{s}^{-1}$, followed by a holding time of 5 minutes. Compounds were separated using a capillary GC column ((14\%-Cyanopropyl-phenyl)-methylpolysiloxane; $70 \mathrm{~m} \times 250 \mu \mathrm{m}$, film thickness $0.25 \mu \mathrm{m}$; Agilent J\&W 122-5562G, DB-5MS + $10 \mathrm{~m} \mathrm{DG).} \mathrm{The} \mathrm{carrier} \mathrm{gas}$ was helium with a constant flow rate of $1.2 \mathrm{ml} \mathrm{min}^{-1}$. The GC oven temperature was held at $40^{\circ} \mathrm{C}$ for two minutes, increased to $80^{\circ} \mathrm{C}$ at a rate of $6^{\circ} \mathrm{C} \mathrm{min}{ }^{-1}$, then to $170^{\circ} \mathrm{C}$ at a rate of $3.4^{\circ} \mathrm{C} \mathrm{min}^{-1}$ and finally to $300^{\circ} \mathrm{C}$ at a rate of $12^{\circ} \mathrm{C} \mathrm{min}^{-1}$.

For chromatogram analysis, an automated screening of the total ion counts (TICs) of all chromatograms was performed by extracting the BVOCs with an identification quality above $90 \%$ in the Wiley data library as described in Müller et al. (2013b). A manual screening was also performed in which previously reported BVOCs of poplar (Arimura et al. 2004; Blande et al. 2007; Behnke et al. 2009; Brilli et al. 2009) were searched in the TICs of all chromatograms. The identification of compounds was confirmed or refuted as previously described (Müller et al. 2013b). We removed 131 compounds from the dataset, as they were produced/released by the sampling material. The representative $\mathrm{m} / \mathrm{z}$ and 
retention indices of the remaining BVOCs were calculated according to van Den Dool and Kratz (1963) and are listed in the final dataset (Table S5.3).

The TIC of each BVOC in the final dataset was recalculated from the absolute abundance of the first representative $\mathrm{m} / \mathrm{z}$ to eliminate the chromatogram noise and finally normalised to overall leaf area. Quantification of the compound concentrations was conducted using the TIC of external standards: isoprene and $\alpha$-pinene were used to quantify the nonoxygenated monoterpenes, linalool for oxygenated monoterpenes, $(E)$-caryophyllene for non-oxygenated sesquiterpenes, nerolidol for oxygenated sesquiterpenes and toluene for the other VOCs (OVOCs).

\subsubsection{Olfactometer Bioassays}

The behavioural response of adult $C$. populi to plant volatiles was investigated in a Y-tube olfactometer (Takabayashi and Dicke 1992) under constant conditions $\left(22^{\circ} \mathrm{C}\right)$. The Y-tube had an internal diameter of $2.6 \mathrm{~cm}$, main arm length of $16.5 \mathrm{~cm}$ and side arm length of 13.5 $\mathrm{cm}$. The studies were conducted immediately after BVOC collection from the poplar genotypes, and the set up was as described for BVOC collection with a flow of $500 \mathrm{ml}$

$\mathrm{min}^{-1}$ from IE trees to one of the side arms and $500 \mathrm{ml} \mathrm{min}^{-1}$ from NE trees into the other side arm of the Y-tube. One beetle at a time was introduced into the downwind part of the olfactometer using a glass vial, and the beetle's behaviour was observed for a maximum of $10 \mathrm{~min}$. A choice was recorded when the beetles stayed at a maximum of $2.5 \mathrm{~cm}$ distance from an end of one of the Y-tube side arms for 15 seconds. Beetles that did not make a choice within $10 \mathrm{~min}$ were discarded from the statistical analysis. Twenty beetles were tested per day and plant set-up. To correct for unforeseen asymmetry in the set-up, the position of the odour sources was switched after every five beetles tested.

\subsubsection{C. populi bioassays under greenhouse conditions}

Cafeteria-like feeding choice studies were performed with $3^{\text {rd }}$ instar larvae and with adult C. populi beetles. Feeding choice studies were performed in plastic boxes $(16 \mathrm{~cm}$ x $11 \mathrm{~cm}$ x $32 \mathrm{~cm}$ (depth $\mathrm{x}$ height $\mathrm{x}$ width)) with holes in the top. A thin cloth stretched over the top of the box prevented the insects from escaping. In the box, individual leaves of IE and NE poplars were placed opposite each other. To avoid leaf desiccation, petioles were placed in water in a $2 \mathrm{ml}$ Eppendorf tube (Sarstedt, Nümbrecht, Germany). Moisturised tissue was 
placed at both ends of the box to provide sufficient humidity in the box. To create homogeneous environmental conditions, the boxes were placed in bigger, $32 \mathrm{~cm} \mathrm{x} 39 \mathrm{~cm} \mathrm{x}$ $60 \mathrm{~cm}$ (depth $\mathrm{x}$ height $\mathrm{x}$ width), open top boxes, which were placed in the climatised acrylic glass cuvettes (size: $80 \mathrm{~cm}$ x $110 \mathrm{~cm}$ x $110 \mathrm{~cm}$ (depth x height x width) at a temperature of $19 \pm 1{ }^{\circ} \mathrm{C}$ and an air humidity of $50 \%$ in a greenhouse under natural daylight. At the start of recording, one insect was placed in the middle of the box. The first choice of the larvae was recorded, and the leaf feeding preference of larvae and adults was determined after $48 \mathrm{~h}$ by analysing the leaf area from the photographs by SigmaScan Pro5 (Systat Software, California, USA). During four weeks, experiments were performed with larvae and adults that had previous experience on either NE or IE plants.

To analyse the feeding behaviour of adult $C$. populi, two IE and two NE plants were placed in glass cuvettes at $19 \pm 1{ }^{\circ} \mathrm{C}$ with an air humidity of $50 \%$ in a greenhouse under natural daylight. Only the shoots were inside the cuvettes and were separated by acrylic glass from the belowground parts (= pot with the roots in the soil) (Fig. S5.1). The bioassays were started by releasing 17 adult beetles and allowing them to feed freely over a 48-h period. The location of the beetles was recorded at hours $0,0.5,2,6,24,30$ and 48 after the beginning of the experiment. At the end of the experiment, the beetles were removed, and all individual leaves were photographed. The leaf area consumed was determined from the photographs as described above. Twenty individual experiments were performed during six weeks in May and June.

The growth and feeding behaviour of $C$. populi larvae were analysed on whole poplar trees in a similar way. Ten $1^{\text {st }}$ instar larvae were positioned in the middle part, i.e., on the $7^{\text {th }}$ and $8^{\text {th }}$ leaves from the apex, of each tree. Each cuvette contained two trees of the same genotype and thus twenty larvae. The development was monitored for 10 days by weighing (Type r180 D, Sartorius GmbH, Göttingen, Germany) the larvae in the beginning and every $3^{\text {rd }}$ day during the experiments. After 10 days, the infested leaf area was recorded as described above, and the data of one cuvette was pooled. Eight individual experiments for each genotype were performed in June and July.

\subsubsection{C. populi bioassays under close-to-natural conditions}

Fourteen-day bioassays (experimental schema in Fig. 5.6a) under outdoor conditions were conducted in eight small cages $(190 \mathrm{~cm} \times 140 \mathrm{~cm} \times 190 \mathrm{~cm})$ covered with mesh screen (mesh size: $1.4 \mathrm{~mm}$; thickness: $0.28 \mathrm{~mm}$ ) (Fig. 5.5b), which were located in Göttingen 
(Germany) in a caged area with permission to work with transgenic plants (Fig. 5.6b). Each small cage was equipped with four Populus x canescens trees per genotype (NE and IE) three weeks before the start of beetle exposure. The shoot height and diameter of stems were measured in the beginning and end of the 14-day experiment. At day zero ( $2 \mathrm{am}), 60$ C. populi individuals were released in the middle of each of the four cages. Four additional cages with plants but without beetles served as the controls. The number of leaves, the location of the beetles, the feeding behaviour and egg deposition were monitored daily. To quantify the feeding behaviour, the following rank scale for the fed leaf area was used: $1:<$ 10\%, 2: 20-to-25\%, 3: 25-to-50\%, 4: 50-to-75\% and 5: > 75\% fed leaf area. Leaves were sampled and immediately frozen in liquid nitrogen on days $0,2,4$ and 8 (at 2 am) from infested (leaf number 5 from apex) and non-infested parts (one leaf between leaf number 10 and 15 from apex = systemic leaf) of the plants as well as from the same position of plants without beetle exposure. Leaf samples of each genotype in one cage, with the upper and lower leaves separated, were pooled for metabolic analysis. The leaves, stem, coarse roots and fine roots of all plants were weighed at harvest after two weeks of beetle exposure.

\subsubsection{Non-targeted metabolome analysis by FT-ICR/MS}

For each sample, $20 \mathrm{mg}$ of powdered leaf material was extracted 2 consecutive times with $1 \mathrm{ml}-20^{\circ} \mathrm{C}$ extraction solvent (methanol/isopropanol/water $1: 1: 1[\mathrm{v} / \mathrm{v} / \mathrm{v}]$ ) in an ultrasonic bath for $15 \mathrm{~min}$. Subsequently, the solution was centrifuged at $10,000 \mathrm{~g}$ for $10 \mathrm{~min}$ at $4^{\circ} \mathrm{C}$. The supernatant was removed and diluted with extraction solvent in a ratio of 1:12.5 (v/v). For non-targeted metabolome analysis, ultra-high-resolution mass spectra were acquired using a Fourier transform ion cyclotron resonance mass spectrometer (FT-ICR/MS, APEX Qe, Bruker, Bremen, Germany) equipped with a 12-Tesla superconducting magnet and an APOLLO II electrospray (ESI) source. Samples were introduced into the microelectrospray source (Agilent sprayer, Waldbronn, Germany) at a flow rate of $120 \mu 1$ $\mathrm{h}^{-1}$ with a nebuliser gas pressure of $20 \mathrm{psi}$ and a drying gas pressure of $15 \mathrm{psi}$ at $180^{\circ} \mathrm{C}$ using a Gilson autosampler (Sample changer 223, Gilson Inc., Middleton, USA). All measurements were performed in the negative ionisation mode over a mass range of $\mathrm{m} / \mathrm{z}$ $122-1200$. The spectra were acquired over a time domain transient of 2 Megawords with 488 accumulated scans for each sample. To exclude memory effects in the electrospray source, samples were randomised, and the mass spectrometer was cleaned with $50 \%$ 
methanol solution between each two successive runs for 7 minutes at a high flow rate of $300 \mathrm{uL} / \mathrm{min}$.

\subsubsection{FT-ICR/MS data analysis}

The resulting mass spectra were aligned, internally calibrated and exported to peak height lists as ascii files at a signal to noise ratio of 4 and a relative threshold intensity of $1 * 10^{-8} \%$ using the Data Analysis 4.1 software package (Bruker, Bremen, Germany). Peak lists were combined to a peak matrix with an error of $1 \mathrm{ppm}$ using an in-house written tool (Lucio et al. 2011). Single mass events, isotopic peaks $\left({ }^{13} \mathrm{C},{ }^{15} \mathrm{~N},{ }^{34} \mathrm{~S}\right.$ and $\left.{ }^{18} \mathrm{O}\right)$ and peaks detected in less than $50 \%$ of the biological samples were removed from the matrix. The zero intensities present in the peak matrix were replaced with the FT-ICR/MS threshold intensity of $1 * 10^{6}$ counts. Next, the intensities were $\log ^{2}$ transformed. For statistical analysis, poplar plants were grouped to their respective isoprene-emission capacity in IE (WT/GUS) and NE (Ra1/Ra22). To have a first overview on the FT-ICR/MS data, unsupervised principal component analysis (PCA) was performed using SIMCA-P 13.0 (Umetrics, Umeå, Sweden). To detect and identify masses (X-variables), which are important for the group separation, e.g., leaf age, treatment and isoprene emission capacity (Y-variables), supervised orthogonal partial least squares discriminant analysis (OPLSDA) was applied. For each Y-variable, a separate OPLS-DA model was calculated and validated by seven cross-validation rounds. Variables with a variable influence of projection score (VIP) > 1 were extracted and further tested with a Wilcoxon-MannWhitney-U Test using Matlab R2011b (MathWorks, Ismaning, Germany). Masses with a VIP score $>1$ and a P-value $<0.05$ were considered as discriminant.

For metabolite identification, the mass list was uploaded to the MassTrix 3 server selecting negative ionisation mode, Kegg/HMDB/LipidMaps and MetaCyc as databases and Populus trichocarpa as organism (Suhre and Schmitt-Kopplin, 2008; Wägele et al. 2012), as well as to the Metlin server (Smith et al. 2005). The maximal error acceptance was 1 ppm.

\subsubsection{Statistical analysis}

Mixed linear models were used to analyze the EAG data, because the experimental design resulted in repeated measurements on antennae and blocking of observations over days, 
leading to correlated responses. We followed the approach as described in Qiu et al. (2013), applying the procedure MIXED of the SAS software program (Littell et al, 2006). Mixed models contain a fixed part, capturing the experimental factors, as in ordinary linear models, and a random part, allowing for possibly complex correlations between observations. As in Qiu et al. (2013), we have chosen the random parts of the mixed model to consist of two components: 1) random coefficients, allowing antennae to follow their own quadratic regression line over time; as proxy for time we took the order of the stimulus, defined as the [serial number minus 15], taking values in the range -14 to 20 ; the number of observations per antenna varied between 17 and 35;2) random effects of days; EAG responses show slight variation among days beyond residual variation and variation already captured by the random coefficients part of the model; 3) residual error.

The fixed part of the model consists of main effects of insect species, gender, compound and compound concentration, and their interactions. Taking the analogy of a split-plot experiment, factors species and gender were defined as main plot factors associated with antennae, whereas compound and concentration were subplot factors, changing within antennae. Variables order and order ${ }^{2}$ were used as covariates in both models to allow for an overall trend of EAG response over time. Instead of analyzing the original EAG recordings $y($ in $-\mathrm{mV})$, we analysed $\ln (-y+0.0001)$ with the small constant added to avoid boundary problems near zero. The transformed variable resulted in a more symmetrical distribution of residuals.

Binomial tests were performed to analyse the choices in the Y-tube olfactometer and cafeteria experiments, and a Mann Whitney $U$ test was used to compare the infested leaf areas in the cafeteria studies. A Kruskal-Wallis test was applied to analyse BVOC patterns between differently treated poplar trees. Significant differences between the treatments and genotypes were further analysed using a Mann Whitney $U$ test. A generalized linear model (GLM) was applied to analyse the weight gain of the larvae, infested leaf areas, eggs laid and beetle occurrence over time. For the statistical analyses, IBM SPSS Statistics version 21 (Armonk, NY, USA) and SigmaPlot version 11 (Systat Software, California, USA) were used. 


\subsection{Results}

\subsubsection{C. populi and $P$. vitellinae detected higher isoprenoids but not isoprene}

We first report on the random part of the model and covariates, and next on the fixed part. We modelled the random variation of the EAG response of Chrysomela populi and Phratora vitellinae to stem from three sources; estimated variance components are shown in Table S5.1.

1) Random variation of quadratic regression lines per antenna over time. The variation due to the random coefficients is visualized in Fig. S5.2 showing predicted regression lines per antenna. To illustrate the large variability between antennae, take the intercept variance of 0.104 , which corresponds to standard deviation 0.32 . Taking extreme antennae to differ 4 $\sigma$ 's, their difference in intercept is $4 \times 0.32=1.3$ units. Transforming to the original $\mathrm{mV}$ scale, the most sensitive antenna may show $\mathrm{e}^{1.3} \approx 3.6$ times higher responses than the least sensitive antenna. The sensitivity of the antennae declines over time with a quadratic trend. Data from an individual and rather typical antenna is plotted along. The overall estimated quadratic regression line for covariate order is shown in black, with highly significant linear (-0.019) and quadratic (0.00058) coefficients (Table 5.1).

2) Between-day variability. The day-to-day variance is relatively low: 0.019 , corresponding to standard deviation $\approx 0.14$, so that we may see differences up to 0.5 unit (or a 1.7-fold multiplication factor on the original $\mathrm{mV}$ scale) due to days.

3) Residual variability. The residual variance is estimated to be 0.099 , roughly equal to the intercept variance of the antenna.

As for fixed effects of species, gender, compound and concentration, the largest and highly significant differences in responses are found between compounds, concentrations, and their combinations, and these responses are species-specific. Gender effects are weak: averaged over species, males tend to respond differently compared to females to (some) compounds $(P=0.02)$. All other interactions with gender are not significant $(P>0.05)$. The highly significant effects of order and $\operatorname{order}^{2}$ indicate the decrease of mean antenna sensitivity over time. The ANOVA table (Table 5.1) gives a compact overview on the importance of the different factors and their interactions. 
Chapter 5: Transgenic non-isoprene emitting poplars

Table 5.1 | Results for F-tests for fixed effects of species, gender, compound, concentration, and their interactions; order and order ${ }^{2}$ are included as covariates in the mixed model.

\begin{tabular}{lrrrr}
\hline Effect & df1 & df2 & F value & P-value \\
\hline species & 1 & 78 & 1.46 & 0.23 \\
gender & 1 & 78 & 0.00 & 0.97 \\
species $\times$ gender & 1 & 78 & 1.90 & 0.17 \\
comp & 7 & 1620 & 273.2 & $<0.0001$ \\
conc & 2 & 1620 & 144.5 & $<0.0001$ \\
comp $\times$ conc & 12 & 1610 & 11.20 & $<0.0001$ \\
species $\times$ comp & 7 & 1610 & 41.88 & $<0.0001$ \\
species $\times$ conc & 2 & 1610 & 17.85 & $<0.0001$ \\
species $\times$ comp $\times$ conc & 12 & 1610 & 5.50 & $<0.0001$ \\
gender $\times$ comp & 7 & 1610 & 2.48 & 0.02 \\
gender $\times$ conc & 2 & 1610 & 0.35 & 0.71 \\
gender $\times$ comp $\times$ conc & 12 & 1610 & 0.72 & 0.72 \\
species $\times$ gender $\times$ comp & 7 & 1610 & 0.92 & 0.49 \\
species $\times$ gender $\times$ conc & 2 & 1610 & 0.81 & 0.44 \\
species $\times$ gender $\times$ comp $\times$ conc & 13 & 1610 & 0.45 & 0.94 \\
order $^{2}$ & 1 & 87 & 132.4 & $<0.0001$ \\
order $^{2}$ & 1 & 87 & 20.9 & $<0.0001$ \\
\hline
\end{tabular}

Absolute EAG response amplitude to the standard compound (Z)-3-hexenyl acetate (10\%) was significantly different between species $(P<0.0001)$, but this species difference is not gender dependent $(P=0.23)$, nor do males and females respond differently $(\mathrm{P}=0.32$; Table S5.2). For the response to hexadecane (at 100\%) no significant differences were found at all.

For both leaf beetle species and for all compounds, no significant interactions between factors dose and gender were found $(P>0.05)$. We conclude that male and females responded with similar sensitivity to compounds (Table 5.2).

For $C$. populi significant dose-response relationships (in order of strength according to the F-statistic) were found for $\alpha$-pinene, $\beta$-pinene, linalool, methylsalicylate, $\beta$ caryophyllene, and ocimene (Table 5.2; Fig. 5.1) . For isoprene no significant doseresponse relationship was found $(P=0.92)$. For $P$. vitellinae significant dose-response relationships were found for linalool, $\beta$-caryophyllene, methylsalicylate and $\alpha$-pinene. No significant dose-response relationships were detected for ocimene, isoprene, and $\beta$-pinene (Fig. 5.1). 
Chapter 5: Transgenic non-isoprene emitting poplars

Table 5.2 | Results for hypothesis tests for dose-response relationships of individual compounds per species, combined for genders, and gender-dose interaction

\begin{tabular}{|c|c|c|c|}
\hline Species & Compound & $\begin{array}{c}\text { dose-response F+M } \\
(\mathrm{F}-\mathrm{val} / \mathbf{P} \text {-val) } \\
(\mathbf{d f}=\mathbf{2 , 1 6 1 0})\end{array}$ & $\begin{array}{c}\Delta \text { dose-response } \\
\text { F/M } \\
(\text { F-val } / \text { P-val }) \\
(\mathbf{d f}=\mathbf{2 , 1 6 1 0})\end{array}$ \\
\hline \multirow{7}{*}{ C. populi } & isoprene & $0.08 / 0.92$ & $1.04 / 0.35$ \\
\hline & linalool & $86.87 /<.0001$ & $0.80 / 0.45$ \\
\hline & methylsalicylate & $19.07 /<.0001$ & $1.13 / 0.32$ \\
\hline & ocimene & $7.87 / 0.0004$ & $1.65 / 0.19$ \\
\hline & $\alpha$-pinene & $183.76 /<.0001$ & $0.29 / 0.75$ \\
\hline & $\beta$-caryophyllene & $18.73 /<.0001$ & $0.12 / 0.88$ \\
\hline & $\beta$-pinene & $94.31 /<.0001$ & $0.39 / 0.67$ \\
\hline \multirow[t]{7}{*}{$P$. vitellinae } & isoprene & $0.19 /<0.83$ & $0.84 / 0.43$ \\
\hline & linalool & $18.66 /<.0001$ & $0.01 / 0.99$ \\
\hline & methylsalicylate & $6.26 / 0.002$ & $0.08 / 0.93$ \\
\hline & ocimene & $0.66 / 0.52$ & $0.64 / 0.53$ \\
\hline & $\alpha$-pinene & $5.14 / 0.006$ & $0.48 / 0.62$ \\
\hline & $\beta$-caryophyllene & $9.36 /<.0001$ & $0.13 / 0.88$ \\
\hline & $\beta$-pinene & $0.09 / 0.91$ & $0.91 / 0.40$ \\
\hline
\end{tabular}



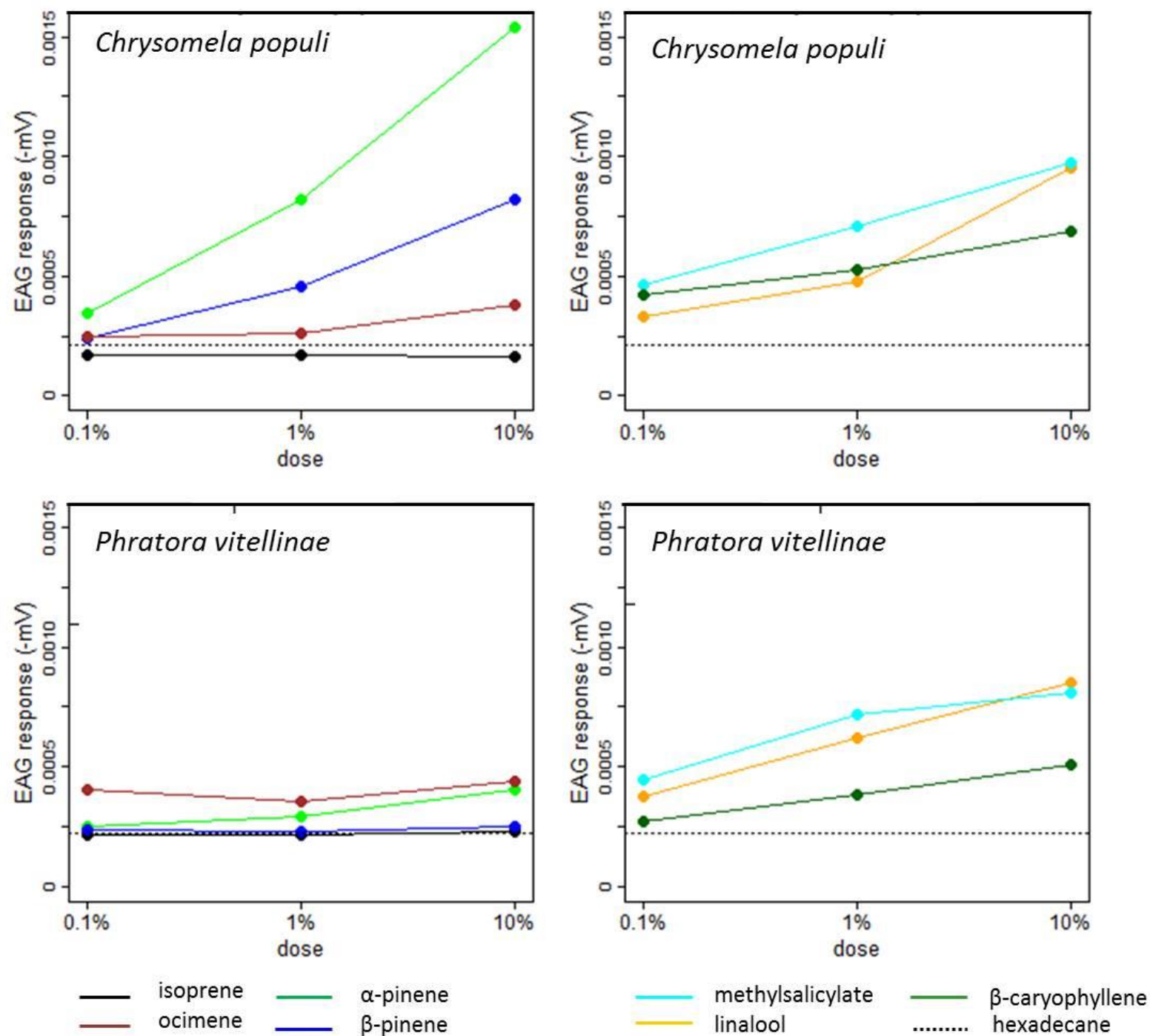

Figure 5.1 | Dose-response curves for EAG responses of Chrysomela populi and Phratora vitellinae to different volatile compounds based on the Mixed Linear Model. Dose is expressed as dilution ( $\mathrm{v} / \mathrm{v}$ ) of the compound in hexadecane. EAG response (expressed as maximum amplitude of depolarization) is expressed in $-\mathrm{mV}$. The mean absolute EAG response amplitude to hexadecane is shown by the dashed line.

\subsubsection{BVOC emission profiles differed between infested and non-infested IE and NE poplars}

We elucidated the individual BVOCs emitted by infested and non-infested IE and NE poplar genotypes (Table S5.3). The foliage of infested poplar trees emitted several individual compounds and total sesquiterpenes more intensively than foliage from noninfested plants (Table S5.1). Interestingly, only the IE plants showed significantly increased monoterpene emission rates after herbivory (Fig. 5.2). This difference in monoterpene emission rates was mostly due to an increase in the emission of $(E)-\beta$ - 
ocimene, which together with allo-ocimene, were approximately twice as high from IE than NE trees $24 \mathrm{~h}$ after the onset of herbivory (Table S5.3).

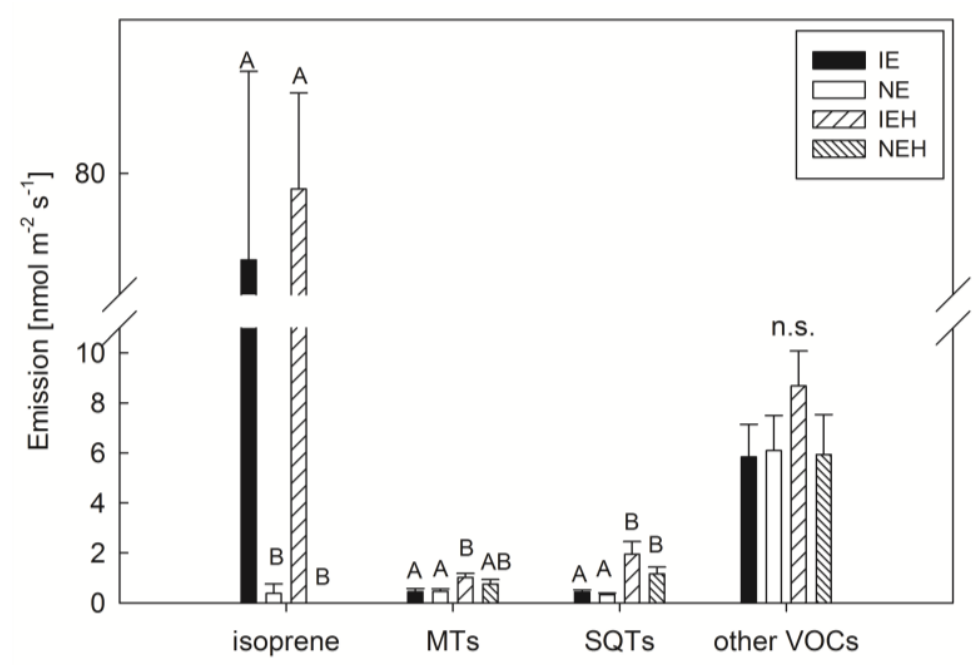

Figure 5.2 | Volatile emission of isoprene emitting (IE) and non-emitting (NE) poplar trees with or without herbivory (H). Isoprene, monoterpene (MT), sesquiterpene (SQT) and other VOC emissions are presented as mean $\pm \mathrm{SE}, \mathrm{n}=6$. Different letters indicate significant differences within each compound class between the genotype and treatment, $P<0.05$. The individual compounds can be found in supplemental Table 5.1 .

$(E, E)-\alpha$-farnesene was the most abundant sesquiterpene, with approximately two-fold higher emission rates from infested IE than NE plants. Other sesquiterpene emissions $(\alpha-$ cubebene, calarene and germacrene D) showed similar tendencies between IE and NE trees. These four volatiles together accounted for the relatively high total sesquiterpene emission rates from IE plants compared to NE plants. In addition to these poplar genotypespecific differences to herbivory, several other BVOCs showed increased emissions after the onset of leaf feeding (3-methylbutanal, 2-ethylfuran, $(E)$-2-hexen-1-ol, salicylaldehyde, methyl benzoate, benzeneethanol, benzeneacetonitrile, eugenol and one unknown compound). The emission of the homoterpene $(E)-4,8$-dimethyl-1,3,7-nonatriene (DMNT) was not increased after poplar beetle herbivory, but its emission was constitutively higher $(P<0.05)$ from the foliage of IE than from NE genotypes (Table S5.1). This observation is interesting because this homoterpene is known as a general herbivore-inducible compound (Dicke, 1994; Degenhardt \& Gershenzon, 2000). 


\subsubsection{C. populi larvae and adults showed no clear preference for NE or IE poplar leaves in Y-tube olfactometer or greenhouse bioassays}

Supporting the fact that $C$. populi cannot sense isoprene, the adult beetles showed no preference to the volatiles from non-infested IE versus NE trees (Fig. 5.3a). Similarly, when larvae of $C$. populi were given a free choice in a cafeteria test setup to feed either on IE or on NE leaves, they did not prefer either plant type in the beginning (first choice) of the experiment (Fig. 5.3b).

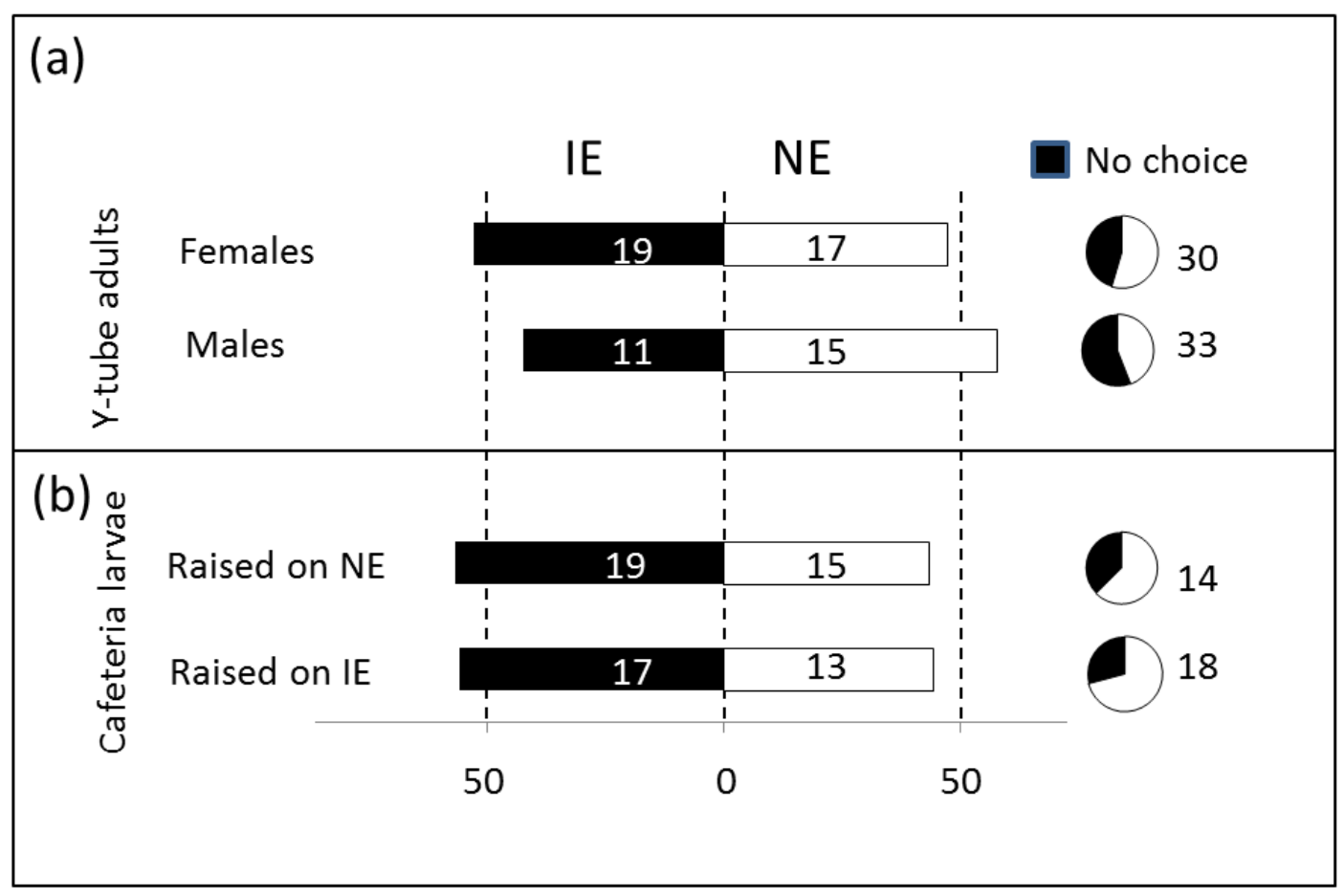

Figure 5.3 | Behavioral responses of Chrysomela populi to isoprene emitting (IE) and non-emitting (NE) poplar. Response of $C$. populi adults (a) to volatiles released by IE and NE plants in a Y-tube olfactometer and response of larvae (b) in cafeteria experiments. Bars represent the overall percentages of beetles choosing either of the odor sources; numbers in bars are the total numbers of beetles choosing that odor source. The percentage of insects not choosing is shown in pie charts.

To perform the cafeteria experiments, the hatched larvae were either raised on NE or IE plants until the $3^{\text {rd }}$ instar stage was reached. They were then given the choice between IE and NE leaves. We observed more feeding damage $(P=0.008$, Fig. 5.4a) on IE leaves when the larvae were reared on NE plants. By contrast, no difference in the feeding damage was detected when the larvae had previous experience on IE plants (Fig. 5.4b). 
We also conducted the cafeteria experiments with adult beetles. However, no difference in the consumption of the leaf material was found in the cafeteria experiments, independent of whether the adults had previous experience on IE or NE (Fig. 5.4c, d).

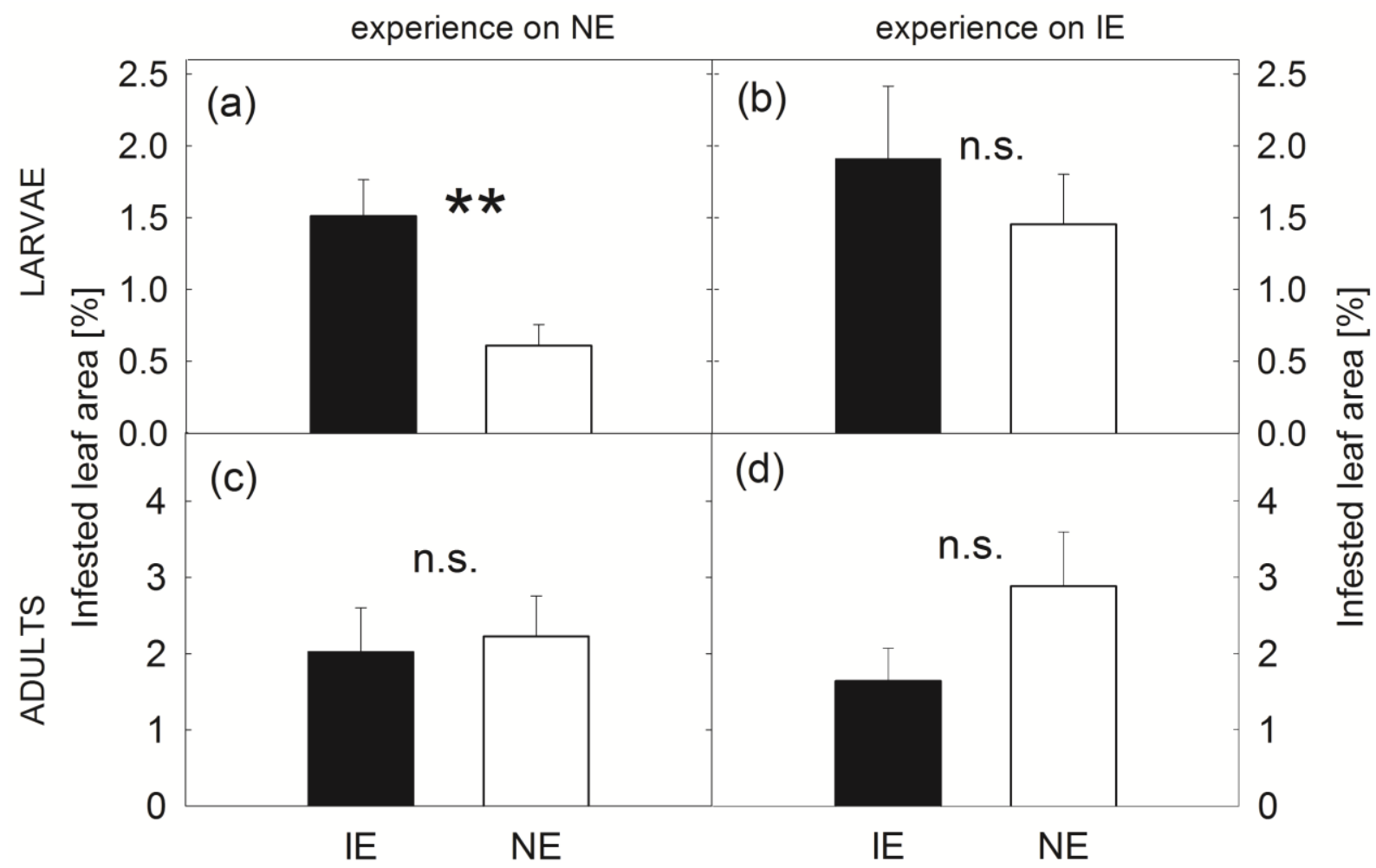

Figure 5.4 | Feeding behavior of $3^{\text {rd }}$ instar C. populi larvae (a, b) and adult beetles $(C$, D) on isoprene emitting (IE; $\square)$ plants or non-emitting (NE; $\square)$ plants. The herbivores had previous feeding experience on NE (a, c) or IE plants $(b, d)$ and they were offered a choice between IE and NE leaves. The infested leaf areas were analyzed like described in Fig. 5.3 and is presented as mean \pm SE, n (a) =35; (b) = 45; $(c, d)=30$; asterisk indicates significant difference between the genotypes, $P<0.01$.

We also observed no clear preference for any poplar genotype when the adult beetles were offered a free choice between whole IE and NE trees (Fig. 5.5a, b). Similarly, the larvae exhibited equal infestation rates and reached similar body weights on IE and on NE plants (Fig. 5.5c, d). No differences were found for the survival rate of the larvae on the genotypes (on average $25 \%$ of the larvae reached the age of 10 days). The most remarkable result for both adults and larvae was the consumption of young leaves that were not yet fully developed (Fig. 5.5a, c). The adults fed significantly more on the two upper most leaves, and larvae fed significantly more on the four upper most leaves compared to the older leaves $(P<0.001$ for all). 
ADULTS
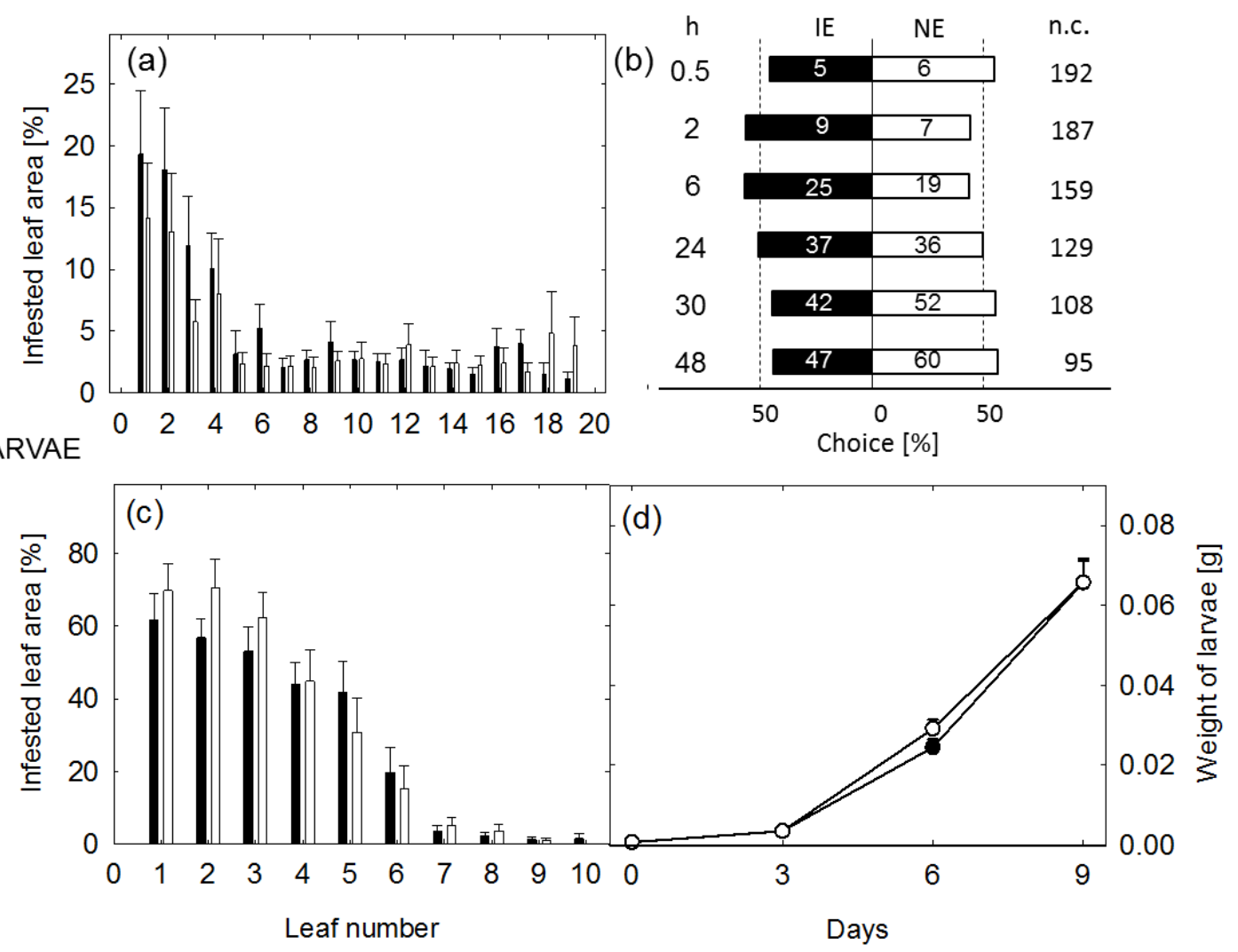

Figure 5.5 | Feeding behavior of adult $C$. populi beetles and larvae on isoprene emitting (IE) and nonemitting (NE) plants in the greenhouse. The mean infested leaf area from apex until lowest leaf by adult $C$. populi beetles (mean $+/$ - SE, $\mathrm{n}=20$ ) (a) and the choices of beetles (b) in a cage with two IE ( - ) and two NE () plants over 48h-period. The beetle choices are shown for hours (h) 0,5, 2, 6, 24, 30 and 48. Bars represent the overall percentages of beetles choosing either of the odor sources; numbers in bars are the total numbers of beetles choosing that odor source; n.c., no choice. The feeding behavior of larvae offered either IE ( $\mathbf{-}$ ) or NE (口) plants over 10 days was assessed by the infested leaf area (c) at the end of experiment and the development (D) of the larvae by weighing them every $3^{\text {rd }}$ day (mean \pm SE; $n$ : (c)=8; (d)=160 (beginning);121 \pm 8 (3 days); 67 \pm 1 ; (6 days); $33 \pm 1$ (10 days)). The infested leaf areas were analyzed from photographs by SigmaScan Pro5 computer program.

\subsubsection{C. populi preferred to feed on IE in close-to-natural conditions}

We found no differences in the distribution of $C$. populi between the IE and NE genotypes under outdoor conditions in cages (Fig. 5.6c). However, the beetles fed significantly more on the IE than on the NE trees over time $(P<0.01)$ (Fig. 5.6d). C. populi females preferred to oviposit on IE compared to NE plants over time (GZLM: $P=0.05$, Fig. 5.6e). The magnitude of these differences was small $(10 \pm 2 \%$ less leaf area and $4 \pm 15 \%$ fewer eggs per plant). 
The biomass of the trees did not show any differences between IE and NE or between the beetle-infested and non-infested trees at the end of the experiment (Fig. S5.3).

\subsubsection{Metabolome-wide changes depended on leaf development, herbivory and isoprene emission capacity}

The unsupervised evaluation of the non-targeted metabolomic data in leaves from the outdoor experiment by PCA revealed strong metabolic differences between old and young leaves in PC1, which accounted for $31 \%$ of the explained variance (Fig. 5.7a). PC2 demonstrated the metabolic difference present between the three sampling days, explaining $19 \%$ of total variance. The difference between infested and control plants is observed in PC3 and describes $8 \%$ of the total variance (Fig. 5.7b). Taken together, the first 3 PCs describe leaf-age, beetle feeding and sampling time and explained 58\% of the total variance. The PCA, however, did not show a separation between IE and NE plants within the first components. Comparing IE and NE poplars separately, we found a total of 2956 masses discriminant for either leaf-development or herbivory. To clarify if the metabolic patterns differ between IE and NE, we compared the leaf-age and beetle-feeding dependent discriminant masses in Venn-Plots (Fig. 5.7c and d). In addition to the conserved metabolic difference between the control and infested leaves (952 masses), we observed genotypic differences (Fig. 5.7c). When comparing the mass changes under herbivory, old and young leaves displayed a local and systemic response (Fig. 5.7d). Noticeably, a more pronounced systemic response in the old leaves of NE (811 masses) than the IE genotypes (89 masses) were detected. In general, the differences in metabolite distribution of NE and IE poplars were comprised of plant phenolics, fatty acids and terpenoids. 
(a)

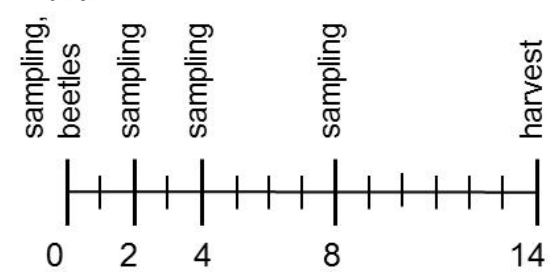

(b)
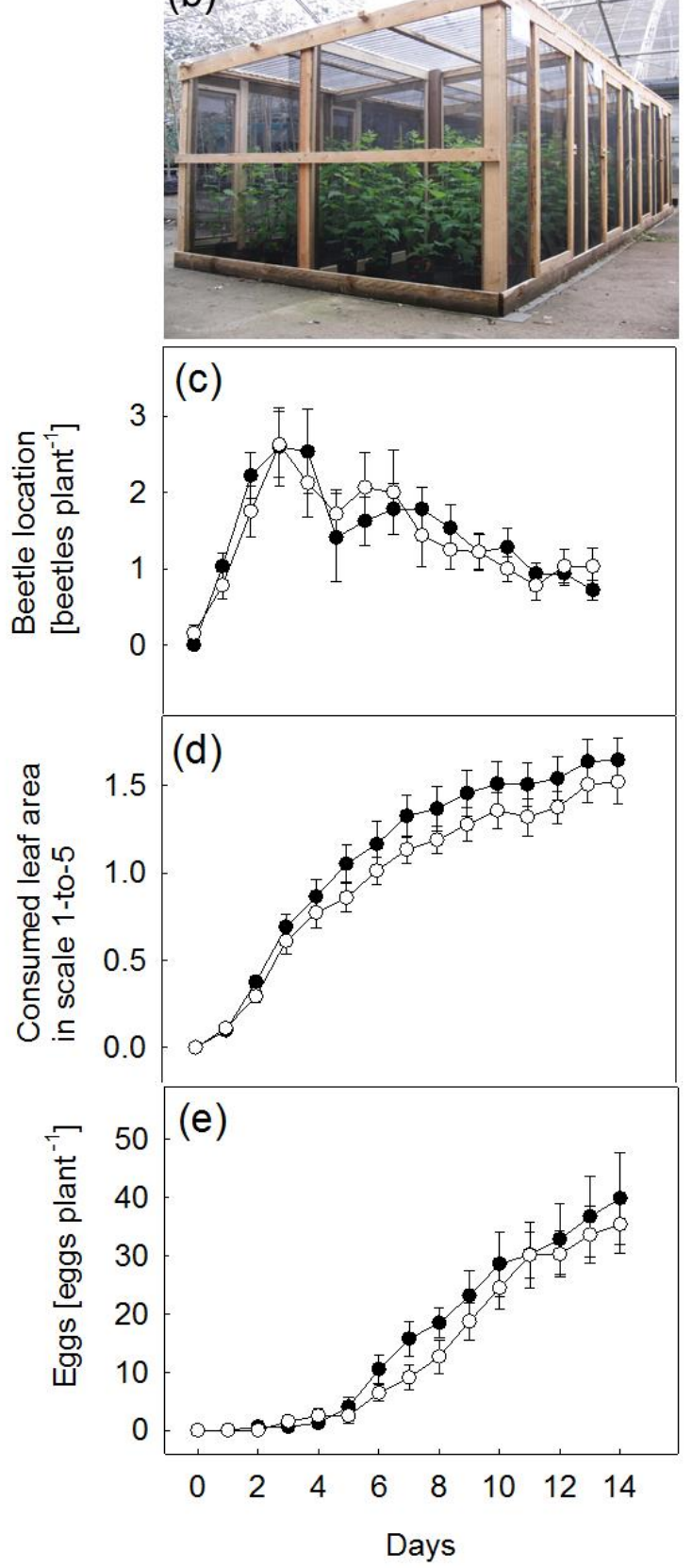

Figure 5.6 $\mid$ C. populi bioassay under outdoor conditions. The experimental scheme shows the days of sampling, harvesting and the release of the beetles (a). A picture of the semi natural experimental cages (b) and C. populi location (c), leaf consumption (d) and laid eggs (e) on isoprene emitting (IE; - $)$ and nonemitting (NE; $\square$ ) poplar trees in cages during a 14-day experiment. Consumed leaf area (b) is a visual approximate in which a scale 0-to-5 (0: no damage; $1<10 \%$ infested leaf, 2: 20-to- $25 \%, 3: 25$-to-50\%, 4: 50to-75\% and $5>75 \%$ infested leaf) was applied. Mean \pm SE of 8 replicates is presented. 

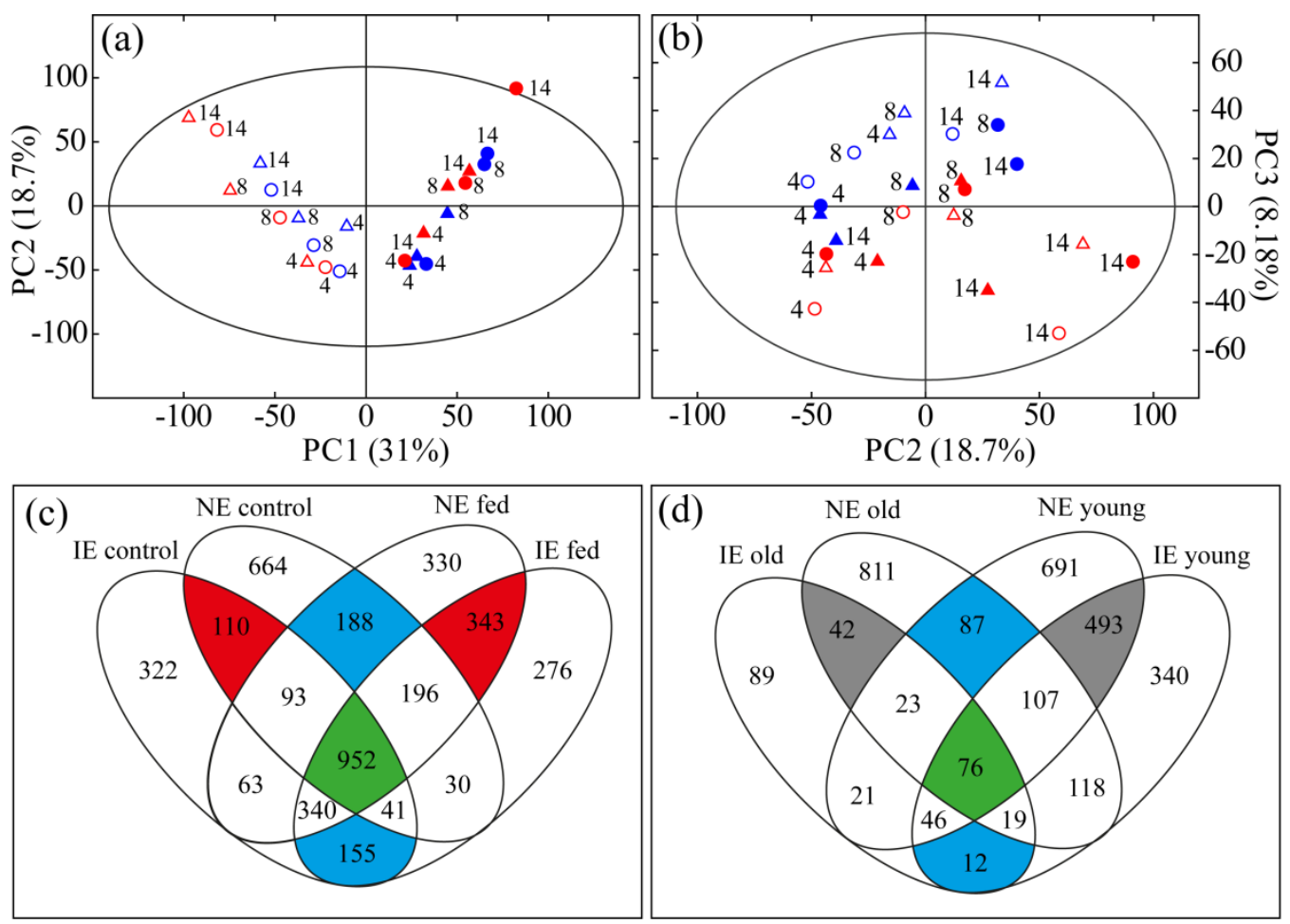

Figure 5.7 | Metabolomics of Chrysomela populi infested isoprene emitting (IE) and non-emitting (NE) poplar grown under outdoor conditions. Score scatter plots of Principal Component Analysis (PCA) of FT-ICR/MS metabolomics data showing (a) PC1 versus PC2 and (b) PC2 versus PC3. Symbols represent the poplar genotypes and leaf age (IE young leaf [o], NE young leaf $[\Delta]$, IE old leaf $[\bullet]$, NE old leaf $[\boldsymbol{\Delta}]$ ). Red symbols represent infested and blue control plants. Venn-Diagramm of discriminant masses (c) responsible for the separation of leaf developmental stage and (d) responsible for the separation of infested from control plants.

The 2956 discriminant masses were subjected to hierarchical clustering analysis (HCA) using the Pearson correlation coefficient (Fig. 5.8a). This analysis revealed that the young leaves clustered separately from old leaves. In addition, the young leaves clustered according to the herbivore treatment and plant age.

Using the databases, we were able to annotate 361 masses (12\%) as metabolites. To further elucidate the poplar response to herbivory, we examined the metabolite changes in young and old leaves under herbivory in more detail. We found that 20 unique metabolites appeared after herbivory in old IE leaves, 121 in old NE leaves, 147 in young IE leaves, and 103 in young NE leaves. In total, 40 metabolites changed in both young and old IE leaves and 45 young and old NE leaves (Fig. 5.8b-c). The metabolites were then grouped according to their respective compound classes and biosynthetic routes (Fig. 5.8d). This revealed an influence of herbivory in both leaf age classes over various pathways. Our results reveal the differential regulation of the phenolics metabolism: in NE poplars, more 
discriminant phenylpropanoids were found in old leaves than in young leaves, whereas the opposite was observed for the IE poplars. Flavonoids, on the other hand, were upregulated in both the leaf ages in infested plants.

(a)

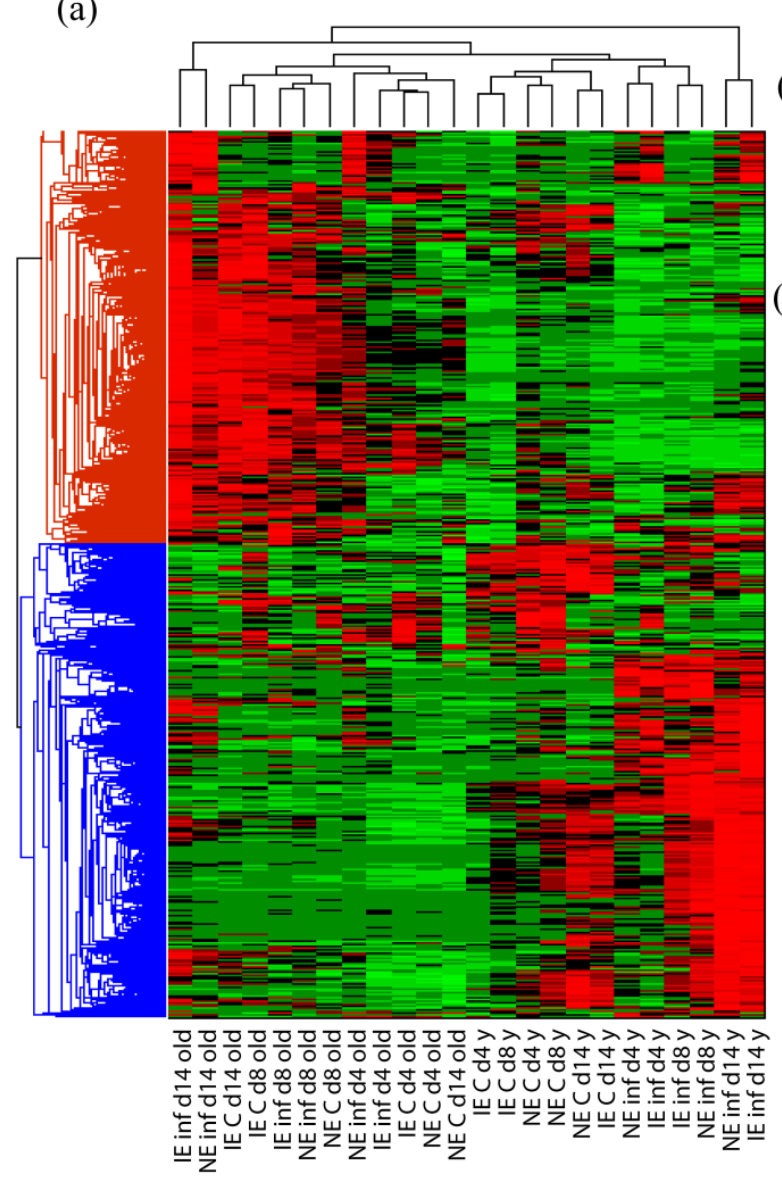

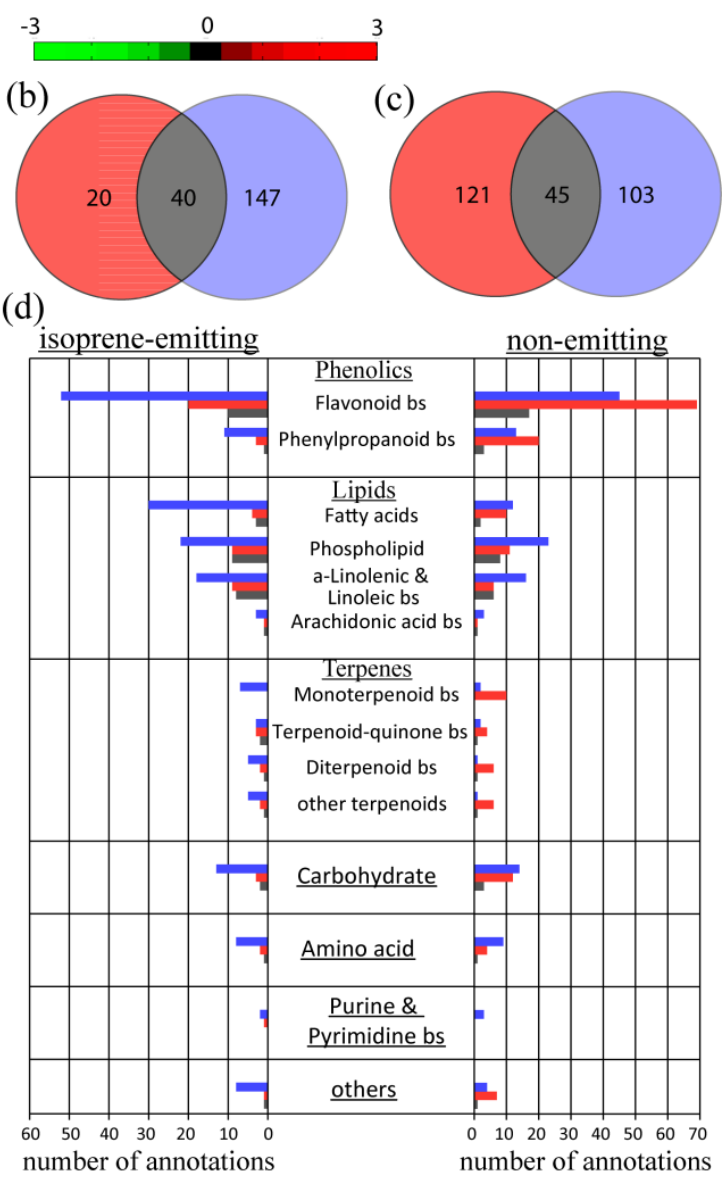

Figure 5.8 Comparison of the metabolomics between young infested and systemic, old leaves in isoprene emitting (IE) and non-emitting (NE) poplar on the days 4, 8 and 14 after the release of Chrysomela populi. Hierachical clustering analysis of FT-ICR/MS intensities of all discriminant masses (a). The Venn plot shows the annotated discriminant metabolites of infested young and old leaves in IE (b) and NE plants(c). The metabolite annotations are shown in the bar chart ordered according to compound classes, pathways and poplar lines (d). Young leaf: $\mathbf{\sim}$, old leaf: $\mathbf{\sim}$ and both leaves: $\mathbf{m}$, bs: biosynthesis.

Furthermore, 3-dehydroquinate and shikimate, which are important precursors of plant phenolics, were upregulated in infested young leaves and showed no change in systemic leaves. Moreover, infested young leaves showed a drastic increase in phospholipids and in metabolites of the $\alpha$-linolenic, linoleic and arachidonic acid biosynthetic pathways. A few of these metabolites, particularly those of the $\alpha$-linolenic acid biosynthetic pathways, were 
also found to be discriminant in old leaves. In addition to these changes, we observed changes in the purine and pyrimidine metabolism in young leaves.

\subsection{Discussion}

\subsubsection{Isoprene does not act as an attractant for $C$. populi or $P$. vitellinae}

An ecologically highly important result is that the leaf-feeding beetles $C$. populi and $P$. vitellinae, which are naturally present on high isoprene-emitting species such as poplar or willow, do not exhibit electroantennographic sensitivity to isoprene over a wide dosage range. Therefore, isoprene itself is unlikely to act as an orientation cue. Any behavioural effects were likely caused by the indirect effects of the lack of isoprene production on leaf metabolism. Both beetle species were able to detect higher terpenoids, which may be used in beetle orientation. Young, developing poplar leaves have been previously shown to emit monoterpenes and sesquiterpenes rather than isoprene, whereas in older leaves isoprene is almost the only volatile terpenoid (Cinege et al. 2009; Brilli et al. 2009; Ghirardo et al. 2011). In agreement with the bioassay studies of Brilli et al. (2009), our results show that C. populi can detect many terpenes emitted by young poplar leaves and that adult beetles prefer to feed on the upper parts of the poplar trees.

Although the poplar specialists $C$. populi or $P$. vitellinae were not able to detect isoprene, previous studies on transgenic Arabidopsis and Tobacco plants modified to emit isoprene have shown that other insect species such as the moth $M$. sexta or the parasitic wasp $D$. semiclausum can recognise this compound (Laothawornkitkul et al. 2008; Loivamäki et al. 2008). The ecological meaning of this observation remains unclear e.g. because the host species parasitised by D. semiclausum is not known to feed on isoprene emitting plants. It is possible that isoprene, which is ubiquitously present in the canopy of poplar trees, is not a specific enough signal for $C$. populi or $P$. vitellinae.

Behnke et al. (2012) showed, however, that $P$. vitellinae preferred to stay on NE rather than IE plants. The lack of isoprene emission cannot directly cause the preference of $P$. vitellinae for isoprene non-emitters. Metabolomic effects (Behnke et al. 2010, 2013; Way et al. 2013; Kaling et al. 2014) or other environmental interactions, such as concurrent infection by pathogenic fungi, may result in altered herbivore behaviour. 


\subsubsection{C. populi shows a slight preference to isoprene emitting plants}

The repression of isoprene biosynthesis and emission in $P . \mathrm{x}$ canescens has direct and indirect effects on the plant's physiology. The metabolic flux through the 2-C-methyl-Derythritol-4-phosphate (MEP)-pathway was strongly reduced (99\%) in NE poplars as a consequence of the feedback inhibition of 1-deoxy-D-xylulose-5-phosphate synthase activity by the accumulation of plastidic dimethylallyl diphosphate (Ghirardo et al. 2014). The MEP pathway is required for monoterpene production, and its suppression may result in the diminished biosynthesis of monoterpenes. This suggestion is supported here by the reduced herbivore-induced monoterpene emission rates. As a consequence, less effective induction of herbivore-inducible VOCs may have occurred in NE plants and influenced the beetle responses in the behavioural experiments.

Our results clearly show that $C$. populi can detect higher terpenes, such as monoterpenes and sesquiterpenes. Therefore, it is possible that their behaviour was altered on NE plants. In the greenhouse bioassays, no clear preference for either of the genotypes was found. Analysis under semi-natural conditions is, however, crucial for woody plants, as shown by experiments with transgenic Bacillus thuringiensis (Bt) poplar. Under laboratory conditions, Bt poplars were more resistant against $P$. vitellinae and had a higher biomass gain than wild type plants (Hjälten et al. 2012); this effect disappeared under semi-natural conditions (Axelsson et al. 2012). Our bioassays in outdoor conditions revealed slightly less feeding on NE than on higher terpene-emitting IE trees despite the similar beetle abundances on the plants. Oviposition was also slightly reduced, indicating moderate effects on poplar leaf beetle ecology, whereas the growth performance of poplars remained unaffected. In another study testing the field performance of transgenic Bt poplar (Populus alba x P. glandulosa), decreased beetle damage was shown due to $B t$ toxins, but no significant negative effect was found on the arthropod community living on the trees (Zhang et al., 2011). Future work should address whether, e.g., the metabolic changes in the NE poplars may result in consequences for their multitrophic interactions or their associated food webs on poplar plantations.

\subsubsection{Leaf age, genotype and treatment dependent differences in IE and NE poplar metabolomics under outdoor conditions}

Genetic modification may sometimes result in unintended effects on innate traits. Hjälten et al. (2013) showed small, unintended changes in Bt poplars, among others in phenolic 
compound content; however, this did not affect the behaviour of $P$. vitellinae on poplar. In our NE poplars, metabolome-wide shifts have been detected under different environmental conditions (Behnke et al. 2013; Way et al. 2013; Kaling et al. 2014), most likely as a result of an adjustment of metabolic flux and transcriptional regulation and the need to replace isoprene function by other metabolites (Behnke et al. 2010). Moreover, Velikova et al. (2014) recently showed a rearrangement of the chloroplast protein profile in the NE genotype to likely overcome the absence of isoprene.

The present results highlight metabolic changes in the defence chemistry in the NE compared with the IE genotypes. These changes might be responsible for the infestation preference of $C$. populi adults in outdoor conditions and larvae in cafeteria studies. Nevertheless, the metabolome-wide changes due to leaf age, plant age, and herbivore feeding were much more pronounced than those induced by the transgenic modification. Several important defence-related compound groups, such as phospholipids, were upregulated in young compared to old leaves. Similar to our results, a metabolome study on maize revealed high up-regulation of phospholipids, among other compounds, as a result of direct infestation by leafworm Spodoptera littoralis (Marti et al. 2013). Several of the in the present study identified fatty acids can have a function in plant signalling. For example, $\alpha$-Linolenic acid (18:3) was upregulated in infested leaves and is a direct precursor of the phytohormone jasmonic acid (JA) which is a well-known signalling molecule in plant defence against pathogens and herbivores (Thomma et al. 1998; Vijayan et al. 1998; Heil, 2008; Smith et al. 2009; Santino et al. 2013). Arachidonic acid, on the other hand, was upregulated in old leaves and is a signalling molecule that elicits plant stress and defence signalling networks (Savchenko et al. 2010). In addition, the salicylic acid-related plant signalling compound azelaic acid (Jung et al. 2009) was differentially regulated between young and old leaves. Azelaic acid can be synthesised for signalling purposes and for priming of improved disease resistance and thus may imply active communication between infested young and associated old leaves. Indeed, compared to the metabolomic differences between the infested young and systemic old leaves, the genotype-dependent differences were minor.

\subsubsection{Conclusions}

In this study, we demonstrate that naturally occurring leaf beetles (C. populi and $P$. vitellinae) on poplar are unable to sense isoprene. Nevertheless, minor differences in insect 
behaviour were found, which may have been related to the changes in leaf terpenoid emission and metabolite composition in the NE poplars. Although C. populi beetles showed moderate preference to isoprene emitters, infestation did not affect the plant biomass production. The present results and those of Behnke et al. (2012) suggest that isoprene emission is of marginal importance for the susceptibility of poplar plantations to their natural herbivore $C$. populi. Therefore, the lack of isoprene is not expected to change the economic losses caused by $C$. populi due to altered productivity in poplar plantations.

The suppression of isoprene production alters the constitutive and induced metabolic profiles of the poplar genotypes. Although the behaviour of $C$. populi was not drastically impaired on NE poplars, the changes in the tree physiology may have consequences for other interactions of poplar plants with their environment (e.g., Behnke et al. 2012). Furthermore, isoprene per se can interfere with the communication between some insects and plants (Loivamäki et al. 2008; Laothawornkitkul et al. 2008) and might function as a repellent for species that are not searching for isoprene-emitting species (Loivamäki et al. 2008). The role of isoprene in the tritrophic interactions (poplar-herbivoreparasitoid/predator) of a natural isoprene emitting species is yet to be elucidated.

\subsection{References}

Arimura G., Huber D.P. \& Bohlmann J. (2004) Forest tent caterpillars (Malacosoma disstria) induce local and systemic diurnal emissions of terpenoid volatiles in hybrid poplar (Populus trichocarpa x deltoides): cDNA cloning, functional characterization, and patterns of gene expression of (-)-germacrene D synthase, PtdTPS1. Plant Journal 37, 603-616.

Arimura G., Kost C. \& Boland W.T. (2005) Herbivore-induced, indirect plant defences. Biochimica Biophysica Acta 1734, 91- 111

Axelsson E.P., Hjalten J. \& LeRoy C.J. (2012) Performance of insect-resistant Bacillus thuringiensis $(B t)$-expressing aspens under semi-natural field conditions including natural herbivory in Sweden. Forest Ecology and Managament 264, 167-171.

Baldwin I.T., Halitschke R., Paschold A., von Dahl C.C. \& Preston C.A. (2006) Volatile signaling in plant-plant interactions: "Talking trees" in the genomics era.Science $311,812-815$. 
Behnke K., Ehlting B., Teuber M., Bauernfeind M., Louis S., Hänsch R., Polle A., Bohlmann J. \& Schnitzler J.P. (2007) Transgenic, non-isoprene emitting poplars don't like it hot. Plant Journal 51, 485-499.

Behnke K., Grote R., Brüggemann N., Zimmer I., Zhou G., Elobeid M., Janz D, Polle A. \& Schnitzler J.P. (2012) Isoprene emission-free poplars -a chance to reduce the impact from poplar plantations on the atmosphere. New Phytology 194, 70-82.

Behnke K., Kaiser A., Zimmer I., Brüggemann N., Janz D., Polle A., Hampp R., Hänsch R., Popko J., Schmitt-Kopplin P., Ehlting B., Rennenberg H., Barta C., Loreto F. \& Schnitzler J.P. (2010) RNAi-mediated suppression of isoprene emission in poplar transiently impacts phenolic metabolism under high temperature and high light intensities: a transcriptomic and metabolomic analysis. Plant Molecular Biology 74, $61-75$.

Behnke K., Kleist E., Uerlings R., Wildt J., Rennenberg H. \& Schnitzler J.P. (2009) RNAimediated suppression of isoprene biosynthesis in hybrid poplars impacts ozone tolerance. Tree Physiology 29, 725-736.

Blande J.D., Tiiva P., Oksanen E. \& Holopainen J.K. (2007) Emission of herbivoreinduced volatile terpenoids from two hybrid aspen (Populus tremula $\mathrm{x}$ tremuloides) clones under ambient and elevated ozone concentrations in the field. Global Change Biology 13, 2538-2550.

Brilli F., Ciccioli P., Frattoni M., Prestininzi M., Spanedda A.F. \& Loreto F. (2009) Constitutive and herbivore-induced monoterpenes emitted by Populus $\mathrm{x}$ euroamericana leaves are key volatiles that orient Chrysomela populi beetles. Plant Cell and Environment 32, 542-552.

Bruce T.J.A. \& Pickett J.A. (2011) Perception of plant volatile blends by herbivorous insects - Finding .the right mix. Phytochemistry 72, 1605-1611.

Bruce T.J.A, Wadhams L.J. \& Woodcock C.M. (2005) Insect host location: a volatile situation. Trends in Plant Sciences 10, 269-274.

Cinege G., Louis S., Hänsch R. \& Schnitzler J.P. (2009) Regulation of isoprene synthase promoter by environmental and internal factors. Plant Molecular Biology 69, 593604 
Claeys, M., Graham B., Vas G., Wang W., Vermeylen R., Pashynska V., ..., Maenhaut W. (2004) Formation of secondary organic aerosols through photooxidation of isoprene. Science 303, 1173-1176.

Dicke M. (1994) Local and systemic production of volatile herbivore-induced terpenoids: Their role in plant-carnivore mutualism. Journal of Plant Physiology 143, 465-472.

Dicke M. \& Baldwin I.T. (2010) The evolutionary context for herbivore-induced plant volatiles: beyond the 'cry for help'. Trends in Plant Science 15, 167-175.

Degenhardt J. \& Gershenzon J. (2000). Demonstration and characterization of $(E)$ nerolidol synthase from maize: a herbivore-inducible terpene synthase participating in (3E)-4, 8-dimethyl-1, 3, 7-nonatriene biosynthesis. Planta ,210, 815-822.

Fernandez P. \& Hilker M. (2007) Host plant location by Chrysomelidae. Basic and Applied Ecology 8, 97-116.

Gershenzon J. \& Dudareva N. (2007) The function of terpene natural products in the natural world. Nature Chemical Biology 3, 408-414.

Ghirardo A., Gutknecht J., Zimmer I., Brüggemann N. \& Schnitzler J.P. (2011): Biogenic volatile organic compound and respiratory $\mathrm{CO}_{2}$ emissions after ${ }^{13} \mathrm{C}$-labeling: online tracing of $\mathrm{C}$ translocation dynamics in poplar plants. Public Library of Science ONE 6, e17393.

Ghirardo A., Wright L.P., Bi Z., Rosenkranz M., Pulido P., Rodriquez-Conception M., Niinemets Ü., Bruggemann N., Gershenzon J. \& Schnitzler JP (2014) Metabolic flux analysis of plastidic isoprenoid biosynthesis in poplar leaves emitting and nonemitting isoprene. Plant Physiology doi: http://dx.doi.org/10.1104/pp.114.236018

Guenther A., Hewitt C.N., Erickson D., Fall R., Geron C., Graedel T., Harley P., Klinger L., Lerdau M., Mckay W.A., Pierce T., Scholes B., Steinbrecher R., Tallamraju R., Taylor J. \& Zimmerman P. (1995) A global-model of natural volatile organiccompound emissions. Journal of Geophysical Research: Atmospheres 100, 88738892.

Heil M. (2008) Indirect defence via tritrophic interactions. New Phytologist 178, 41-61. Hjälten J., Axelsson E.P., Julkunen-tiitto R., Wennström A. \& Pilate G. (2013) Innate and introduced resistance traits in genetically modified aspen trees and their 
effect on leaf beetle feeding. Public Library of Science ONE, 8, DOI: 10.1371/journal.pone.0073819

Hjälten J., Axelsson A.P., Whitham T.G., LeRoy C.J., Julkunen-Tiitto R., Wennström A. \& Pilate G. (2012) Increased resistance of Bt aspens to Phratora vitellinae (Coleoptera) leads to increased plant growth under experimental conditions. Public Library of Science ONE 7, e30640

Jung H.W., Tschaplinski T.J., Wang L., Glazebrook J. \& Greenberg J.T. (2009) Priming in systemic plant immunity. Science 324, 89-91.

Kaling M., Kanawati B., Ghirardo A., Albert A., Winkler J.B., Heller W., Barta C., Loreto F., Schmitt-Koplin P., Schnitzler J-P (2014): UV-B mediated metabolic rearrangements in poplar revealed by non-targeted metabolomics. Plant Cell and Environment: early view.

Laothawornkitkul J., Paul N.D., Vickers C.E., Possell M., Taylor J.E., Mullineaux P.M., Hewitt C.N. (2008) Isoprene emissions influence herbivore feeding decisions. Plant Cell and Environment 31, 1410-1415.

Lerdau M. (2007) Ecology. A positive feedback with negative consequences. Science 316, 212-213.

Littell R.C., Milliken G.A., Stroup W.W., Wolfinger R.D. \& Schabenberger O. (2006) SAS $^{\circledR}$ for Mixed Models, 2nd ed. SAS Institute Inc., Cary, N.C.

Loivamäki M., Mumm R., Dicke M. \& Schnitzler J.P. (2008): Isoprene interferes with the attraction of bodyguards by herbaceous plants. Proceeding of the National Academy of Sciences of the United States of America 105, 17430-17435.

Lucio M., Fekete A., Frommberger M. \& Schmitt-Kopplin P. (2011) Metabolomics: High Resolution Tools Offer to Follow Bacterial Growth on a Molecular Level. Handbook of Molecular Microbial Ecology I. John Wiley \& Sons, Inc.

Marti G., Erb M., Boccard J., Glauser G., Doyen G.R., Villard N., Robert C. A.M., Turlings T. C.J., Rudaz S. \&Wolfender J.-L. (2013) Metabolomics reveals herbivore-induced metabolites of resistance and susceptibility in maize leaves and roots. Plant Cell and Environment 36, 621-639. 
Müller A., Faubert P., Hagen M., zu Castell W., Polle A., Schnitzler J.P. \& Rosenkranz M. (2013b) Volatile profiles of fungi - chemotyping of species and ecological functions. Fungal Genetics and Biology 54, 25-33.

Müller A., Volmer K., Mishra-Knyrim M. \& Polle A. (2013a) Growing poplars for research with and without mycorrhizas. Frontiers in Plant Science 4, 332.

Peñuelas J., Asensio D., Tholl D., Wenke K., Rosenkranz M., Piechulla B. \& Schnitzler J.P. (2014) Biogenic volatile emissions from the soil. Plant Cell and Environment 37, 1866-1891.

Puttick G.M. \& Bowers M.D. (1988) Effect of qualitative and quantitative variation in allelochemicals on a generalist insect: Iridoid glycosides and the southern armyworm. Journal of Chemical Ecology 14, 335-351.

Qiu Y.T., Gort G., Torricelli R., Takken W. \& Van Loon J.J.A. (2013) Effects of bloodfeeding on olfactory sensitivity of the malaria mosquito Anopheles gambiae: application of mixed linear models to account for repeated measurements. Journal of Insect Physiology 59 (11): 1111-1118.

Rank N.E., Kopf A., Julkunen-Tiitto R. \& Tahvanainen J. (1998) Host preference and larval performance of the salicylate-using leaf beetle Phratora vitellinae. Ecology $79,618-631$.

Rosenkranz M. \& Schnitzler J.P. (2013) Genetic engineering of BVOC emissions from trees. In 'Biology, controls and models of tree volatile organic compound emissions', Niinemets Ü, Monson RK (eds.). Springer Netherlands, Tree Physiology 5, 95-118.

Santino A., Taurino M., De Domenico S., Bonsegna S., Poltronieri P., Pastor V. \& Flors V. (2013) Jasmonate signaling in plant development and defense response to multiple (a)biotic stresses. Plant Cell Reports 32, 1085-1098.

Savchenko T., Walley J.W., Chehab E.W., Xiao Y., Kaspi R., Pye M.F..., Dehesha K. (2010) Arachidonic acid: an evolutionarily conserved signaling molecule modulates plant stress signaling network. Plant Cell 22, 3193-3205.

Smid H.M., van Loon J.J.A., Posthumus M.A., Vet L.E.M. (2002) GC-EAG-analysis of volatiles from Brussels sprouts plants damaged by two species of Pieris 
caterpillars: Olfactory receptive range of a specialist and generalist parasitoid wasp species. Chemoecology 12, 169-176.

Smith C., O’Maille G., Want E., Qin C., Trauger S., Brandon T., Custodio D. E., Abagyan R. \& Siuzdak G. (2005) METLIN - A metabolite mass spectral database. Therapeutic Drug Monitoring 27, 747-751.

Smith J.L., De Moraes C.M. \& Mescher M.C. (2009) Jasmonate- and salicylate-mediated plant defense responses to insect herbivores, pathogens and parasitic plants. Pest Management Science 65, 497-503.

Stam J.M., Kroes A., Li Y., Gols R., van Loon J.J.A., Poelman E.H. \& Dicke M. (2014) Plant interactions with multiple insect herbivores: from community to genes. Annual Revews of Plant Biology 65, 689-713.

Suhre K. \& Schmitt-Kopplin P. (2008) MassTRIX: mass translator into pathways. Nucleic Acids Research 36, 481-484.

Takabayashi J. \& Dicke M. (1992) Response of predatory mites with different rearing histories to volatiles of un-infested plants. Entomologia experimentalis et applicata 64,187-193.

Thomma B.P.H.J., Eggermont K., Penninckx I.A.M.A., Mauch-Mani B., Vogelsang R., Cammue B.P.A. \& Broekaert W.F. (1998) Separate jasmonate-dependent and salicylate-dependent defense-response pathways in Arabidopsis are essential for resistance to distinct microbial pathogens. Proceeding of the National Academy of Sciences of the United States of America 95,15107-15111.

Urban J. (2006) Occurrence, bionomics and harmfulness of Chrysomela populi L. (Coleoptera, Chrysomelidae) Journal of Forest Science 52, 255-284.

van Den Dool H. \& Kratz P.D. (1963) A generalization of the retention index system including linear temperature programmed gas-liquid partition chromatography. Journal of Chromatography 11, 463-471.

Way D.A., Ghirardo A., Kanawati B., Esperschütz J., Monson R.K., Jackson R.B., Schmitt-Kopplin P., Schnitzler J.P. (2013) Increasing atmospheric CO2 reduces metabolic and physiological differences between isoprene and non-isopreneemitting poplars. New Phytologist 200, 534-546. 
Wägele B., Witting M., Schmitt-Kopplin P. \& Suhre K. (2012) MassTRIX Reloaded: Combined Analysis and Visualization of Transcriptome and Metabolome Data. Public Library of Science ONE 7, e39860.

Velikova V., Ghirardo A., Vanzo E., Merl J., Hauck S.M. \& Schnitzler J.P. (2014) The genetic manipulation of isoprene emission in poplar plants remodels the chloroplast proteome. Journal of Proteome Research 13, 2005-2018.

Vijayan P., Shockey J., _Levesque C.A., Cook R.J. \& Browse J. (1998) A role for jasmonatein pathogen defense of Arabidopsis. Proceeding of the National Academy of Sciences of the United States of America 95, 7209-7214.

Zhang B, Chen M, Zhang X, Luan H, Tian Y, Su X (2011) Expression of Bt-Cry3A in transgenic Populus alba x P. glandulosa and its effects on target and non-target pests and the arthropod community. Transgenic Research 20, 523-532. 
Chapter 5: Transgenic non-isoprene emitting poplars

Table S5.1 | Estimated variances for the different sources of variation of the random part of the Mixed Linear Model applied on EAG data.

\begin{tabular}{ll}
\hline Source of variation & Estimated variance \\
\hline intercept & 0.104 \\
linear coefficient & 0.00011 \\
quadratic coefficient & $1.56 \mathrm{e}-7$ \\
day & 0.019 \\
residual & 0.099 \\
\hline
\end{tabular}

Table S5.2 | Results for hypothesis tests of species and gender effects on control compounds.

\begin{tabular}{lccc}
\hline Compound & $\begin{array}{c}\text { Species main } \\
(\mathbf{F} \text {-val / P-val) } \\
(\mathbf{d f}=\mathbf{1 , 7 8})\end{array}$ & $\begin{array}{c}\text { Gender main } \\
(\mathbf{F} \text {-val / P-val) } \\
(\mathbf{d f}=\mathbf{1 , 7 8})\end{array}$ & $\begin{array}{c}\text { Species } \times \text { gender } \\
\text { interaction } \\
(\mathbf{F}-\mathbf{v a l} / \mathbf{P} \text {-val }) \\
(\mathbf{d f}=\mathbf{1 , 7 8})\end{array}$ \\
\hline $\begin{array}{l}(Z) \text {-3-hexenyl-acetate } \\
\text { hexadecane }\end{array}$ & $26.83 /<.0001$ & $1.02 / 0.32$ & $1.48 / 0.23$ \\
\hline
\end{tabular}


Chapter 5: Transgenic non-isoprene emitting poplars

Table S5.3 | Biogenic volatile organic compounds (BVOCs) emitted by isoprene emitting (IE) and nonemitting (NE), and Chrysomela populi infested or un-infested $P$. $x$ canescens trees, mean $\pm \mathrm{SE}, \mathrm{n}=6$.

\begin{tabular}{|c|c|c|c|c|}
\hline \multicolumn{5}{|l|}{ BVOCs $\left[\mathrm{pmol} \mathrm{m} \mathrm{m}^{-2} \mathrm{~s}^{-1}\right]$} \\
\hline $\begin{array}{l}\text { Treatment } \\
P . \mathrm{x} \text { canescens genotypes }\end{array}$ & $\mathrm{IE}$ & $\mathrm{NE}$ & IE & $\mathrm{NE}$ \\
\hline Isoprene & $69.3 \pm 23.288^{\mathrm{A}}$ & $0.38 \pm 0.38^{\mathbf{B}}$ & $78.05 \pm 11.95^{\mathbf{A}}$ & $/^{B}$ \\
\hline \multicolumn{5}{|l|}{ Monoterpenes } \\
\hline Tricyclene & l & / & $0.01 \pm 0.006$ & $0.01 \pm 0.004$ \\
\hline Cyclofenchene & l & l & l & $0.01 \pm 0.005$ \\
\hline$\alpha$-Thujene & $/^{\mathbf{A}}$ & $0.02 \pm 0.015^{\mathrm{AB}}$ & $0.01 \pm 0.005^{\mathrm{AB}}$ & $0.04 \pm 0.011^{\mathrm{B}}$ \\
\hline$\alpha$-Phellandrene & $0.01 \pm 0.010$ & l & $0.01 \pm 0.007$ & $0.01 \pm 0.008$ \\
\hline$\alpha$-Pinene & $0.05 \pm 0.035$ & $0.02 \pm 0.016$ & $0.11 \pm 0.059$ & $0.11 \pm 0.062$ \\
\hline 2- $\beta$-Pinene & $0.21 \pm 0.032$ & $0.28 \pm 0.038$ & $0.27 \pm 0.026$ & $0.29 \pm 0.044$ \\
\hline Myrcene & $<0.01$ & $0.02 \pm 0.012$ & $0.02 \pm 0.007$ & $0.01 \pm 0.050$ \\
\hline Sabinene & l & $<0.01$ & I & $<0.01$ \\
\hline 1,8-Cineole & $0.02 \pm 0.005$ & $0.03 \pm 0.011$ & $0.04 \pm 0.012$ & $0.02 \pm 0.012$ \\
\hline Citronellal & I & $<0.01$ & $<0.01$ & 1 \\
\hline$(E)-\beta$-ocimene & $0.13 \pm 0.039^{\mathbf{A B}}$ & $0.04 \pm 0.010^{\mathbf{A}}$ & $0.48 \pm 0.151^{\mathrm{C}}$ & $0.23 \pm 0.065^{\mathrm{BC}}$ \\
\hline$\gamma$-Terpinene & $0.02 \pm 0.015$ & $0.04 \pm 0.021$ & $0.02 \pm 0.006$ & $0.01 \pm 0.006$ \\
\hline allo-Ocimene & $<0.01^{\mathrm{A}}$ & $l^{\mathrm{A}}$ & $0.02 \pm 0.005^{\mathbf{B}}$ & $0.01 \pm 0.006^{\mathrm{AB}}$ \\
\hline Borneol & $<0.01$ & $<0.01$ & $0.01 \pm 0.003$ & $0.01 \pm 0.004$ \\
\hline$\beta$-Cyclocitral & I & I & $<0.01$ & \\
\hline Monoterpenes total & $0.45 \pm 0.118^{\mathbf{A}}$ & $0.46 \pm 0.100^{\mathbf{A}}$ & $1.02 \pm 0.157^{\mathbf{B}}$ & $0.75 \pm 0.182^{\mathrm{AB}}$ \\
\hline \multicolumn{5}{|l|}{ Sesquiterpenes } \\
\hline Bicyclogermacrene & I & / & $<0.01$ & $<0.01$ \\
\hline$\alpha$-Ylangene & $0.01 \pm 0.007$ & I & I & $0.01 \pm 0.007$ \\
\hline$\alpha$-Cubebene & $<0.01^{\mathrm{AB}}$ & $f^{\mathbf{A}}$ & $0.01 \pm 0.005^{\mathbf{B C}}$ & $0.01 \pm 0.004^{\mathrm{C}}$ \\
\hline$\alpha$-Copaene & $<0.01$ & $0.01 \pm 0.001$ & $0.01 \pm 0.001$ & $0.01 \pm 0.002$ \\
\hline$\beta$-Elemene & / & $<0.01$ & $0.01 \pm 0.006$ & $0.01 \pm 0.006$ \\
\hline Aromadendrene & I & $0.01 \pm 0.003$ & l & I \\
\hline (Z)-caryophyllene & $<0.01$ & l & l & I \\
\hline (E)-caryophyllene & $0.08 \pm 0.021$ & $0.09 \pm 0.038$ & $0.11 \pm 0.029$ & $0.07 \pm 0.013$ \\
\hline$\beta$-Cubebene & $0.01 \pm 0.004^{\mathrm{AB}}$ & $0.01 \pm 0.003^{\mathrm{A}}$ & $0.03 \pm 0.012^{\mathrm{AB}}$ & $0.03 \pm 0.008^{\mathrm{B}}$ \\
\hline$\alpha$-Guaiene & $<0.01$ & $0.01 \pm 0.004$ & I & I \\
\hline Calarene & $<0.01^{\mathrm{A}}$ & $<0.01^{\mathrm{A}}$ & $0.01 \pm 0.005^{\mathrm{AB}}$ & $0.02 \pm 0.008^{\mathrm{B}}$ \\
\hline$\alpha$-Amorphene & l & $0.01 \pm 0.006$ & $<0.01$ & I \\
\hline$\alpha$-Humulene & $0.01 \pm 0.005$ & $<0.01$ & $0.02 \pm 0.007$ & $0.01 \pm 0.004$ \\
\hline Germacrene-d & $0.08 \pm 0.024^{\mathrm{AB}}$ & $0.07 \pm 0.013^{\mathbf{A}}$ & $0.2 \pm 0.078^{\mathrm{AB}}$ & $0.2 \pm 0.061^{\mathrm{B}}$ \\
\hline$\alpha$-Farnesene & $0.2 \pm 0.058^{\mathbf{A}}$ & $0.1 \pm 0.025^{\mathrm{A}}$ & $1.51 \pm 0.449^{\mathbf{B}}$ & $0.75 \pm 0.179^{\mathbf{B}}$ \\
\hline d-Cadinene & $0.01 \pm 0.002$ & $0.02 \pm 0.007$ & $0.02 \pm 0.006$ & $0.03 \pm 0.011$ \\
\hline Nerolidol & / & l & $<0.01$ & l \\
\hline Patchoulialcohol & $<0.01$ & $0.01 \pm 0.003$ & $<0.01$ & $<0.01$ \\
\hline Sesquiterpenes total & $0.43 \pm 0.09^{\mathbf{A}}$ & $0.33 \pm 0.061^{\mathbf{A}}$ & $1.95 \pm 0.545^{\mathrm{B}}$ & $1.16 \pm 0.273^{B}$ \\
\hline \multicolumn{5}{|l|}{ Other BVOCs } \\
\hline propanenitrile, 2 -methyl & I & I & $0.02 \pm 0.010$ & $0.01 \pm 0.009$ \\
\hline 3-methylbutanal & $/^{\mathbf{A}}$ & $/^{\mathbf{A}}$ & $0.02 \pm 0.004^{\mathbf{B}}$ & $0.01 \pm 0.010^{\mathrm{AB}}$ \\
\hline 2-ethylfuran & $\rho^{\mathbf{A}}$ & $0.04 \pm 0.027^{\mathbf{A B C}}$ & $0.1 \pm 0.013^{\mathbf{B}}$ & $0.04 \pm 0.017^{\mathrm{AC}}$ \\
\hline \multicolumn{5}{|l|}{ (E)-1-Butyl-2- } \\
\hline methylcyclopropane & l & $0.01 \pm 0.011$ & $<0.01$ & $<0.01$ \\
\hline (Z)-3-Hexen-1-ol & $1.03 \pm 0.222$ & $1.08 \pm 0.28$ & $2.1 \pm 0.739$ & $1.05 \pm 0.307$ \\
\hline (E)-2-Hexenal & I & I & $0.15 \pm 0.155$ & $0.55 \pm 0.444$ \\
\hline (E)-2-Hexen-1-ol & $\rho^{\mathbf{A}}$ & $\rho^{\mathbf{A}}$ & $0.11 \pm 0.037^{\mathbf{B}}$ & $0.03 \pm 0.035^{\mathrm{AB}}$ \\
\hline 1-Nonene & l & l & $<0.01$ & $0.01 \pm 0.009$ \\
\hline $\begin{array}{l}\text { 2-Methyl-2-cyclopenten- } \\
\text { 1-one }\end{array}$ & I & $<0.01$ & $0.01 \pm 0.003$ & $<0.01$ \\
\hline
\end{tabular}


Chapter 5: Transgenic non-isoprene emitting poplars

\begin{tabular}{|c|c|c|c|c|}
\hline \multirow{2}{*}{$\begin{array}{l}\text { BVOCs }\left[\mathrm{pmol} \mathrm{m}{ }^{-2} \mathrm{~s}^{-1}\right] \\
\text { Treatment } \\
P . \mathrm{x} \text { canescens genotypes }\end{array}$} & \multicolumn{2}{|l|}{ No herbivory } & \multicolumn{2}{|l|}{ Herbivory } \\
\hline & $\mathrm{IE}$ & $\mathrm{NE}$ & IE & $\mathrm{NE}$ \\
\hline$(E, E)-$-2,4-Hexadienal & 1 & I & $0.02 \pm 0.010$ & $<0.01$ \\
\hline Cumene & $0.01 \pm 0.007$ & $0.01 \pm 0.009$ & l & $0.01 \pm 0.003$ \\
\hline (Z)-3-Hexen-1-ol acetate & $3.69 \pm 0.786$ & $4.52 \pm 1.042$ & $3.52 \pm 1.012$ & $2.41 \pm 0.718$ \\
\hline p-Cymol & $0.01 \pm 0.005$ & $0.01 \pm 0.006$ & $0.02 \pm 0.008$ & $0.03 \pm 0.010$ \\
\hline Salicylaldehyde & $0.03 \pm 0.007^{\mathrm{A}}$ & $0.05 \pm 0.010^{\mathbf{A}}$ & $0.42 \pm 0.086^{\mathbf{B}}$ & $0.58 \pm 0.317^{\mathbf{A B}}$ \\
\hline 2-Methylphenol & $0.01 \pm 0.007$ & $0.01 \pm 0.007$ & I & $0.01 \pm 0.006$ \\
\hline Acetophenone & / & 1 & $0.04 \pm 0.024$ & $0.06 \pm 0.03$ \\
\hline o-Isopropenyltoluene & & l & $0.01 \pm 0.007$ & $0.01 \pm 0.009$ \\
\hline Methyl benzoate & $0.02 \pm 0.012^{\mathbf{A B}}$ & $0.01 \pm 0.005^{\mathrm{A}}$ & $0.05 \pm 0.016^{\mathrm{BC}}$ & $0.05 \pm 0.015^{\mathrm{C}}$ \\
\hline $\begin{array}{l}\text { (E)-4,8-dimethyl-1,3,7- } \\
\text { nonatriene }\end{array}$ & $0.59 \pm 0.143^{\mathrm{A}}$ & $0.15 \pm 0.018^{\mathbf{B}}$ & $0.66 \pm 0.269^{A}$ & $0.26 \pm 0.059^{\mathrm{AB}}$ \\
\hline Benzeneethanol & $0.02 \pm 0.007^{\mathbf{A}}$ & $0.03 \pm 0.004^{\mathrm{AB}}$ & $0.10 \pm 0.025^{\mathrm{C}}$ & $0.13 \pm 0.078^{\mathrm{BC}}$ \\
\hline Benzeneacetonitrile & $<0.01^{\mathrm{A}}$ & $/^{\mathrm{A}}$ & $0.07 \pm 0.013^{\mathrm{B}}$ & $0.12 \pm 0.041^{\mathbf{B}}$ \\
\hline $\begin{array}{l}\text { (Z)-3-hexenyl iso- } \\
\text { butyrate }\end{array}$ & $0.01 \pm 0.005$ & $<0.01$ & $0.03 \pm 0.011$ & $0.03 \pm 0.012$ \\
\hline Methyl salicylate & $0.34 \pm 0.125$ & $0.11 \pm 0.009$ & $1.05 \pm 0.517$ & $0.35 \pm 0.092$ \\
\hline 1H-Indole & $0.01 \pm 0.004$ & $<0.01$ & $0.03 \pm 0.020$ & $0.03 \pm 0.022$ \\
\hline Eugenol & $/^{\mathrm{A}}$ & $\mu^{A}$ & $0.04 \pm 0.009^{\mathbf{B}}$ & $0.06 \pm 0.033^{\mathrm{B}}$ \\
\hline 2-ethyl-naphthalene & $<0.01$ & I & I & 1 \\
\hline Decyl acetate & 1 & I & $<0.01$ & 1 \\
\hline$\beta$-Ionone & l & I & $0.01 \pm 0.009$ & 1 \\
\hline dihydroactinidiolide & $\rho^{A}$ & $A^{A}$ & $0.01 \pm 0.003^{\mathbf{B}}$ & $f^{\mathrm{A}}$ \\
\hline (Z)-3-hexenyl benzoate & $0.08 \pm 0.034$ & $0.06 \pm 0.029$ & $0.07 \pm 0.012$ & $0.04 \pm 0.009$ \\
\hline n-Hexyl benzoate & 1 & 1 & $0.01 \pm 0.007$ & $<0.01$ \\
\hline Unknown compound & $\rho^{\mathrm{A}}$ & $A^{\mathbf{A}}$ & $0.02 \pm 0.005^{\mathbf{B}}$ & $0.02 \pm 0.009^{\mathbf{A B}}$ \\
\hline TOTAL other BVOCs & $5.84 \pm 1.283$ & $6.09 \pm 1.393$ & $8.68 \pm 1.440$ & $5.93 \pm 1.576$ \\
\hline
\end{tabular}

Different letters indicate statistically significant differences between genotypes and/or treatments, $P<0.05$. 
Table S5.4 | Characteristics of the biogenic volatile organic compounds (BVOC) sampled by isoprene emitting (IE) and non-emitting (NE), and Chrysomela populi infested or un-infested $P$. $x$ canescens trees (see Table S5.3).

\begin{tabular}{llllll}
\hline BVOC & $\begin{array}{l}\text { CAS } \\
\text { registry no }\end{array}$ & RT & $I$ & $1^{\text {st }} \mathrm{m} / \mathrm{z}$ & $\begin{array}{l}\text { Absolute } \\
\text { abundance }\end{array}$ \\
\end{tabular}
$(\%)$ of $1^{\mathrm{st}} \mathrm{m} / \mathrm{z}$

\section{Isoprene}

Monoterpenes

Tricyclene

Cyclofenchene

$\alpha$-Thujene

$\alpha$-Phellandrene

$\alpha$-Pinene

2- $\beta$-Pinene

Myrcene

Sabinene

1,8-Cineole

Citronellal

(E)- $\beta$-ocimene

$\gamma$-Terpinene

allo-Ocimene

Borneol

$\beta$-Cyclocitral

Monoterpenes total

\section{Sesquiterpenes}

Bicyclogermacrene

$\alpha$-Ylangene

$\alpha$-Cubebene

$\alpha$-Copaene

$\beta$-Elemene

Aromadendrene

(Z)-caryophyllene

(E)-caryophyllene

$\beta$-Cubebene

$\alpha$-Guaiene

Calarene

$\alpha$-Amorphene

$\alpha$-Humulene

Germacrene-d

$\alpha$-Farnesene

d -Cadinene

Nerolidol

Patchoulialcohol

Sesquiterpenes total

\section{Other BVOCs}

propanenitrile, 2-methyl

3-methylbutanal

2-ethylfuran

(E)-1-Butyl-2-

methylcyclopropane

(Z)-3-Hexen-1-ol

(E)-2-Hexenal

(E)-2-Hexen-1-ol

1-Nonene

$\begin{array}{llll}78795 & 5.99 & 578 & 67\end{array}$

25.1

$\begin{array}{rr}508327 & 14.88 \\ 488971 & 14.89 \\ 2867052 & 14.96 \\ 99832 & 15 \\ 7785708 & 15.36 \\ 127913 & 17.35 \\ 123353 & 17.62 \\ 3387415 & 19.73 \\ 470826 & 19.8 \\ 106230 & 20.04 \\ 3779611 & 20.24 \\ 99854 & 20.88 \\ 673847 & 24 \\ 10385781 & 26.26 \\ 432257 & 28.27\end{array}$

$909 \quad 93$

19.3

$909 \quad 121$

$911 \quad 77$

13.3

24.7

912

921

11.0

22.3

969

975

1027

1028

1034

1039

1055

1131

1185

1234

8.1

6.9

7.3

27.1

17.8

19.5

13.8

4.8

6.2

8.7

$\begin{array}{rrrrr}24703353 & 33.06 & 1351 & 93 & 25.5 \\ 14912448 & 33.64 & 1365 & 161 & 17.8 \\ 17699148 & 33.64 & 1365 & 105 & 16.6 \\ 3856255 & 34.88 & 1395 & 105 & 29.1 \\ 515139 & 35.33 & 1406 & 93 & 12.9 \\ 489394 & 35.34 & 1406 & 161 & 26.6 \\ 13877935 & 36.07 & 1424 & 93 & 3.9 \\ 87445 & 36.68 & 1439 & 93 & 2.6 \\ 13744155 & 37.03 & 1447 & 161 & 18.5 \\ 3691121 & 37.15 & 1450 & 105 & 25.3 \\ 17334553 & 37.85 & 1467 & 105 & 7.5 \\ 23515880 & 37.87 & 1468 & 161 & 8.8 \\ 6753986 & 38.05 & 1472 & 93 & 13.5 \\ 23986745 & 38.93 & 1493 & 161 & 6.2 \\ 502614 & 39.35 & 1504 & 93 & 17.2 \\ 483761 & 39.93 & 1518 & 161 & 4.9 \\ 7212444 & 40.89 & 1541 & 69 & 3.4 \\ 5986550 & 43.48 & 1604 & 161 & \end{array}$

\begin{tabular}{rrrrr}
78820 & 7.13 & 610 & 42 & 30.5 \\
590863 & 7.39 & 617 & 44 & 24.7 \\
3208160 & 8.11 & 637 & 81 & 15.1 \\
& & & & \\
38851706 & 10.26 & 797 & 55 & 28.2 \\
928961 & 12.09 & 841 & 67 & 4.2 \\
505577 & 12.1 & 841 & 69 & 34.9 \\
928950 & 12.43 & 849 & 82 & 3.9 \\
124118 & 13.41 & 873 & 55 & 2.1 \\
\hline
\end{tabular}


Chapter 5: Transgenic non-isoprene emitting poplars

\begin{tabular}{|c|c|c|c|c|c|}
\hline BVOC & $\begin{array}{l}\text { CAS } \\
\text { registry no }\end{array}$ & RT & $I$ & $1^{\mathrm{st}} \mathrm{m} / \mathrm{z}$ & $\begin{array}{l}\text { Absolute } \\
\text { abundance } \\
\text { (\%) of } 1^{\text {st }} \mathrm{m} / \mathrm{z}\end{array}$ \\
\hline $\begin{array}{l}\text { 2-Methyl-2-cyclopenten-1- } \\
\text { one }\end{array}$ & 1120736 & 14.02 & 888 & 67 & 10.8 \\
\hline$(E, E)--2,4$-Hexadienal & 142836 & 14.26 & 894 & 81 & 3.5 \\
\hline Cumene & 98828 & 14.87 & 909 & 105 & 10.5 \\
\hline (Z)-3-Hexen-1-ol acetate & 3681718 & 18.28 & 992 & 67 & 5.1 \\
\hline p-Cymol & 99876 & 19.11 & 1012 & 119 & 5.2 \\
\hline Salicylaldehyde & 90028 & 20.37 & 1042 & 122 & 16.0 \\
\hline 2-Methylphenol & 95487 & 20.51 & 1046 & 108 & 5.7 \\
\hline Acetophenone & 98862 & 21.29 & 1065 & 105 & 4.6 \\
\hline o-Isopropenyltoluene & 7399497 & 22.39 & 1091 & 117 & 6.4 \\
\hline $\begin{array}{l}\text { Methyl benzoate } \\
(F)-4 \text { 8-dimethyl-137- }\end{array}$ & 93583 & 22.58 & 1096 & 105 & 16.9 \\
\hline nonatriene & 0 & 23.32 & 1114 & 79 & 7.2 \\
\hline Benzeneethanol & 60128 & 23.48 & 1118 & 91 & 4.2 \\
\hline Benzeneacetonitrile & 140294 & 24.56 & 1144 & 117 & 5.9 \\
\hline (Z)-3-hexenyl iso-butyrate & 41519237 & 26.51 & 1192 & 71 & 13.8 \\
\hline Methyl salicylate & 119368 & 27.07 & 1205 & 120 & 9.6 \\
\hline 1H-Indole & 120729 & 31.35 & 1309 & 117 & 17.8 \\
\hline Eugenol & 97530 & 33.71 & 1367 & 121 & 12.3 \\
\hline 2-ethyl-naphthalene & 939275 & 35.62 & 1413 & 141 & 6.5 \\
\hline Decyl acetate & 112174 & 35.78 & 1417 & 55 & 11.6 \\
\hline$\beta$-Ionone & 14901076 & 38.65 & 1487 & 177 & 8.0 \\
\hline dihydroactinidiolide & 15356748 & 40.34 & 1528 & 11 & 24.3 \\
\hline (Z)-3-hexenyl benzoate & 25152856 & 41.2 & 1549 & 105 & 27.6 \\
\hline n-Hexyl benzoate & 6789884 & 41.36 & 1553 & 105 & 1.6 \\
\hline Unknown compound & & 46.83 & 1685 & 149 & 19.4 \\
\hline
\end{tabular}

CAS: Chemical Abstracts Service

RT: retention time

I: retention index calculated according to van Den Dool and Kratz (1963)

$\mathrm{m} / \mathrm{z}$ : mass to charge ratio 


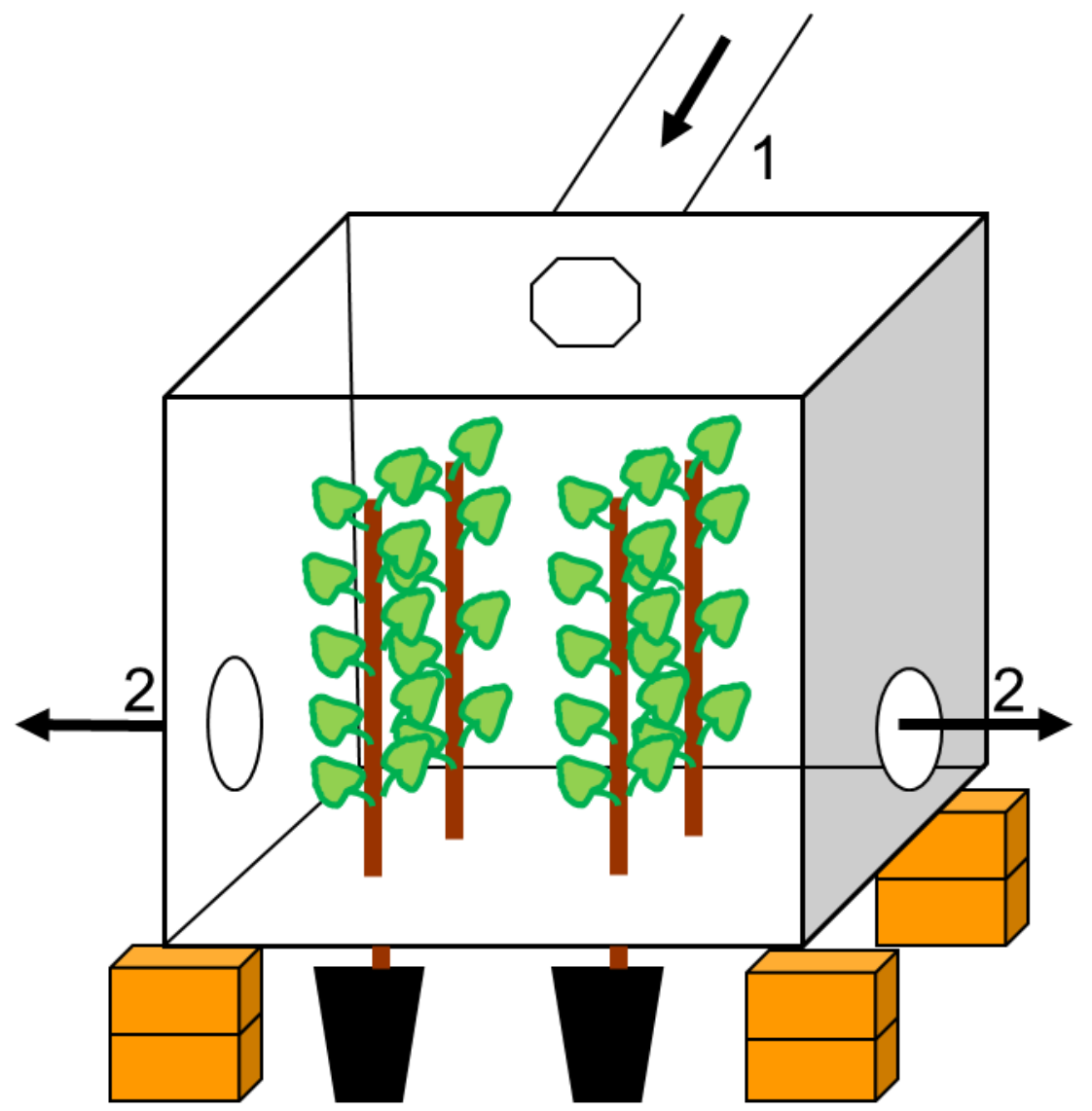

Figure S5.1 | A schema of an acclimatized cuvette for conducting bioassays. The numbers indicate the inlet (1) and outlet (2) airflow. 
Chapter 5: Transgenic non-isoprene emitting poplars

Progress of antenna sensitivity over time

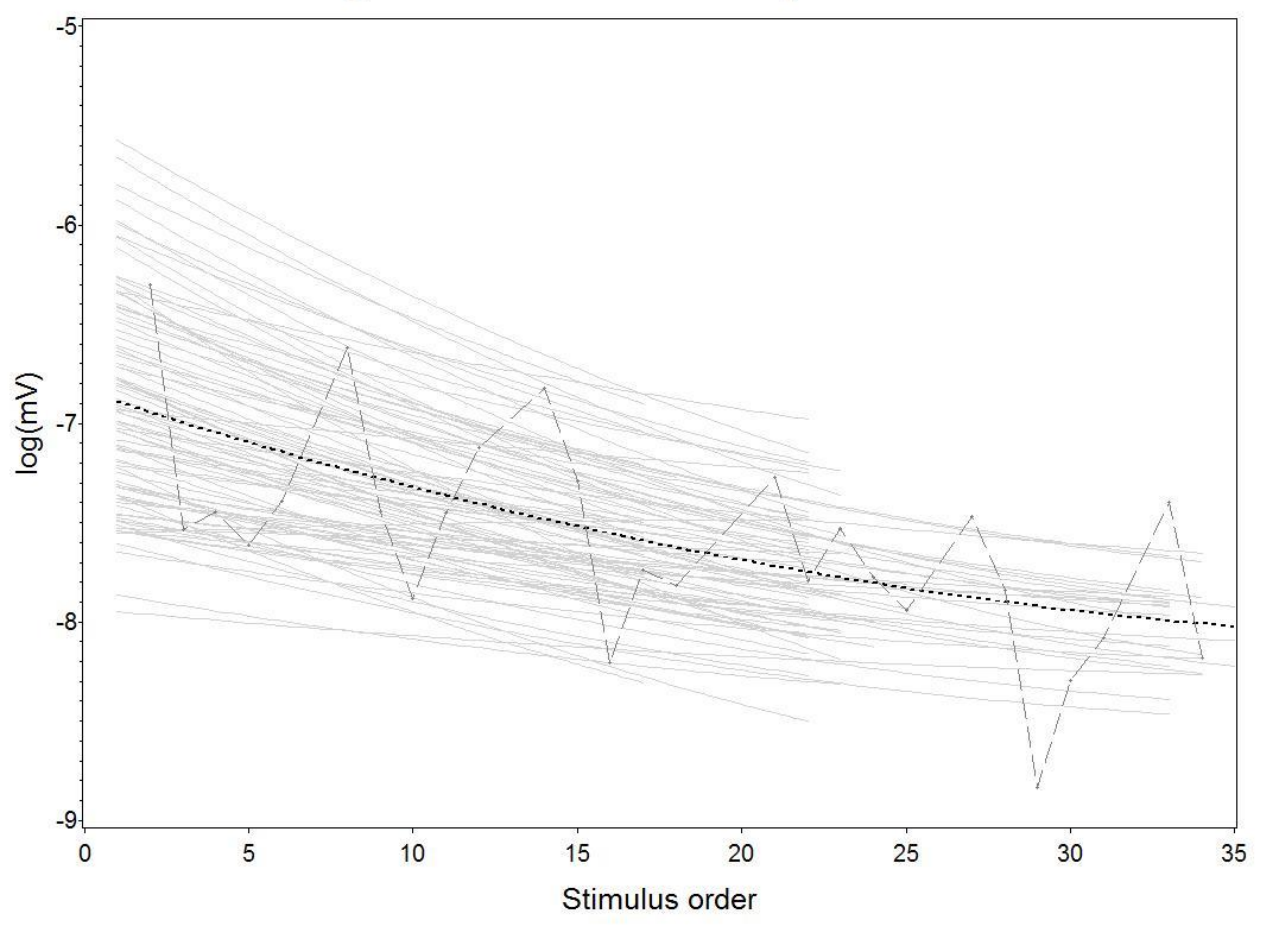

Figure S5.2 | Predicted relationships between stimulus order and response by quadratic regression for individual antennae and overall; data from an individual antenna are shown as example. 

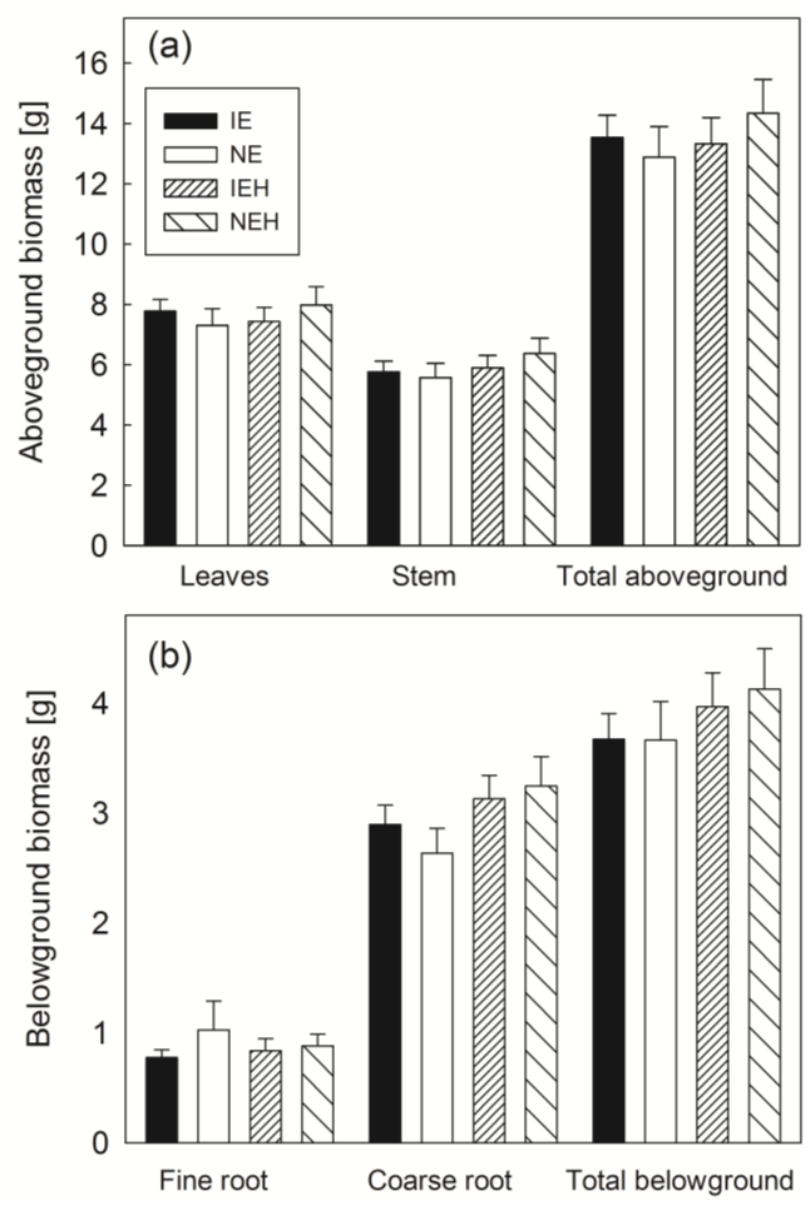

Figure S5.3 | The biomass of isoprene emitting (IE) and isoprene non-emitting (NE) and Chrysomela populi infested (H) and non-infested Populus $\mathrm{x}$ canescens trees in outdoor conditions. The biomass of the aboveground (a) and belowground (b) parts was measured after 14-d lasting experiment. 


\subsection{Declaration}

The following data shown in this chapter have been provided by other authors:

- The electroantennography recordings were provided by Patrick Faubert ${ }^{2,4}$, Hans M Smid ${ }^{6}$, Joop JA van Loon $^{6}$ and Gerrit Gort ${ }^{5}$.

- The VOC collections were performed by Patrick Faubert ${ }^{2,4}$ and Maaria Rosenkranz ${ }^{2}$.

- The insect bioassays in the greenhouse and the olfactometer bioassays were conducted by Patrick Faubert ${ }^{2,4}$ and Maaria Rosenkranz ${ }^{2}$.

- Maaria Rosenkranz ${ }^{2}$ contributed to the C. populi bioassay under close-to-natural conditions conducted by Anna Müller ${ }^{1}$ by the colllection and release of the beetles and data analysis.

- Metabolome analyses were performed by Moritz Kaling ${ }^{2,3}$.

The manuscript was written by Maaria Rosenkranz ${ }^{2}$, Moritz Kaling ${ }^{2,3}$, Anna Müller ${ }^{1}$, Marcel Dicke ${ }^{6}$, Jörg-Peter Schnitzler ${ }^{2}$ and Andrea Polle ${ }^{1}$. All authors commented on the final version.

${ }^{1}$ Büsgen Institute, Forest Botany and Tree Physiology, University of Göttingen, Germany

${ }^{2}$ Research Unit Environmental Simulation, Institute of Biochemical Plant Pathology, Helmholtz Zentrum München, Germany

${ }^{3}$ Research Unit Analytical BioGeoChemistry, Helmholtz Zentrum München, Germany

${ }^{4}$ Present address: Département des Sciences Fondamentales, Chaire en éco-conseil, Université du Québec à Chicoutimi, Canada

${ }^{5}$ Mathematical and Statistical Methods Group, Wageningen University, The Netherlands ${ }^{6}$ Laboratory of Entomology, Wageningen University, The Netherlands 


\section{Chapter 6}

Influence of EMF inoculation on transcriptomic profiles of poplar leaves and the behaviour of $C$. populi beetles 


\section{Influence of EMF inoculation on transcriptomic profiles of poplar leaves and the behaviour of $C$. populi beetles}

\subsection{Introduction}

Plant health is influenced by the complex interaction with above- and belowground organisms like herbivores and ectomycorrhizal fungi (EMF). Mycorrhizal colonisation can affect plant growth (Colpaert et al., 1992; Manninen et al., 1998) and enhance nutrient uptake and stress tolerance of the host plant (Nehls et al., 2010). These effects can lead to a plant-mediated interaction between mycorrhizal fungi and aboveground herbivores (Gehring and Bennett, 2009).

To gain further knowledge on the tripartite interaction between plants, mycorrhizal fungi and herbivores numerous studies were performed in the last decade (Manninen et al., 1998; Gange et al., 1999; Saikkonen et al., 1999; Goverde et al., 2000; Halldórsson et al., 2000; Wamberg et al., 2003; Gange et al., 2005; Mueller et al., 2005; Gehring and Bennett, 2009; Koricheva et al., 2009; Laird and Addicott, 2008; Hartley and Gange, 2009; Sthultz et al., 2009; Younginger et al., 2009; Leitner et al., 2010; Oddsdottir et al., 2010; Pineda et al., 2010; Jung et al., 2012; Pineda et al., 2013). Reports about EMF demonstrate that the influence of the EMF association on herbivores is highly variable and depends on the plant, fungal and insect species. For example, inoculation of Timor mountain gum (Eucalyptus urophylla) with the EMF Laccaria laccata decreased herbivory of the leaf chewing Green flower beetle (Anomala cupripes) (Gange et al., 2005). A positive effect on the leaf chewing gypsy moth (Lymantria dispar) was shown for pure American chestnut (Castanea dentate) inoculated with the EMF Pisolithus tinctorius (Rieske et al., 2003).

So far, the mechanisms underlying the increase or decrease in herbivory after mycorrhization remain largely unknown. Changes of the leaf quality can alter the attractiveness of plants for herbivorous insects (Awmack and Leather, 2002; Fernandez and Hilker, 2007). For example, the presence of the EMF Paxillus involutus influenced leaf physiology and the levels of nutrient elements in Grey poplars (Populus $\times$ canescens) (Luo et al., 2011). Buckhorn plantain plants (Plantago lanceolata L.) that were attacked by cotton leafworm (Spodoptera littoralis Boisd) emitted less sesquiterpenes when the plants formed mycorrhiza with the arbuscular mycorrhizal fungus (AMF) Glomus intraradices compared to the non-mycorrhizal plants (Fontana et al., 2010). Leaves of P. lanceolota had 
increased amounts of the feeding deterrents aucubin and catalpol in AM plants compared to non-AM plants (Gange and West, 1994). AM colonisation of white clover (Trifolium repens) changed the flavonoid metabolism in the roots and shoot (Larose et al., 2002). In Grey poplar (Populus $\times$ canescens) inoculated with the EMF Paxillus involutus (Luo et al., 2009a) and in poplar (Populus trichocarpa $\times$ deltoides) inoculated with the EMF Hebeloma mesophaeum (Pfabel et al., 2012) the EMF inoculation led to changes in the primary and secondary plant metabolism.

Poplars are of high economic value and are grown worldwide for the production of biomass and bioenergy (Polle and Douglas, 2010). The poplar leaf beetle (Chrysomela populi) is one of the main poplar herbivores (Brilli et al., 2009). The adult beetles as well as the larvae prefer to feed on the young leaves of the trees (Harrell et al., 1981). Infestation of poplar plantations with the poplar leaf beetle $C$. populi can lead to great damage (Georgi et al., 2012).

Poplars use phenolic secondary metabolites like phenolic glycosides, hydroxycinnamate derivatives or condensed tannins for defence against herbivores (Tsai et al., 2006). Furthermore benzene cyanide, volatiles, anti-digestive proteins, aldoximes and physical defences like leaf trichomes play a role in defence against biotic stress (Arimura et al., 2004; Philippe and Bohlmann, 2007; Irmisch et al., 2013).

In this study it was analysed whether the inoculation of poplar with EMF induces molecular changes in the leaves and whether these changes influence herbivores. $P . \times$ canescens plantlets were inoculated with the EMF Laccaria bicolor and exposed to $C$. populi beetles under outdoor conditions. The hypotheses were tested (i) that the EMF inoculation reduces infestation by $C$. populi beetles of inoculated poplars compared to noninoculated poplars, (ii) that the $C$. populi feeding induces strong defence reactions in inoculated and non-inoculated poplars and (iii) that inoculated poplars differ from noninoculated poplars in the transcript abundance of genes involved in these defence reactions as well as in hormone signalling pathways and flavonoid biosynthesis pathways. The feeding behaviour and oviposition of $C$. populi beetles on inoculated and non-inoculated poplars were compared. Leaf samples were used for RNA sequencing to investigate the molecular basis for changes in beetle behaviour. 


\subsection{Materials and methods}

\subsubsection{Plant material and inoculation of poplar with the mycorrhizal fungus Laccaria bicolor}

The ectomycorrhizal fungus Laccaria bicolor (Maire P.D. Orton) was cultivated for three weeks in a sandwich system on a sand/peat mixture (two parts peat (REWE, Köln, Germany), eight parts coarse sand (Ø 0.71-1.25 mm Melo, Göttingen, Germany) and two parts fine sand (Ø 0.4-0.8 mm Melo, Göttingen) as described by Müller et al. (2013). For controls, a sand/peat mixture without adding the fungus was prepared in the same way.

Before planting of the poplars, the sand/peat mixture with the fungus was mixed with 31 of the same sand/peat mixture as described by Müller et al. (2013). For control plants, the sand/peat mixture without fungal inoculum was mixed with the sand/peat mixture in 31 pots. Grey poplars (Populus $\times$ canescens) were grown under axenic conditions for two weeks on rooting media and directly planted in the sand/peat mixture in 31 pots, either with or without fungal inoculum, and gradually acclimated to outdoor conditions as described by Müller et al. (2013). The poplars were automatically irrigated three times daily with $10 \mathrm{ml}$ for the first 5 weeks and thereafter with $20 \mathrm{ml}$ using an irrigation system with a Long Ashton solution [0.074 $\mathrm{g} \mathrm{l}^{-1}$ magnesium sulphate heptahydrate (Merck, Darmstadt, Germany), $21.25 \times 10^{-2} \mathrm{~g} \mathrm{l}^{-1}$ calcium nitrate tetrahydrate (Merck, Darmstadt, Germany), $81.64 \times 10^{-3} \mathrm{~g}^{-1}$ potassium phosphate (Merck, Darmstadt, Germany), 20.22 x $10^{-3} \mathrm{~g}^{-1}$ potassium nitrate (Merck, Darmstadt, Germany), $72 \times 10^{-4} \mathrm{~g}^{-1}$ dipotassium phosphate (Merck, Darmstadt, Germany), $32 \times 10^{-6} \mathrm{~g} \mathrm{l}^{-1}$ copper sulfate pentahydrate (Merck, Darmstadt, Germany), $36.71 \times 10^{-4} \mathrm{~g} \mathrm{l}^{-1}$ iron sodium ethylenediaminotetraacetate (Sigma, Steinheim, Germany), $6.18 \times 10^{-4} \mathrm{~g}^{-1}$ boric acid (Carl Roth, Karlsruhe, Germany), $3.38 \times 10^{-4} \mathrm{~g} \mathrm{l}^{-1}$ manganese sulfate monohydrate (Merck, Darmstadt, Germany), $16.92 \times 10^{-}$ ${ }^{4} \mathrm{~g} \mathrm{l}^{-1}$ sodium molybdate dihydrate (Merck, Darmstadt, Germany), $5.76 \times 10^{-5} \mathrm{~g} \mathrm{l}^{-1}$ zinc sulfate heptahydrate (Merck, Darmstadt, Germany), $1.12 \times 10^{-5} \mathrm{~g} \mathrm{l}^{-1}$ cobalt (II) sulfate heptahydrate (Merck, Darmstadt, Germany)] as described by Müller et al. (2013).

After inoculation the poplars were grown under outdoor conditions at $17.9^{\circ} \mathrm{C} \pm 0.5^{\circ} \mathrm{C}$ and $68.7 \% \pm 2.4 \%$ humidity. Three weeks before the beetle bioassay the plants were placed in cages $(190 \mathrm{~cm} \times 140 \mathrm{~cm} \times 190 \mathrm{~cm})$ covered with mesh screen (mesh size: $1.4 \mathrm{~mm}$; thickness: $0.28 \mathrm{~mm}$ ) (Fig. 6.1A). In each cage eight inoculated [M] and eight noninoculated $[\mathrm{N}]$ poplars were placed (Fig. 6.1B). In four cages beetles were released [B]. Plants in the other four cages $[\mathrm{C}]$ were used as a control. The plants were arranged as such, 
that the C. populi beetles (Fig. 6.1C) had the choice between the inoculated MB poplars and the non-inoculated NB poplars when being in between two plants. The height of each plant was measured every 14 days until the end of the experiment.
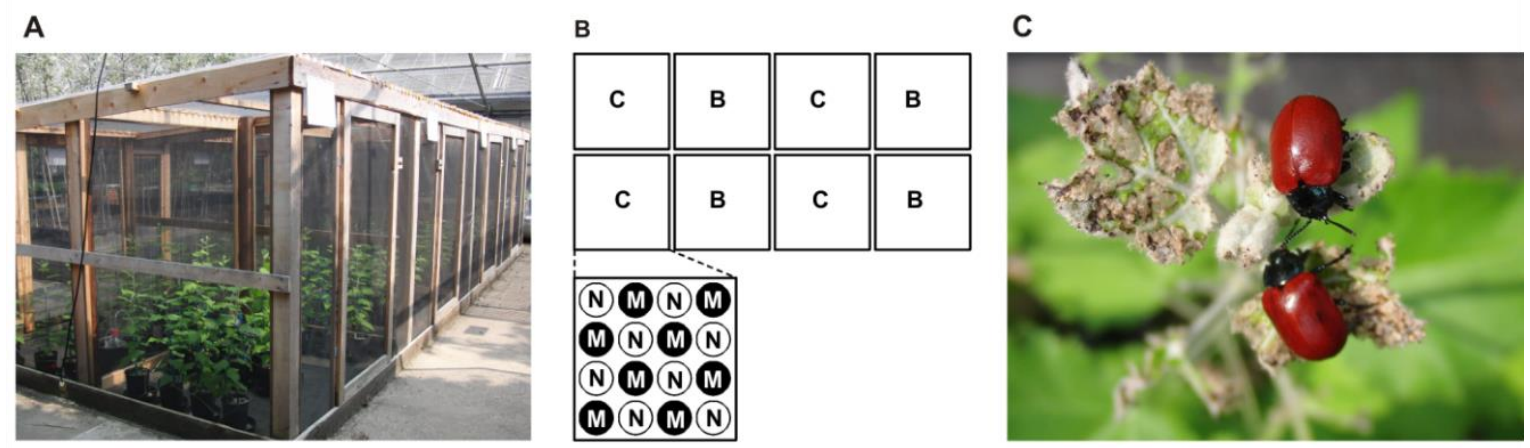

Fig. 6.1 Chrysomela populi behaviour experiment with Populus $\times$ canescens plants inoculated or noninoculated with the EMF Laccaria bicolor under outdoor conditions. A) Photograph of the cages and B) scheme of the arrangement of control cages [C] and cages with C. populi beetles [B] as well as the arrangement of the poplars in each cage. The poplars were either inoculated with the EMF L. bicolor [M] or non-inoculated [N]. C) Photograph of C. populi beetles.

\subsubsection{Exposition of poplar to $C$. populi beetles}

Ten weeks after the mycorrhizal inoculation, the NB and MB poplars were exposed to $C$. populi beetles. Adult $C$. populi beetles were collected from poplar plantations in south Germany. 320 beetles were released in four cages ( 80 beetles per cage). For the following 14 days the beetles had the choice between NB and MB plants. The localisation of the beetles as well as the egg deposition was recorded every day. To investigate the feeding behaviour of the beetles a visual scale for the fed leaf area of each single leaf was used. The visual scale ranged from 0 (undamaged), 1 (<10\% fed), 2 (10 - $25 \%$ fed), 3 (25 $50 \%$ fed), 4 (50-75\% fed) to 5 (> $75 \%$ fed) (Fig. 6.2).

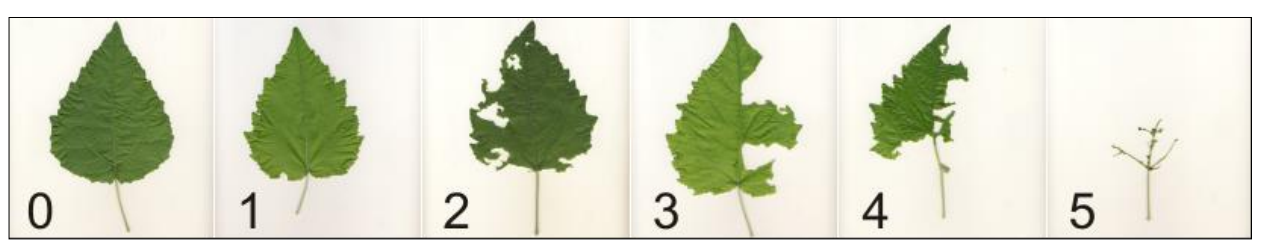

Fig. 6.2 To determine the leaf damage by $\boldsymbol{C}$. populi feeding a visual scale was used. The scale ranged from $0=$ undamaged, $1=<10 \%$ fed, $2=10-25 \%$ fed, $3=25-50 \%$ fed, $4=50-75 \%$ fed to $5=>75 \%$ fed. 


\subsubsection{Harvest of plant material}

For transcriptional analysis leaf samples were harvested eight days after release of the beetles. Of each plant, leaf number five from apex was taken. Leaf samples of all MB, NB, MC or NC poplars in one cage were pooled. Leaves were immediately frozen in liquid nitrogen and stored at $-80^{\circ} \mathrm{C}$.

After 14 days of beetle exposure all plants were harvested. The root system was washed, separated into fine $(<2 \mathrm{~mm}$ in diameter) and coarse roots and weighed. Root samples were kept at $4^{\circ} \mathrm{C}$ in plastic bags for further root analysis.

Fresh mass of stem and leaves were recorded. Two fresh leaves of each plant (= aliquot) were scanned and weighed to calculate the total leaf area with the equation:

$$
\text { total leaf area }\left(\mathrm{m}^{2}\right)=\frac{\text { total leaf biomass }(\mathrm{g}) \mathrm{x} \text { leaf area of aliquot }\left(\mathrm{m}^{2}\right)}{\text { leaf biomass of aliquot }(\mathrm{g})} \text {. }
$$

To determine dry weight the plant materials were dried at $60^{\circ} \mathrm{C}$ for seven days.

\subsubsection{Root analysis}

Randomly selected subsamples of the roots were examined under a stereomicroscope (Leica DFC 420 C, Wetzlar, Germany). To calculate the mycorrhization rate, the number of mycorrhized, non-mycorrhized, vital and non-vital root tips were counted for 200 root tips per plant. The mycorrhization rate was calculated with the equation:

$$
\text { Mycorrhization }(\%)=\frac{n \text { mycorrhizal root tips }}{n \text { vital root tips }} \times 100
$$

After root analysis the dry weight of the roots was determined as described before.

\subsubsection{RNA extraction}

Total RNA was extracted from the biological replicates of the $\mathrm{NC}, \mathrm{MC}, \mathrm{NB}$ and $\mathrm{MB}$ treatments. The leaves were ground in liquid nitrogen in a ball mill (Retsch, Haan, Germany). $500 \mathrm{mg}$ powder was used for RNA extraction according to the method described by Chang et al. 1993. 


\subsubsection{RNA sequencing and bioinformatical analysis}

RNA quality check on a Bioanalyzer (Agilent 2100, Agilent, Santa Clara, CA, USA), library construction and sequencing were conducted at Chronix Biomedical (Chronix Biomedical, Inc., Göttingen, Germany). RNA libraries were prepared using the Mint-2 Kit (Evrogen, Moscow, Russia). Single-end reads were sequenced with a length of $100 \mathrm{bp}$ on two lanes on an Illumina HighSeq 2000 (Illumina, San Diego, CA, USA). On each lane six samples were sequenced. Before processing, each sample consisted of $\sim 31$ to 39 million reads (Table S6.1). Processing of the raw sequence data was performed with the FASTX toolkit (http://hannonlab.cshl.edu/fastx_toolkit/). Using FASTQ Trimmer all nucleotides with a Phred score quality below 20 were removed from the end of the reads and sequences smaller than 50 bp or sequences with a Phred score below 20 of $10 \%$ of the nucleotides were discarded (http://hannonlab.cshl.edu/fastx_toolkit/). Adapter sequences as well as primers were removed with the FASTQ Clipper (http://hannonlab.cshl.edu/fastx_toolkit/). After processing 25 to 32 million reads per sample remained (Table S6.1).

The processed sequences were mapped against the Populus trichocarpa transcriptome (downloaded from http://phytozome.net) using Bowtie (http://bowtie-bio.sourceforge.net). Furthermore, using Bowtie (http://bowtie-bio.sourceforge.net) count tables of transcripts were generated. Transcripts were assigned to Populus trichocarpa IDs and annotated to homologous Arabidopsis thaliana gene IDs (AGI IDs) using the Affymetrix Poplar Chip annotation (Tsai et al. 2011; http://aspendb.uga.edu/downloads). To find transcripts with significantly increased or decreased transcript abundance the package edgeR (Robinson et al. 2010; http://www.bioconductor.org/packages/release/bioc/html/edgeR.html), implemented in R (http://www.r-project.org/) was used. To estimate overrepresented gene ontology (GO) terms, an enrichment analysis with the software "The Ontologizer" (Bauer et al. 2008; http://compbio.charite.de/contao/index.php/ontologizer2.html) was performed. Overrepresented GO terms with a $\mathrm{P}<0.05$ were determined by parent-child union with Benjamini-Hochberg correction (Benjamini and Hochberg, 1995).

To visualize pathways, transcriptomic data were uploaded in the software Paintomics (Version 2.0, http://www.paintomics.org). The software associated the transcripts to KEGG pathways and painted the pathways.

A weighted gene coexpression network analysis (WGCNA) was performed with normalized count tables, generated with the package edgeR, using the R package WGCNA (Langfelder and Horvath, 2008; http://labs.genetics.ucla.edu/horvath/Coexpression 
Network/Rpackages/WGCNA/). Values of modules were compared by conducting multiple comparisons between $\mathrm{MC} / \mathrm{NC}, \mathrm{MB} / \mathrm{NB}, \mathrm{NB} / \mathrm{NC}$ and $\mathrm{MB} / \mathrm{MC}$ with the $\mathrm{R}$ package multcomp (Hothorn et al., 2008; http://multcomp.r-forge.r-project.org). Cluster analysis of modules was done with the $\mathrm{R}$ package fastcluster (Müllner, 2013; http://danifold.net/fastcluster.html). Genes of each co-expression module were used for GO term analysis. Based on these results a principal component analysis (PCA) was performed with the R package prcomp (Mardia et al., 1979; Becker et al., 1988; Venables and Ripley, 2002; https://stat.ethz.ch/R-manual/R-devel/library/stats/html/prcomp.html). A heatmap was constructed using the package gplots (Warnes et al., 2014; http://cran.rproject.org/web/packages/gplots/index.html), implemented in R.

\subsubsection{Statistical analysis of behavioural, biomass and growth data}

All statistical analyses of behavioural, biomass and growth data were done using $\mathrm{R}$ (http://www.r-project.org/). Normal distribution of data was tested with the $\mathrm{r}$ function shapiro.test (Roysten, 1982a; Roysten, 1982b; Roysten, 1995; https://stat.ethz.ch/Rmanual/R-devel/library/stats/html/shapiro.test.html). Values of beetle location were compared by a test of proportions using the $\mathrm{r}$ function prop.test (Newcombe, 1998a; Newcombe, 1998b; https://stat.ethz.ch/R-manual/R-devel/library/stats/html/prop.test.html). With Wilcoxon rank sum test (Bauer, 1972; Hollander and Wolfe, 1973; https://stat.ethz.ch/R-manual/R-devel/library/stats/html/wilcox.test.html) values of feeding behaviour were compared. Values of plant height and biomass were compared by ANOVA followed by post-hoc Tukey test (Hothorn et al., 2008; http://multcomp.r-forge.rproject.org). $P$ values $\leq 0.05$ indicated significant differences.

\subsection{Results}

\subsubsection{Effect of EMF inoculation on feeding and egg deposition of $C$. populi}

Of the inoculated poplars $9.5 \pm 0.6 \%$ of the root tips were mycorrhized, whereas no mycorrhizas were observed on the non-inoculated plants. Half of the poplars that were inoculated with the mycorrhizal fungus L. bicolor $[\mathrm{M}]$ or non-inoculated $[\mathrm{N}]$ were exposed to $C$. populi beetles (MB, NB poplars) and the other half were grown under control conditions without beetles (MC, NC poplars). When the beetles were given the choice between NB and MB poplars, the beetles showed a preference for NB poplars, as 
significantly more beetles selected NB than MB poplars during the 14 days of the study ( $P$ $=0.003)($ Fig. 6.3A). The beetles also caused significantly higher feeding damage on NB than on MB poplars $(P=0.015$; Fig. $6.3 \mathrm{~B})$ and deposited significantly more eggs on NB than on MB poplars $(P=0.018$; Fig. 6.3C).

After eight days a mean leaf damage score of $3.5 \pm 0.2$ was observed for the upper part of the plants, which corresponds to about $75 \%$ fed leaf area. Thereafter the number of beetles on plants generally decreased, and the beetles were found at the meshwork of the cage or on the ground. In agreement with that observation both the leaf damage as well as oviposition increased only moderately after day eight compared to the previous days.

\subsubsection{Plant performance after EMF inoculation and beetle infestation}

Analysis of plant performance confirmed the preference of the beetles for NB compared with MB poplars, because the beetle infestation significantly decreased the height increment, leaf biomass and stem biomass of non-inoculated poplars (NB/NC) but not of inoculated poplars (MB/MC) (Fig. 6.4A,B). The total leaf area of infested poplars (NB or $\mathrm{MB}$ ) was significantly reduced compared with control plants (NC or MC) (Fig. 6.4C).

Inoculation of the poplars with L. bicolor also affected the plant growth. At the beginning of the experiment there was no significant difference in the plant height of $\mathrm{MC}$ and $\mathrm{NC}$ poplars, whereas at the end of the study the plant height increment of MC poplars was significantly lower compared with NC poplars (Fig. 6.4A). Furthermore, compared to NC poplars the MC poplars had $18 \%$ less total biomass, of which $17.8 \%$ was due to less above ground biomass. Leaf biomass of NC poplars was significantly higher than that of MC poplars (Fig. 6.4B). 

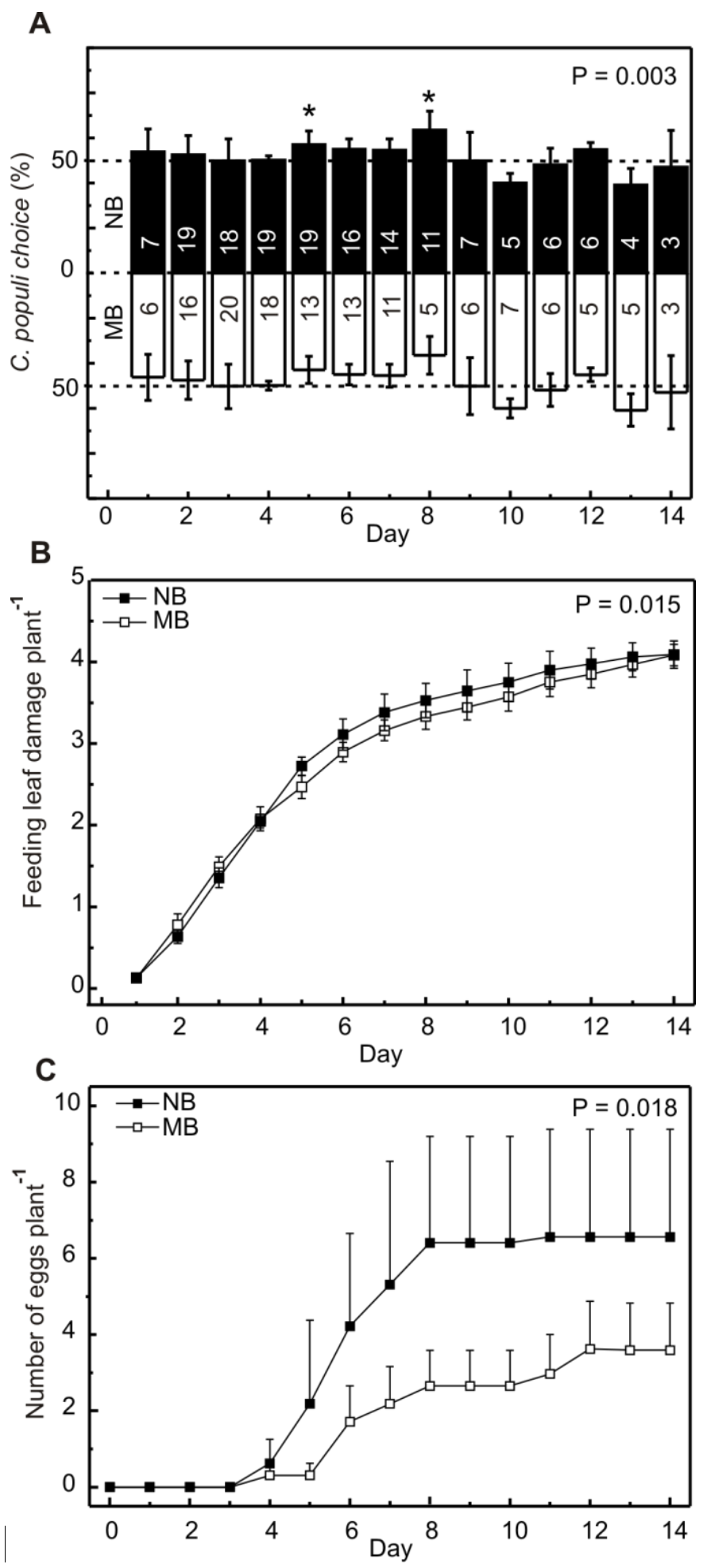

Fig. 6.3 $\mid$ C. populi showed a preference for non-inoculated poplars than for poplars inoculated with $L$. bicolor. Poplars were exposed to C. populi beetles in four cages. In each cage eight inoculated (MB) and eight non-inoculated (NB) poplars were grown. A) Bars represent the overall percentage of beetles choosing the location of $\mathrm{NB}$ or MB poplars (mean $\pm \mathrm{SE}$ ). Numbers in the bars represent the mean number of beetles choosing either NB or MB poplars. Stars indicate a significant difference at $\mathrm{P}<0.05$ (test of proportions). B) Leaf damage of the upper ten leaves based on a visual scale $(0=$ undamaged, $1=<10 \%$ fed, $2=10-25 \%$ fed, $3=25-50 \%$ fed, $4=50-75 \%$ fed to $5=>75 \%$ fed) (mean \pm SE; Wilcoxon rank test). C) Cumulative number of eggs deposited during the beetle exposure (mean \pm SE; Wilcoxon rank test). 

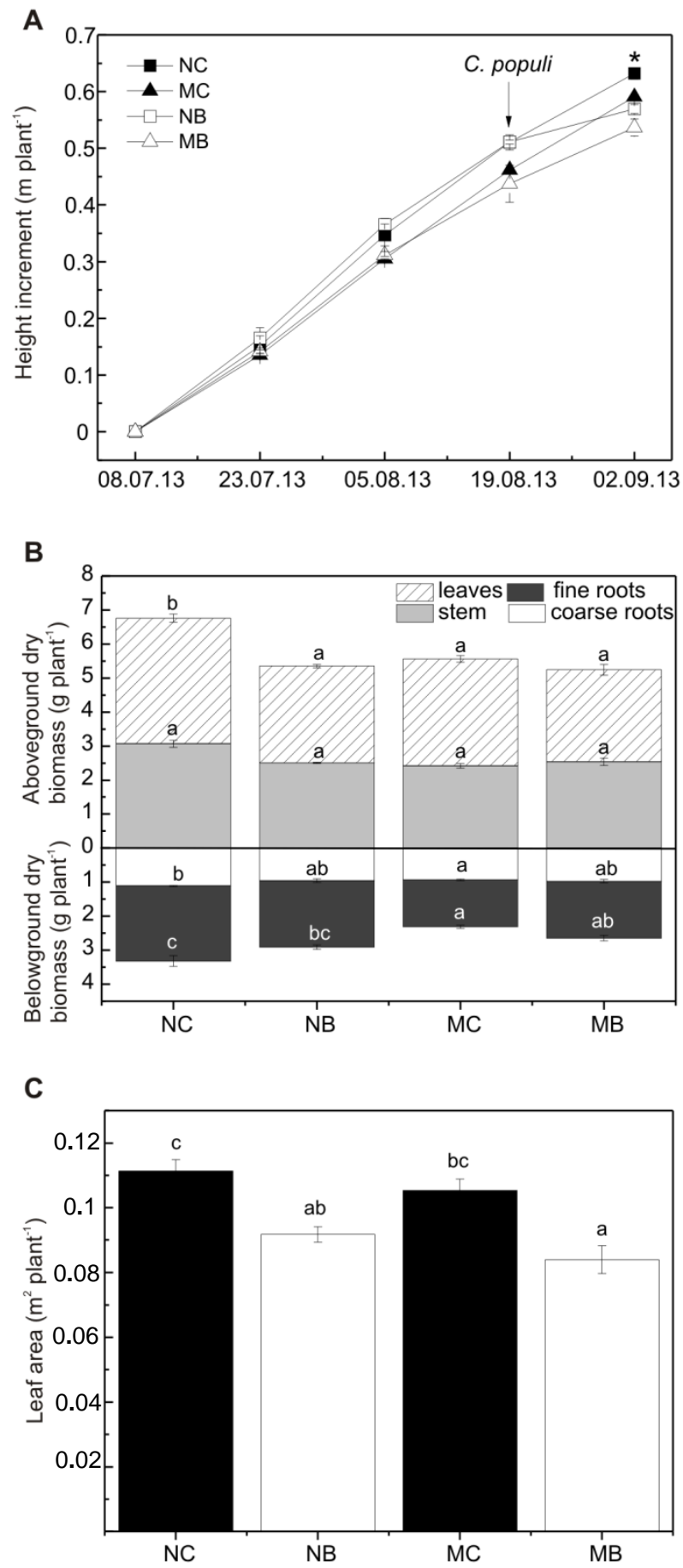

Fig. 6.4 Growth and biomass of $C$. populi infested and non-infested poplars inoculated or noninoculated with $L$. bicolor. Poplars were exposed to C. populi beetles in four cages. The other four cages served as a control. In each cage eight inoculated (MB) and eight non-inoculated (NB) poplars were grown. A) Plant height increment before and after infestation with $C$. populi beetles (mean $\pm \mathrm{SE}$ ). The beetles were released on the 19th of August 2013 and allowed to infest the plants for 14 days. B) Stem, leaf, fine root and coarse root biomass of control poplars and of infested poplars 14 days after release of the beetles (mean \pm $\mathrm{SE}$ ). C) Total leaf area of control poplars and poplars 14 days after beetle infestation (mean \pm SE). Stars or different letters indicate significant differences at $\mathrm{P}<0.05$ (Tukey test). $\mathrm{NC}=$ non-inoculated poplars in control cages, $\mathrm{MC}=$ poplars inoculated with $L$. bicolor in control cages, $\mathrm{NB}=$ non-inoculated poplars exposed to C. populi, $\mathrm{MB}=$ poplars inoculated with L. bicolor exposed to C. populi. 


\subsubsection{Effect of EMF inoculation and beetle infestation on molecular changes at the}

\section{transcriptional level}

To find out which molecular processes in the leaves were affected either by the inoculation of poplar with $L$. bicolor or the infestation with $C$. populi beetles, leaf samples from poplars of the different treatments (NC, MC, NB and MB) were used for RNA sequencing and the abundance of transcripts was compared between the treatments (Table 6.1, Table S6.2). The EMF inoculation led to a significant difference in the abundance of 146 transcripts under the control conditions (MC/NC) and to that of 70 transcripts under beetle infestation (MB/NB) (Table 6.1).

Beetle attack elicited a stronger transcriptional response compared with EMF inoculation. Feeding by beetles caused a significant difference in the transcript abundance of 4419 genes in non-inoculated poplars (NB/NC) and to that of 4065 genes in inoculated poplars (MB/MC) (Table 6.1). Comparing the beetle effect in non-inoculated (NB/NC) and inoculated (MB/MC) poplars there was an overlap of 1902 genes with an increased and 969 genes with a decreased transcript abundance (Table 6.1).

Table 6.1 | Number of significant genes with an increased or decreased transcript abundance after inoculation of poplar with the EMF $L$. bicolor or infestation with $C$. populi beetles. NC = non-inoculated poplars in control cages, $\mathrm{MC}=$ poplars inoculated with $L$. bicolor in control cages, $\mathrm{NB}=$ non-inoculated poplars exposed to $C$. populi, $\mathrm{MB}=$ poplars inoculated with $L$. bicolor exposed to C. populi.

\begin{tabular}{lccccccc}
\hline & \multicolumn{3}{c}{ EMF effect } & & \multicolumn{3}{c}{ Beetle effect } \\
\cline { 2 - 4 } & $\begin{array}{c}\text { MC/N } \\
\mathbf{C}\end{array}$ & $\begin{array}{c}\text { MB/N } \\
\mathbf{B}\end{array}$ & $\begin{array}{c}\text { Overlap } \\
\text { MC/NC and } \\
\text { MB/NB }\end{array}$ & & NB/NC & MB/MC & $\begin{array}{c}\text { MB/NC and } \\
\text { NB/MCrlap } \\
\text { MB/MC }\end{array}$ \\
\hline $\begin{array}{l}\text { Increased transcript } \\
\text { abundance }\end{array}$ & 77 & 22 & 2 & 2753 & 2476 & 1902 \\
$\begin{array}{l}\text { Decreased transcript } \\
\text { abundance }\end{array}$ & 69 & 48 & 28 & & 1639 & 1561 & 969 \\
Total & 146 & 70 & 30 & & 4419 & 4065 & 2871 \\
\hline
\end{tabular}

Gene ontology (GO) analysis (Table 6.2) revealed that the genes with significantly different transcript abundance in response to EMF inoculation were mainly categorised under terms of secondary metabolism like "secondary metabolic process", "flavonoid biosynthetic process" and "phenylpropanoid biosynthetic process". In the absence of beetles $(\mathrm{MC} / \mathrm{NC})$ enriched GO terms were also found in the categories of signalling and hormone pathways. For instance, MC/NC differed in particular in "response to auxin 
stimulus" and "abscisic acid mediated signalling pathway". In the presence of beetles (MB/NB) transcripts with enriched abundance were assigned to GO terms associated with biotic stress, such as "induced systemic resistance", "phytoalexin metabolic process" and "phytoalexin biosynthetic process" (Table 6.2).

C. populi infestation strongly affected the transcript abundance of genes in growth, signalling and defence related pathways in NB/NC as well as MB/MC (Table 6.2). Transcripts with enriched abundance in both comparisons were assigned to GO terms of hormone signalling such as "jasmonic acid mediated signalling pathway", "abscisic acid mediated signalling pathway" and "salicylic acid mediated signalling pathway". Furthermore, in these comparisons GO terms of biotic stress were enriched, e.g. "systemic acquired resistance, salicylic acid mediated signalling pathway", "respiratory burst involved in defence response", "regulation of cell death", "phytoalexin biosynthetic process" and "defence response by callose deposition". Assigned genes of these GO terms were PR Proteins, e.g. trypsin and protease inhibitor family proteins belonging to the Kunitz family proteins, terpene synthases, e.g. of 1,8-cineole, $\alpha$-humulene and $\beta$ caryophyllene, and transcription factors, e.g. various WRKY DNA-binding proteins (7, 11, $23,33,40,46,48,57,69,71$ and 75). Transcripts with a decreased abundance in noninoculated (NB/NC) and inoculated $(\mathrm{MB} / \mathrm{MC})$ poplars were mainly retrieved in the GO term "photosynthesis". 
Table 6.2 | Enriched Gene ontology (GO) terms of genes with significant differences in the transcript abundance in leaves of $\boldsymbol{P}$. $\boldsymbol{x}$ canescens in response to EMF inoculation or beetle infestation. RNA sequencing was performed with the leaf samples of the biological replicates of the NC, MC, NB and MB treatments. Given are GO terms with adjusted P-values < 0.05 after Benjamini-Hochberg correction (n.s. = not significant). $\mathrm{NC}=$ non-inoculated poplars in control cages, $\mathrm{MC}=$ poplars inoculated with L. bicolor in control cages, $\mathrm{NB}=$ non-inoculated poplars exposed to $C$. populi, $\mathrm{MB}=$ poplars inoculated with L. bicolor exposed to $C$. populi.

\begin{tabular}{|c|c|c|c|c|}
\hline \multirow[t]{2}{*}{ Go term } & \multicolumn{2}{|c|}{ EMF effect } & \multicolumn{2}{|c|}{ Beetle effect } \\
\hline & $\begin{array}{l}\text { MC/NC } \\
\text { (P-value) }\end{array}$ & $\begin{array}{l}\text { MB/NB } \\
\text { (P-value) }\end{array}$ & $\begin{array}{l}\text { NB/NC } \\
\text { (P-value) }\end{array}$ & $\begin{array}{l}\text { MB/MC } \\
\text { (P-value) }\end{array}$ \\
\hline \multicolumn{5}{|l|}{ secondary metabolism } \\
\hline secondary metabolic process & $<0.001$ & $<0.001$ & $<0.001$ & $<0.001$ \\
\hline flavonoid biosynthetic process & 0.005 & 0.013 & n.s. & n.s. \\
\hline anthocyanin biosynthetic process & $<0.001$ & $<0.001$ & 0.007 & n.s. \\
\hline dihydrokaempferol 4-reductase activity & 0.006 & 0.002 & n.s. & n.s. \\
\hline phenylpropanoid biosynthetic process & $<0.001$ & $<0.001$ & $<0.001$ & $<0.001$ \\
\hline \multicolumn{5}{|l|}{ hormones } \\
\hline hormone-mediated signaling pathway & 0.005 & n.s. & $<0.001$ & $<0.001$ \\
\hline auxin metabolic process & n.s. & n.s. & 0.016 & $<0.001$ \\
\hline response to auxin stimulus & 0.008 & n.s. & n.s. & n.s. \\
\hline jasmonic acid mediated signaling pathway & n.s. & n.s. & $<0.001$ & $<0.001$ \\
\hline abscisic acid mediated signaling pathway & 0.016 & n.s. & 0.020 & 0.003 \\
\hline salicylic acid mediated signaling pathway & n.s. & n.s. & $<0.001$ & 0.018 \\
\hline \multicolumn{5}{|l|}{ photosynthesis and growth } \\
\hline photosynthesis & n.s. & n.s. & $<0.001$ & $<0.001$ \\
\hline thylakoid & n.s. & n.s. & $<0.001$ & $<0.001$ \\
\hline light-harvesting complex & n.s. & n.s. & $<0.001$ & $<0.001$ \\
\hline regulation of cell development & 0.009 & n.s. & n.s. & n.s. \\
\hline regulation of cell morphogenesis involved in & & & & \\
\hline differentiation & 0.025 & n.s. & n.s. & n.s. \\
\hline regulation of meristem development & n.s. & n.s. & n.s. & $<0.001$ \\
\hline cellular cell wall organization or biogenesis & n.s. & n.s. & 0.016 & 0.007 \\
\hline negative regulation of cell growth & n.s. & n.s. & 0.031 & 0.038 \\
\hline plant-type cell wall loosening & n.s. & n.s. & 0.003 & 0.001 \\
\hline \multicolumn{5}{|l|}{ lipid metabolism } \\
\hline lipid metabolic process & $<0.001$ & n.s. & $<0.001$ & $<0.001$ \\
\hline lipid biosynthetic process & n.s. & n.s. & $<0.001$ & $<0.001$ \\
\hline fatty acid metabolic process & 0.001 & n.s. & $<0.001$ & $<0.001$ \\
\hline fatty acid biosynthetic process & n.s. & n.s. & $<0.001$ & $<0.001$ \\
\hline \multicolumn{5}{|l|}{ biotic stress } \\
\hline $\begin{array}{l}\text { regulation of immune system process } \\
\text { systemic acquired resistance, SA mediated }\end{array}$ & n.s. & n.s. & $<0.001$ & $<0.001$ \\
\hline signaling pathway & n.s. & n.s. & 0.001 & $<0.001$ \\
\hline respiratory burst involved in defense response & n.s. & n.s. & 0.041 & $<0.001$ \\
\hline plant-type hypersensitive response & n.s. & n.s. & $<0.001$ & $<0.001$ \\
\hline regulation of cell death & n.s. & n.s. & $<0.001$ & $<0.001$ \\
\hline induced systemic resistance & n.s. & 0.046 & n.s. & 0.036 \\
\hline phytoalexin metabolic process & n.s. & 0.016 & 0.005 & 0.012 \\
\hline phytoalexin biosynthetic process & n.s. & 0.030 & 0.008 & 0.014 \\
\hline monoterpenoid biosynthetic process & n.s. & n.s. & 0.020 & 0.021 \\
\hline toxin metabolic process & 0.028 & n.s. & 0.007 & 0.001 \\
\hline defense response by callose deposition & n.s. & n.s. & 0.003 & 0.005 \\
\hline defense response by cell wall thickening & n.s. & 0.016 & n.s. & n.s. \\
\hline
\end{tabular}




\subsubsection{Co-expression network analysis}

A WGCNA was performed to further investigate co-expression patterns affected by the EMF inoculation or the beetle attack. The WGCNA grouped the genes into 43 different gene co-expression modules and eight different types of expression modules (MT) (Fig. 6.5). Modules of the types MT1 to MT3 had highest eigengene values under control conditions without beetles (Fig. 6.5A-C), whereas modules of the types MT4 to MT8 had highest eigengene values under beetle infestation (Fig. 6.5D-H). A significant influence by the EMF inoculation was found for the modules plum1 $\left(\mathrm{P}_{\mathrm{MB} / \mathrm{NB}}=0.023\right)$ and mediumpurple3 $\left(\mathrm{P}_{\mathrm{MB} / \mathrm{NB}}=0.025\right)$ of the module type MT4 (Table S6.3). For most modules of the other types a significant beetle effect was observed in non-inoculated poplars (NB/NC), inoculated poplars (MB/MC) or both (Table S6.3).

In a PCA the first principal component pointed out the beetle effect and explained $72 \%$ of total variance (Fig. 6.6). The second principal component explained $23 \%$ of total variance and separated mycorrhizal and non-mycorrhizal effects. Score values of variables and loadings of PCA are given in Table S6.4. PCA separated NC poplars together with the module types MT1 and MT2 and plant performance (plant height, total leaf area and biomass of coarse roots, fine roots, stem and leaves) from the NB poplars together with the module types MT4 to MT7 and beetle behaviour (egg deposition, feeding damage and insect choice). MC poplars and the module type MT3 were separated from MB poplars and the module type MT8. 


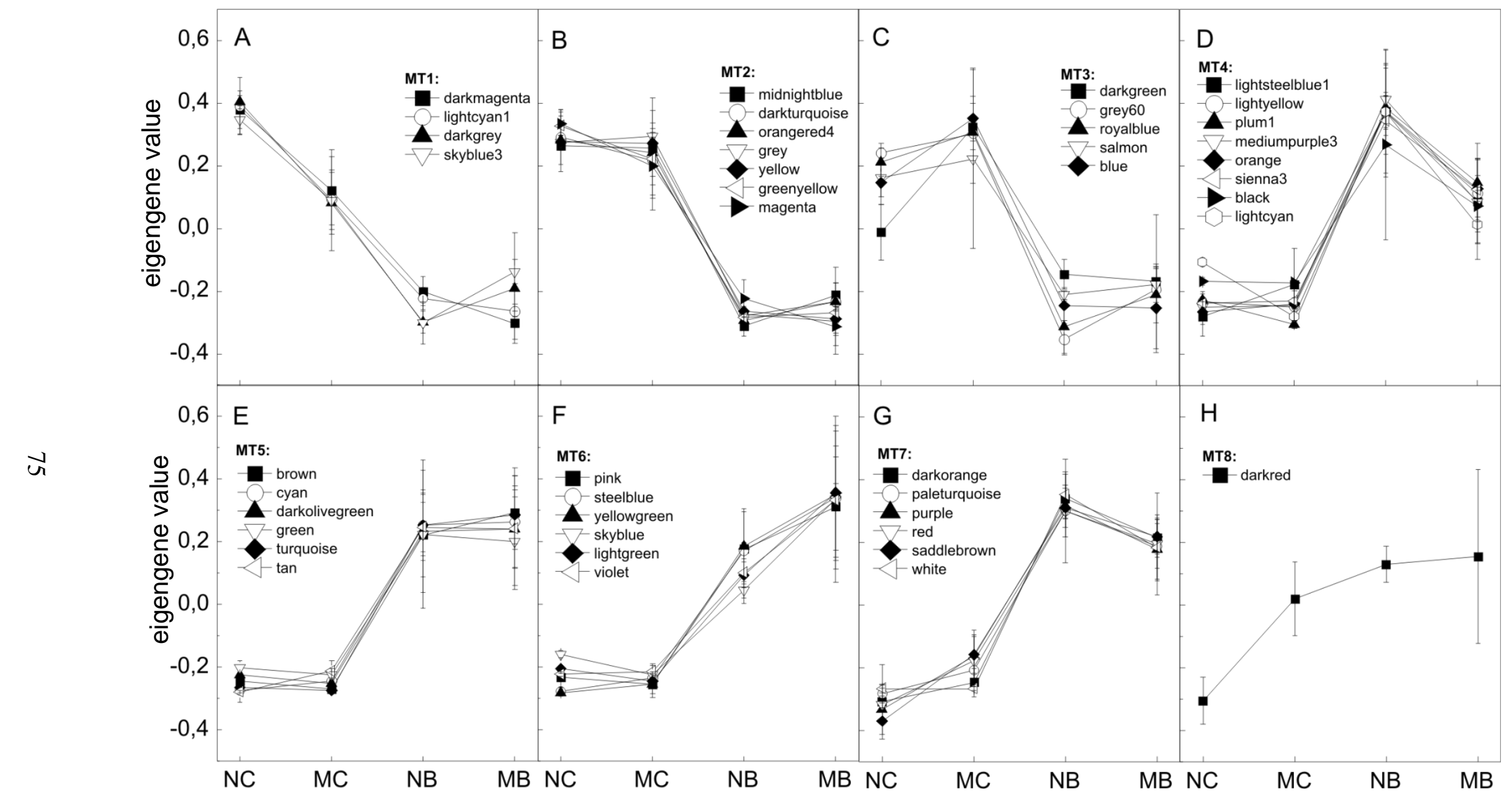

Fig. 6.5 Co-expression network analysis. Based on WGCNA genes with significant differences in the transcript abundance between the treatments (MB, MC, NC, NB) were grouped into 43 modules with 8 different $(\mathrm{A}-\mathrm{H}$ ) module types (mean eigengene value $\pm \mathrm{SE}$ ). $\mathrm{NC}=$ non-inoculated poplars in control cages, $\mathrm{MC}=$ poplars inoculated with $L$. bicolor in control cages, $\mathrm{NB}=$ non-inoculated poplars exposed to $C$. populi, $\mathrm{MB}=$ poplars inoculated with L. bicolor exposed to C. populi. 
Chapter 6: Influence of EMF inoculation on the behaviour of $C$. populi beetles

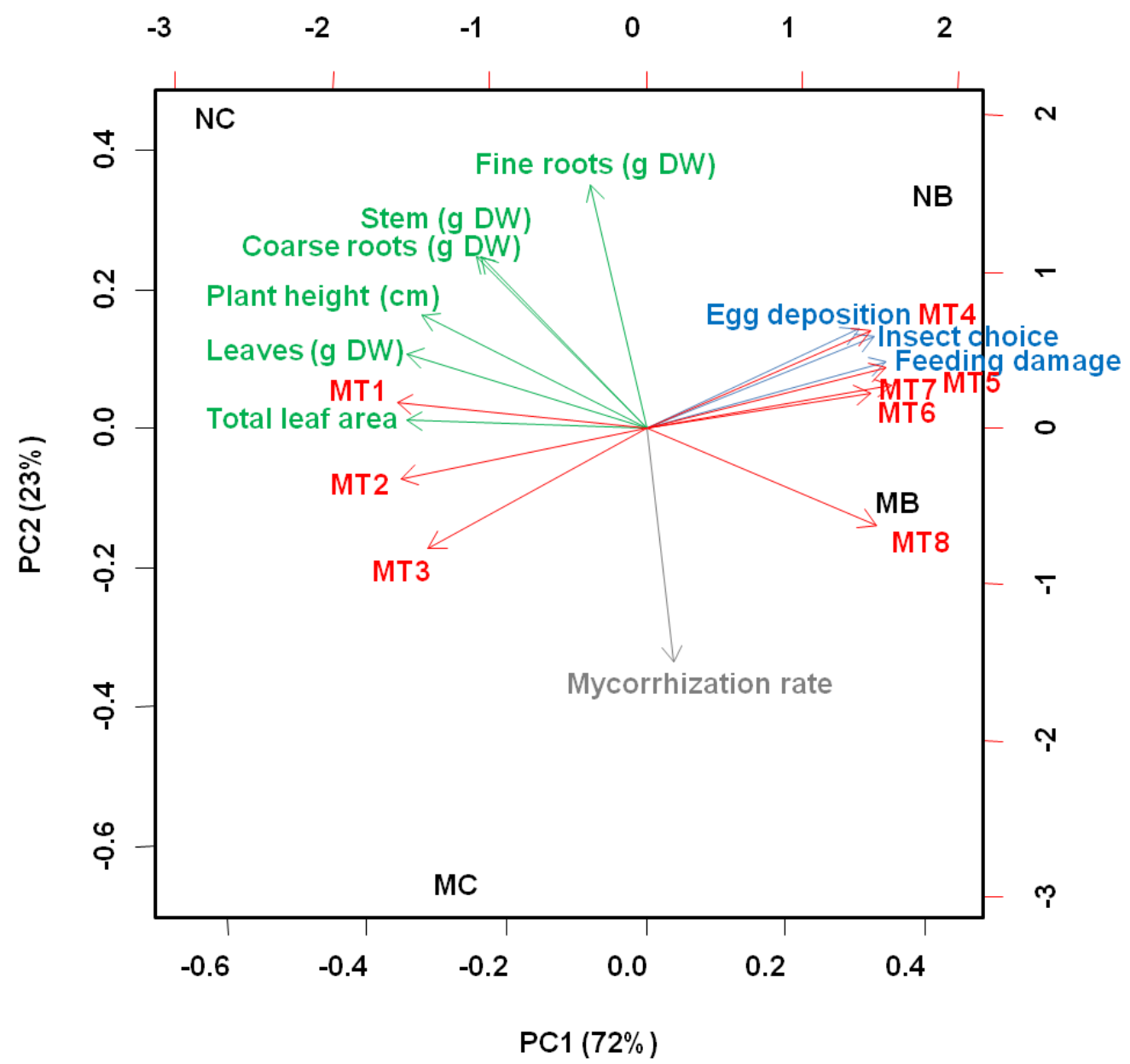

Fig. 6.6 | Principal component analysis performed with the variables module types (red), plant growth and biomass parameters (green), mycorrhization rate (grey) and parameters of beetle behaviour (blue). Percentage values of each axis indicate the percentage of total variation explained by the axis.

To elucidate the molecular function of the co-expressed genes, the module types were clustered based on GO term analysis (Fig. 6.7). Co-expressed genes of MT1, MT2 and MT3, which were associated with plant growth and above- and belowground biomass, were clustered in GO terms such as "photosynthesis", "regulation of growth" ( $\mathrm{Cl} 1)$, "negative regulation of photosynthesis" ( $\mathrm{Cl} 7)$, "cell wall organization" and "flavone biosynthetic process" ( $\mathrm{Cl}$ 9). Clusters of the other module types, which had been associated to the beetle attack, revealed co-expression of genes assigned to defence related GO terms such as "regulation of immune response", "cellular response to jasmonic acid stimulus" (Cl 2), "response to wounding", "plant type hypersensitive response", "abscicic acid mediated signalling pathway" ( $\mathrm{Cl} 4)$, "response to herbivore" and "jasmonic and ethylene-dependent systemic resistence" ( $\mathrm{Cl}$ 6). In $\mathrm{Cl} 8$ the $\mathrm{GO}$ terms "salicylic acid mediated signalling", "regulation of flavonoid biosynthetic process" and "phytoalexin biosynthetic process" were 
significantly enriched. These terms belonged to the MT4 modules, for which a significant EMF effect was shown.

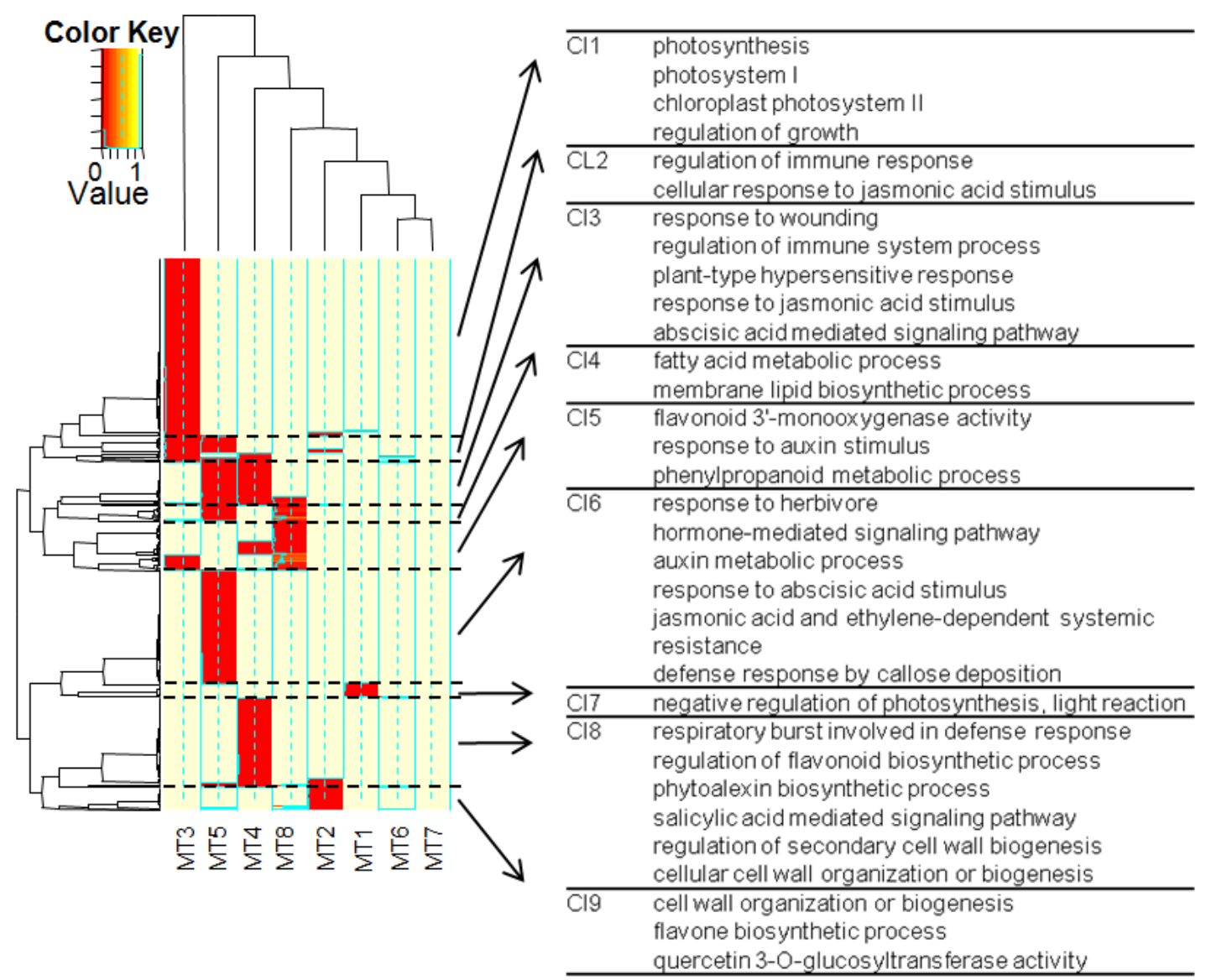

Fig. 6.7 | Functional analysis of co-expressed genes. A heatmap of the module types (MT) from WGCNA was constructed based on P-values of GO term analysis. Colours display P-values from dark red $(\mathrm{p}<0.01)$ to yellow $(\mathrm{p}=1)$. Dashed lines indicate clusters $(\mathrm{Cl})$ of GO terms. The corresponding GO terms are listed on the right side.

\subsubsection{Hormone signalling pathways, flavonoid biosynthesis pathways and aldoxime biosynthesis in response to EMF inoculation and beetle infestation}

Based on the results of the co-expression analysis, which indicated that co-expressed genes in the pathways of hormone signalling, flavonoid biosynthesis and phytoalexin biosynthesis were influenced by the EMF inoculation and associated to the beetle infestation, these pathways were chosen for further analysis and the $\log \mathrm{FC}$ of genes with significant differences in the transcript abundance between the treatments was used to map the genes to KEGG pathways. 
Both the EMF inoculation and the beetle attack affected the transcript abundance of genes in hormone signalling pathways (Fig. 6.8). Without beetles, in MC compared to NC poplars the transcript abundance of genes in the abscisic acid mediated signalling pathway was decreased and the response to auxin increased. Beetle attack elicited an increased transcript abundances of genes in the hormone pathways of abscisic acid, ethylene, jasmonic acid, salicylic acid and cytokinin in non-inoculated poplars (NB/NC) as well as inoculated poplars (MB/MC).

In the absence of beetles (MC/NC) and in the presence of beetles (MB/NB) the EMF inoculation led to a decreased transcript abundance of many genes in the flavonoid pathway (Fig. 6.9). Almost thirty percent of the genes with a decreased transcript abundance (21 of the 69 genes) of MC compared to NC poplars were annotated to the flavonoid biosynthetic process. Contrary to that, the beetle infestation led to an increased transcript abundance of genes involved in the flavonoid pathway in both non-inoculated poplars $(\mathrm{NB} / \mathrm{NC})$ and inoculated poplars $(\mathrm{MB} / \mathrm{MC})$.

Annotated genes of the GO term "phytoalexin biosynthetic process" were the cytochrome P450 enzymes of the CYP79 family in the aldoxime biosynthesis (Fig. 6.10). In response to the beetle attack the transcript abundance of P450 genes CYP79D5, CYP79D6 and CYP79D7, leading to the formation of aldoximes, was increased in both comparisons of $\mathrm{NB} / \mathrm{NC}$ poplars and MB/MC poplars. An increased transcript abundance of these genes was also observed in response to the EMF inoculation in the comparison MB/NB poplars. 
Chapter 6: Influence of EMF inoculation on the behaviour of $C$. populi beetles

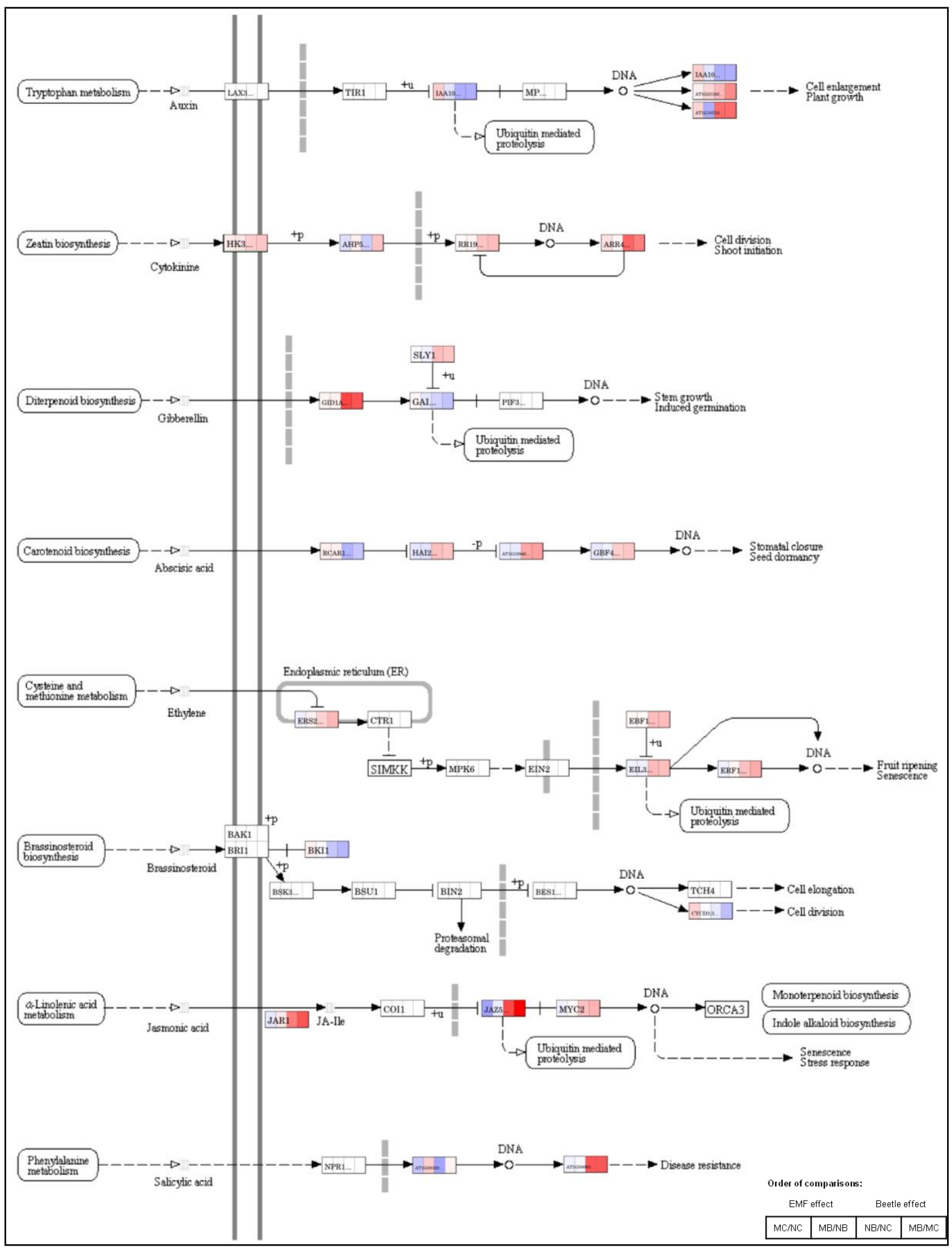

Fig. 6.8 | Transcript abundance in plant hormone signal transduction. Blue colours display decreased transcript abundance and red colours display increased transcript abundance in each comparison (MC/NC; $\mathrm{MB} / \mathrm{NB}$; NB/NC; $\mathrm{MB} / \mathrm{MC}$ ) based on logFC. Order of sections in the boxes: comparison of $\mathrm{MC}$ and $\mathrm{NC}$ poplars (EMF effect), of MB and NB poplars (EMF effect), of NB and NC poplars (beetle effect) and of MB and $\mathrm{MC}$ poplars (beetle effect). $\mathrm{NC}=$ non-inoculated poplars in control cages, $\mathrm{MC}=$ poplars inoculated with L. bicolor in control cages, $\mathrm{NB}=$ non-inoculated poplars exposed to $C$. populi, $\mathrm{MB}=$ poplars inoculated with L. bicolor exposed to C. populi. 


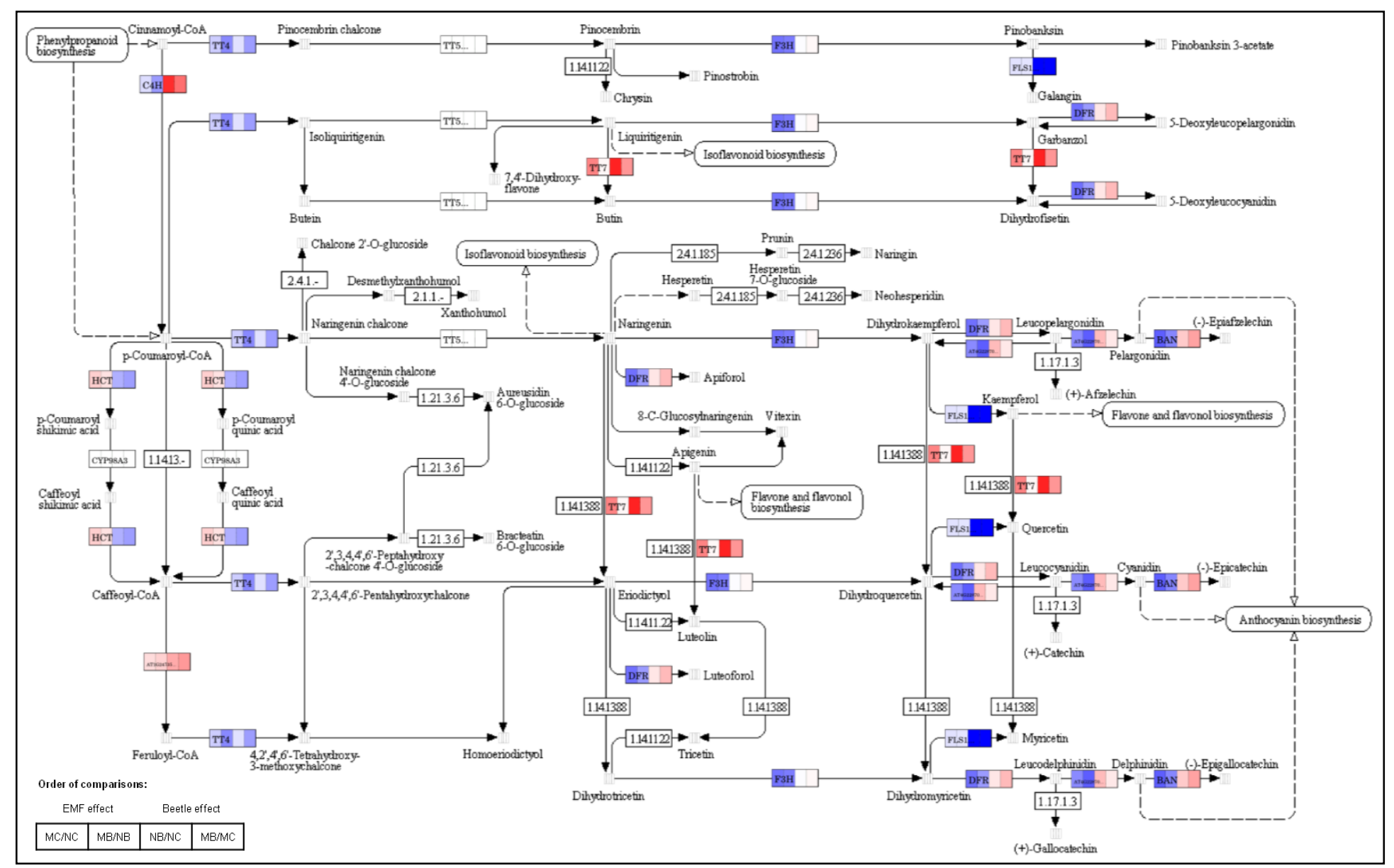

Fig. 6.9 | Pathway analysis of flavonoid biosynthesis. Decreased transcript abundance based on logFC of each comparison (MC/NC; MB/NB; NB/NC; MB/MC) shown by blue colours and increased transcript abundance by red colours. Order of sections in the boxes: comparison of MC and NC poplars (EMF effect), MB and NB poplars (EMF effect), NB and NC poplars (beetle effect) and of MB and MC poplars (beetle effect). $\mathrm{NC}=$ non-inoculated poplars in control cages, $\mathrm{MC}=$ poplars inoculated with $L$. bicolor in control cages, $\mathrm{NB}=$ non-inoculated poplars exposed to $C$. populi, $\mathrm{MB}=$ poplars inoculated with $\mathrm{L}$. bicolor exposed to $C$. populi. 


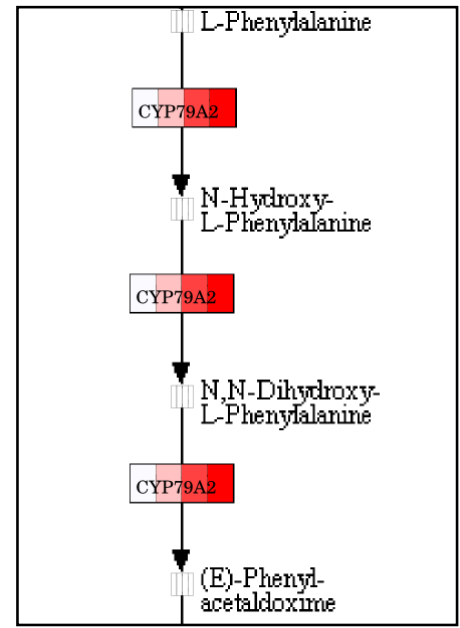

Fig. 6.10 | Phenyl-acetaldoxime biosynthesis. Red colours indicate increased transcript abundance in each comparison based on logFC. Order of sections in the boxes: comparison of MC and NC poplars (EMF effect), MB and NB poplars (EMF effect), NB and NC poplars (beetle effect) and of MB and MC poplars (beetle effect). $\mathrm{NC}=$ non-inoculated poplars in control cages, $\mathrm{MC}=$ poplars inoculated with L. bicolor in control cages, $\mathrm{NB}=$ non-inoculated poplars exposed to $C$. populi, $\mathrm{MB}=$ poplars inoculated with $L$. bicolor exposed to C. populi.

\subsection{Discussion}

\subsubsection{C. populi beetles prefer non-inoculated over inoculated poplars}

EMF inoculation reduced feeding and oviposition of $C$. populi beetles on the leaves of inoculated compared to non-inoculated poplars. This influence of EMF on herbivores corresponds to other studies about mycorrhiza-herbivore interactions. For example, the herbivory of the leaf chewing Green flower beetle (Anomala cupripes) on Timor mountain gum (Eucalyptus urophylla) was decreased on plants inoculated with the EMF Laccaria laccata compared to non-inoculated plants (Gange et al., 2005).

In the present study more than $75 \%$ of the leaf area in the upper plant part of the poplars were fed by the beetles after eight days. Poplar leaf beetles cause high economic losses in poplar plantations (Georgi et al., 2012). The finding, that poplars inoculated with L. bicolor were less attractive for the beetles than the non-inoculated poplars suggests that inoculation with L. bicolor may be used to develop strategies of pest management in poplar plantations. For example, inoculation of poplars with L. bicolor may be desirable in the plantations to reduce the biomass loss caused by $C$. populi beetles. 


\subsubsection{C. populi beetles induce strong defence reactions in inoculated and non- inoculated poplars}

Both inoculated and non-inoculated poplars showed a strong defence response to C. populi feeding like an increased transcript abundance of genes of the hypersensitive response and of PR (Pathogenesis-related) proteins, e.g. protease inhibitors of the Kunitz type. The Kunitz protease inhibitors influence the digestion of insects by inhibiting proteases in the gut (Philippe and Bohlmann, 2007). The enhanced transcript abundance of cytochrome P450 genes of the CYP79 family (CYP79D5, CYP79D6 and CYP79D7) suggests an involvement of aldoximes in the defence reaction of poplars to the beetle attack. Only recently the poplar P450 enzymes CYP79D6 and CYP79D7 were shown to be involved in the defence against gypsy moth caterpillars (Lymantria dispar) (Irmisch et al., 2013). Furthermore, the feeding enhanced the transcript abundance of genes in the salicylic acid (SA) and jasmonic acid (JA) signalling pathways in both inoculated and non-inoculated poplars compared to undamaged control poplars. This result on transcript level is confirmed by increased metabolite levels in the $\alpha$-linolenic acid metabolism (Kaling, personal communication), which plays a role in plant hormone biosynthesis. SA and JA are known to be long distance signals involved in defence reactions (Heil and Ton, 2008).

Here, beetle feeding reduced the transcript levels of many photosynthesis related genes. Major and Constabel (2006) profiled poplar leaf transcripts after the attack of forest tent caterpillars and also found a repression of photosynthetic genes and an enhanced JA level. Treatments of leaves with high JA concentrations decrease the expression of photosynthetic genes in choloroplasts and nucleus (Creelman and Mullet, 1997; Major and Constabel, 2006). Therefore, an enhanced JA signalling may be related to the suppressed transcript abundance of photosynthetic genes. Overall, these results indicate that both inoculated and non-inoculated poplars have many similarities in the defence response to $C$. populi feeding.

\subsubsection{EMF inoculated poplars differ from non-inoculated poplars in hormone signalling pathway, flavonoid biosynthesis pathway and aldoxime biosynthesis}

The preference of the $C$. populi beetles for non-inoculated poplars is suggested to be caused by EMF induced molecular changes in the leaves. Mycorrhizal associations of plants can influence metabolites in the leaves. For example, the production of iridoid glycosides was induced in leaves of AMF-inoculated Buckhorn plantain plants (Plantago 
lanceolata L.) (Fontana et al., 2009). Gange and West (1994) observed an increased level of the feeding deterrents aucubin and catalpol in the leaves of AMF-inoculated compared to non-inoculated $P$. lanceolota and a reduced growth rate of the Garden tiger moth (Arctia caja) on mycorrhizal plants.

The inoculation of poplar with L. bicolor affected the leaf tanscriptome, but of only few genes. Recently, the response of $P . \times$ canescens to the EMF $P$. involutus was studied at the transcript level in EM roots and the transcriptional response of only $0.3 \%$ genes was changed (Luo et al., 2009a). This intensity found in the roots agrees with the response to the EM inoculation in poplar leaves, observed in the present study. Here, the EMF inoculation affected the transcript abundance in distinct pathways in the leaves such as hormone signalling pathways, flavonoid biosynthesis pathways and aldoxime biosynthesis.

Inoculation of poplars with $L$. bicolor decreased the transcript abundance of genes in the ABA signalling pathway. Hormonal changes in mycorrhizal plants were expected and have been detected in below and aboveground parts of mycorrhizal plants with contrasting reports about $\mathrm{ABA}$. An increased transcript abundance of genes related to ABA was detected in roots and a decreased abundance in shoots of AMF-inoculated tomato plants (Solanum lycopersicum L.) (Fiorilli et al., 2009). AMF-inoculated S. lycopersicum plants had lower ABA levels in the leaves (Fiorilli et al., 2011) and EMF-inoculated poplars increased ABA levels in the roots (Luo et al. 2009a). An involvement of ABA in the development of arbuscules was shown using ABA-deficient tomato mutants (Lycopersicon esculentum) that were less susceptible to AMF (Herrera-Medina et al., 2007). ABA also plays important roles in plant development, signalling and response to biotic and abiotic stress (Lee and Luan, 2012).

In the present study, the transcriptional results indicated a decreased abundance of genes in the flavonoid biosynthesis pathway, which was supported by metabolomic analysis (Kaling, personal communication). Decreased concentrations of 35 flavonoids such as catechin, dihydrokaempferol, dihydromycetrin and quercetin were detected in inoculated compared to non-inoculated poplars (Kaling, personal communication). The decreased transcript abundance of genes in flavonoid biosynthesis pathway may be related to that of the ABA signalling pathway. In Orthosiphon stamineus Benth (Cat's Whiskers) the ABA concentration was found to be positively correlated with the biosynthesis of flavonoids by analysing the production of secondary metabolites under different levels of ABA applications (Ibrahim and Jaafar, 2013). 
Effects of a symbiotic partner on flavonoids in plant roots have been demonstrated. For example, in symbioses with rhizobia, root flavonoids induce nod genes in rhizobia and are therefore important for the initiation of root nodules (Wasson et al., 2006). In AM formation, flavonoids are important signalling compounds in the AM symbiosis (Larose et al., 2002; Ponce et al., 2004). However, it was assumed that specific flavonoids are not involved in the establishment of EM associations in Scots pine (Pinus sylvestris L.) (Niemi et al., 2007). Niemi et al. (2007) investigated the content of flavonoids and polyamines in Scots pine during ectomycorrhizal formation with Suillus variegatus and found quantitative changes in flavonols, catechins and tannins but no qualitative changes of the flavonoid composition in the shoots. Flavonoids have diverse biological functions (Buer et al., 2010), which include signalling via the auxin transport (Peer and Murphy, 2007) and defence against stress, pathogens and herbivores (Treutter, 2005; Bais et al., 2006). Flavonoids may play a role in the defence of poplars against herbivores such as $C$. populi. Because the transcript abundance of genes in the flavonoid biosynthesis was decreased in inoculated poplars compared to non-inoculated plants, other defensive compounds might be responsible for deterring $C$. populi beetles. For example, in EMF-inoculated beech (Fagus sylvatica) mycorrhizal inoculation induced the production of defensive compounds such as tannins in roots (Beyeler and Heyser 1997).

In the present study, differences in the defence reaction in inoculated and non-inoculated poplars were related to phytoalexins in the leaves. Upon beetle attack, poplars inoculated with L. bicolor had significantly higher transcript abundances of the cytochrome P450 genes of the CYP79 family, i.e. CYP79D5, CYP79D6 and CYP79D7, compared to noninoculated plants. These genes are involved in the synthesis of aldoximes like phenylacetaldoxime (Irmisch et al., 2013). As demonstrated by Irmisch et al. (2013) higher phenyl-acetaldoxime concentrations reduced the survival of gypsy moth caterpillars (Lymantria dispar), decreased the weight growth of larvae and extended the time until pupation. Therefore, an enhanced biosynthesis of aldoximes in poplar leaves may be responsible for the decreased preference of $C$. populi to select these leaves for consumption and as oviposition sites. To gain a deeper understanding of the connection between aldoxime emission and $C$. populi behaviour, aldoxime concentrations in mycorrhizal poplar leaves should be measured and the reaction of $C$. populi beetles to plants with modified aldoxime metabolism tested. 
Inoculation of poplars with L. bicolor also affected plant growth and biomass. Under control conditions inoculated poplars had significant lower leaf biomass and plant height increment compared to non-inoculated poplars. The finding that inoculation with mycorrhiza has a positive effect on the plant reaction to stress, but reduces growth performance agrees with the study of Luo et al. (2009b). In that study P. euphratica inoculated with the EMF $P$. involutus had an increased osmolality in leaves under drought conditions and an increased stress tolerance, but also a reduced plant growth compared to the non-inoculated poplars. The reasons for the reduced growth in the inoculated plants needs to be elucidated in future work.

\subsubsection{Conclusion}

To conclude, inoculation of poplar with the EMF L. bicolor decreased plant growth and biomass. However the plants benefited from the EMF inoculation by a decreased attractiveness for $C$. populi beetles. The beetles preferred feeding and oviposition on noninoculated plants. The feeding elicited stronger transcriptional changes in both inoculated and non-inoculated poplars compared to the EMF inoculation. Distinct pathways were affected by the beetle feeding and the EMF inoculation. Besides changes in the transcript abundance of genes in hormonal pathways, the transcript abundance of genes in the flavonoid biosynthesis was decreased in leaves of EMF inoculated poplars by an unknown mechanism. Upon beetle attack, EMF poplars displayed enhanced transcript abundances of genes in aldoxime pathways compared to non-inoculated plants. Therefore, aldoximes may play a role in deterring $C$. populi beetles.

Studies on the interaction between mycorrhizal fungi, plants and herbivores are of huge importance to deepen our understanding about the complex interaction between above- and belowground organisms and may help in the biological control of plants against herbivores. For instance, this study supported the hypothesis that inoculation of poplar with the EMF L. bicolor reduced infestation of poplars with $C$. populi and this information could be used for strategies of plant protection of poplars against herbivory. Further studies should investigate specificity of the tritrophic interaction and address the questions whether other herbivores are also affected by inoculation of poplar with L. bicolor and whether mycorrhizal formation of poplar with other EMF has the same potential to reduce herbivory or not. 
Chapter 6: Influence of EMF inoculation on the behaviour of $C$. populi beetles

\subsection{References}

Abu-Zeyad R, Khan AG, Khoo, C. (1999) Occurrence of arbuscular mycorrhiza in Castanospermum australe A. Cunn. \& C. Fraser and effects on growth and production of castanospermine. Mycorrhiza 9: 111-117

Arimura G, Huber DPW, Bohlmann J (2004) Forest tent caterpillars (Malacosoma disstria) induce local and systemic diurnal emissions of terpenoid volatiles in hybrid poplar (Populus trichocarpa $\times$ deltoides): cDNA cloning, functional characterization, and patterns of gene expression of (-)-germacr: Insect-induced volatile emission in poplar. Plant J 37: 603-616

Awmack CS, Leather SR (2002) Host plant quality and fecundity in herbivorous insects. Annu Rev Entomol 47: 817-844

Bais HP, Weir TL, Perry LG, Gilroy S, Vivanco JM (2006) The role of root exudates in rhizosphere interactions with plants and other organisms. Annu Rev Plant Biol 57: 233-266

Barker SJ, Tagu D (2000) The roles of auxins and cytokinins in mycorrhizal symbioses. J Plant Growth Regul 19: 144-154

Bauer DF (1972) Constructing confidence sets using rank statistics. Journal of the American Statistical Association 67, 687-690

Becker RA, Chambers JM, Wilks AR (1988) The New S Language. Wadsworth \& Brooks/Cole, 1

Benjamini, Y, Hochberg Y (1995) Controlling the False Discovery Rate: A Practical and Powerful Approach to Multiple Testin. J. R. Stat. Soc. 57: 289-300

Beyeler M, Heyser W (1997) The influence of mycorrhizal colonization on growth in the greenhouse and on catechin, epicatechin and procyanidin in roots of Fagus sylvatica L. Mycorrhiza 7: 171-177

Brilli F, Ciccioli P, Frattoni M, Prestininzi M, Spanedda AF, Loreto F (2009) Constitutive and herbivore-induced monoterpenes emitted by Populus $\times$ euroamericana leaves are key volatiles that orient Chrysomela populi beetles. Plant Cell Environ 32: 542 552

Buer CS, Imin N, Djordjevic MA (2010) Flavonoids: New Roles for Old Molecules. J Integr Plant Biol 52: 98-111 
Chapter 6: Influence of EMF inoculation on the behaviour of $C$. populi beetles

Colpaert JV, Van Assche JA, Luijtens K (1992) The growth of the extramatrical mycelium of ectomycorrhizal fungi and the growth response of Pinus sylvestris L. New Phytol 120: $127-135$

Creelman RA, Mullet JE (1997) Biosynthesis and action of jasmonates in plants. Annu Rev Plant Biol 48: 355-381

Dosskey MG, Linderman RG, Boersma L (1990) Carbon-sink stimulation of photosynthesis in Douglas fir seedlings by some ectomycorrhizas. New Phytol 115: 269-274

Van Dam NM, Qiu B-L, Hordijk CA, Vet LEM, Jansen JJ (2010) Identification of biologically relevant compounds in aboveground and belowground induced volatile blends. J Chem Ecol 36: 1006-1016

Fernandez P, Hilker M (2007) Host plant location by Chrysomelidae. Basic Appl Ecol 8: $97-116$

Fiorilli V, Catoni M, Francia D, Cardinale F, Lanfranco L (2011) The arbuscular mycorrhizal symbiosis reduces disease severity in tomato plants infected by Botrytis cinerea. J Plant Pathol: 237-242

Fiorilli V, Catoni M, Miozzi L, Novero M, Accotto GP, Lanfranco L (2009) Global and cell-type gene expression profiles in tomato plants colonized by an arbuscular mycorrhizal fungus. New Phytol 184: 975-987

Fontana A, Reichelt M, Hempel S, Gershenzon J, Unsicker SB (2009) The effects of arbuscular mycorrhizal fungi on direct and indirect defense metabolites of Plantago lanceolata L. J Chem Ecol 35: 833-843

Gange AC, Gane DR, Chen Y, Gong M (2005) Dual colonization of Eucalyptus urophylla ST Blake by arbuscular and ectomycorrhizal fungi affects levels of insect herbivore attack. Agric For Entomol 7: 253-263

Gange AC, West HM (1994) Interactions between arbuscular mycorrhizal fungi and foliarfeeding insects in Plantago lanceolata L. New Phytol 128: 79-87

Gehring C, Bennett A (2009) Mycorrhizal fungal-plant-insect interactions: The importance of a community approach. Environ Entomol 38: 93-102

Georgi R, Helbig C, Schubert M (2012) The red poplar leaf beetle in short rotation coppice. AFZ/Der Wald, Allgemeine Forst Zeitschrift für Waldwirtschaft und Umweltvorsorge 67: 11-13 
Chapter 6: Influence of EMF inoculation on the behaviour of $C$. populi beetles

Goverde M, Heijden M van der, Wiemken A, I. S, Erhardt A (2000) Arbuscular mycorrhizal fungi influence life history traits of a lepidopteran herbivore. Oecologia 125: 362-369

Halldórsson G, Sverrisson H, Eyjólfsdóttir GG, Oddsdóttir ES (2000) Ectomycorrhizae reduce damage to Russian Larch by Otiorhyncus larvae. Scand J For Res 15: 354358

Hartley SE, Gange AC (2009) Impacts of plant symbiotic fungi on insect herbivores: mutualism in a multitrophic context. Annu Rev Entomol 54: 323-342

Hause B, Mrosk C, Isayenkov S, Strack D (2007) Jasmonates in arbuscular mycorrhizal interactions. Phytochemistry 68: 101-110

Heil M, Ton J (2008) Long-distance signalling in plant defence. Trends Plant Sci 13: 264272

Herrera-Medina MJ, Steinkellner S, Vierheilig H, Ocampo Bote JA, García Garrido JM (2007) Abscisic acid determines arbuscule development and functionality in the tomato arbuscular mycorrhiza. New Phytol 175: 554-564

Hollander M, Wolfe DA (1973) Nonparametric statistical methods. New York: John Wiley \& Sons

Hothorn T, Bretz F, Westfall P, Heiberger RM, Schuetzenmeister A (2008) multcomp: Simultaneous inference in general parametric models. Models. Biom J 50: 346-363

Ibrahim M, Jaafar H (2013) Abscisic acid induced changes in production of primary and secondary metabolites, photosynthetic capacity, antioxidant capability, antioxidant enzymes and lipoxygenase inhibitory activity of Orthosiphon stamineus Benth. Molecules 18: 7957-7976

Irmisch S, Clavijo McCormick A, Boeckler GA, Schmidt A, Reichelt M, Schneider B, Block K, Schnitzler J-P, Gershenzon J, Unsicker SB, et al (2013) Two herbivoreinduced cytochrome P450 enzymes CYP79D6 and CYP79D7 catalyze the formation of volatile aldoximes involved in poplar defense. Plant Cell 25: 47374754

Jung SC, Martinez-Medina A, Lopez-Raez JA, Pozo MJ (2012) Mycorrhiza-induced resistance and priming of plant defenses. J Chem Ecol 38: 651-664 
Chapter 6: Influence of EMF inoculation on the behaviour of $C$. populi beetles

Koricheva J, Gange AC, Jones T (2009) Effects of mycorrhizal fungi on insect herbivores: a meta-analysis. Ecology 90: 2088-2097

Laird RA, Addicott JF (2008) Neutral indirect effects of mycorrhizal fungi on a specialist insect herbivore. Environ Entomol 37: 1017-1024

Langfelder P, Horvath S (2008) WGCNA: an R package for weighted correlation network analysis. BMC Bioinformatics 9: 559

Larose G, Chênevert R, Moutoglis P, Gagné S, Piché Y, Vierheilig H (2002) Flavonoid levels in roots of Medicago sativa are modulated by the developmental stage of the symbiosis and the root colonizing arbuscular mycorrhizal fungus. J Plant Physiol 159: 1329-1339

Lee SC, Luan S (2012) ABA signal transduction at the crossroad of biotic and abiotic stress responses: ABA in drought and pathogen responses. Plant Cell Environ 35: $53-60$

Leitner M, Kaiser R, Hause B, Boland W, Mithöfer A (2010) Does mycorrhization influence herbivore-induced volatile emission in Medicago truncatula? Mycorrhiza 20: $89-101$

Luo Z-B, Janz D, Jiang X, Gobel C, Wildhagen H, Tan Y, Rennenberg H, Feussner I, Polle A (2009a) Upgrading root physiology for stress tolerance by ectomycorrhizas: Insights from metabolite and transcriptional profiling into reprogramming for stress anticipation. Plant Physiol 151: 1902-1917

Luo Z-B, Li K, Gai Y, Göbel C, Wildhagen H, Jiang X, Feußner I, Rennenberg H, Polle A (2011) The ectomycorrhizal fungus (Paxillus involutus) modulates leaf physiology of poplar towards improved salt tolerance. Environ Exp Bot 72: 304-311

Luo Z-B, Li K, Jiang X, Polle A (2009b) Ectomycorrhizal fungus (Paxillus involutus) and hydrogels affect performance of Populus euphratica exposed to drought stress. Ann For Sci 66: 106-106

Major IT, Constabel CP (2006) Molecular analysis of poplar defense against herbivory: comparison of wound- and insect elicitor-induced gene expression. New Phytol 172: 617-635

Manninen A-M, Holopainen T, Holopainen JK (1998) Susceptibility of ectomycorrhizal and non-mycorrhizal Scots pine (Pinus sylvestris) seedlings to a generalist insect 
Chapter 6: Influence of EMF inoculation on the behaviour of $C$. populi beetles

herbivore, Lygus rugulipennis, at two nitrogen availability levels. New Phytol 140: $55-63$

Manninen A-M, Holopainen T, Holopainen JK (1999) Performance of grey pine aphid, Schizolachnus pineti, on ectomycorrhizal and non-mycorrhizal Scots pine seedlings at different levels of nitrogen availability. Entomol Exp Appl 93: 117-120

Manninen A-M, Holopainen T, Lyytikainen-Saarenmaa P, Holopainen JK (2000) The role of low-level ozone exposure and mycorrhizas in chemical quality and insect herbivore performance on Scots pine seedlings. Glob Change Biol 6: 111-121

Mardia KV, Kent JT, Bibby JM (1979) Multivariate Analysis, London: Academic Press

Martínez-Medina A, Roldán A, Albacete A, Pascual JA (2011) The interaction with arbuscular mycorrhizal fungi or Trichoderma harzianum alters the shoot hormonal profile in melon plants. Phytochemistry 72: 223-229

Mueller RC, Sthultz CM, Martinez T, Gehring CA, Whitham TG (2005) The relationship between stem-galling wasps and mycorrhizal colonization of Quercus turbinella. Can J Bot 83: 1349-1353

Müller A, Volmer K, Mishra-Knyrim M, Polle A (2013) Growing poplars for research with and without mycorrhizas. Front Plant Sci. 4

Müllner D (2013) fastcluster: Fast hierarchical clustering routines for R and Python. Journal of Statistical Software, 53(9), 1-18

Nehls U, Göhringer F, Wittulsky S, Dietz S (2010) Fungal carbohydrate support in the ectomycorrhizal symbiosis: a review. Plant Biol 12: 292-301

Nerg A-M, Kasurinen A, Holopainen T, Julkunen-Tiitto R, Neuvonen S, Holopainen JK (2008) The significance of ectomycorrhizas in chemical quality of Silver birch foliage and above-ground insect herbivore performance. J Chem Ecol 34: 13221330

Newcombe RG (1998a) Two-sided confidence intervals for the single proportion: Comparison of seven methods. Statistics in Medicine 17, 857-872

Newcombe RG (1998b) Interval estimation for the difference between independent proportions: Comparison of eleven methods. Statistics in Medicine 17, 873-890 
Chapter 6: Influence of EMF inoculation on the behaviour of $C$. populi beetles

Niemi K, Julkunen-Tiitto R, Häggman H, Sarjala T (2007) Suillus variegatus causes significant changes in the content of individual polyamines and flavonoids in Scots pine seedlings during mycorrhiza formation in vitro. J Exp Bot 58: 391-401

Oddsdottir ES, Eilenberg J, Sen R, Harding S, Halldorsson G (2010) Early reduction of Otiorhynchus spp. larval root herbivory on Betula pubescens by beneficial soil fungi. Appl Soil Ecol 45: 168-174

Patrick R (1982a) An extension of Shapiro and Wilk's W test for normality to large samples. Applied Statistics 31: 115-124

Patrick R (1982b) Algorithm AS 181: The W test for Normality. Applied Statistics 31: $176-180$

Patrick R (1995) Remark AS R94: A remark on Algorithm AS 181: The W test for normality. Applied Statistics 44: 547-551

Peer WA, Murphy AS (2007) Flavonoids and auxin transport: modulators or regulators? Trends Plant Sci 12: 556-563

Pfabel C, Eckhardt K-U, Baum C, Struck C, Frey P, Weih M (2012) Impact of ectomycorrhizal colonization and rust infection on the secondary metabolism of poplar (Populus trichocarpa x deltoides). Tree Physiol 32: 1357-1364

Philippe RN, Bohlmann J (2007) Poplar defense against insect herbivoresThis review is one of a selection of papers published in the Special Issue on Poplar Research in Canada. Can J Bot 85: 1111-1126

Pineda A, Dicke M, Pieterse CMJ, Pozo MJ (2013) Beneficial microbes in a changing environment: are they always helping plants to deal with insects? Funct Ecol 27: $574-586$

Polle A, Douglas C (2010) The molecular physiology of poplars: paving the way for knowledge-based biomass production. Plant Biol 12: 239-241

Ponce MA, Scervino JM, Erra-Balsells R, Ocampo JA, Godeas AM (2004) Flavonoids from shoots and roots of Trifolium repens (white clover) grown in presence or absence of the arbuscular mycorrhizal fungus Glomus intraradices. Phytochemistry 65: $1925-1930$

Pozo MJ, Azcón-Aguilar C (2007) Unraveling mycorrhiza-induced resistance. Curr Opin Plant Biol 10: 393-398 
Rabin LB, Pacovsky R S (1985) Reduced larva growth of two lepidoptera (Noctuidae) on excised leaves of soybean infected with a mycorrhizal fungus. Journal of Economic Entomology 78: 1358-1363

Rieske LK, Rhoades CC, Miller SP (2003) Foliar chemistry and gypsy moth, Lymantria dispar (L.), herbivory on pure American chestnut, Castanea dentata (Fam: Fagaceae), and a disease-resistant hybrid. Environ Entomol 32: 359-365

Stafford HA (1997) Roles of flavonoids in symbiotic and defense functions in legume roots. Bot Rev 63: 27-39

Steinkellner S, Lendzemo V, Langer I, Schweiger P, Khaosaad T, Toussaint J-P, Vierheilig $\mathrm{H}$ (2007) Flavonoids and strigolactones in root exudates as signals in symbiotic and pathogenic plant-fungus interactions. Molecules 12: 1290-1306

Treutter D (2005) Significance of flavonoids in plant resistance and enhancement of their biosynthesis. Plant Biol 7: 581-591

Tsai C-J, Harding SA, Tschaplinski TJ, Lindroth RL, Yuan Y (2006) Genome-wide analysis of the structural genes regulating defense phenylpropanoid metabolism in Populus. New Phytol 172: 47-62

Tsai C-J, Ranjan P, DiFazio SP, Tuskan GA, Johnson V (2011) Poplar genome microarrays. In Joshi CP, DiFazio SP and Kole C, eds, Genetics, Genomics and Breeding of Poplars. Science Publishers, Enfield, 112-127

Venables WN, Ripley BD (2002) Modern Applied Statistics with S, Springer Berlin Heidelberg, Berlin, Heidelberg

Warnes GR, Bolker B, Bonebakker L, Gentleman R, Liaw WHA, Lumley T, Maechler M, Magnusson A, Moeller S, Schwartz M, Venables B (2014) gplots: Various R programming tools for plotting data, http://cran.r-project.org/web/packages/gplots/ index.html

Wasson AP, Pellerone FI, Mathesius U (2006) Silencing the flavonoid pathway in Medicago truncatula inhibits root nodule formation and prevents auxin transport regulation by rhizobia. Plant Cell Online 18: 1617-1629

Younginger B, Barnouti J, Moon DC (2009) Interactive effects of mycorrhizal fungi, salt stress, and competition on the herbivores of Baccharis halimifolia. Ecol Entomol 34: 580-587 
Chapter 6: Influence of EMF inoculation on the behaviour of $C$. populi beetles

Table S6.1 | Number of reads before and after processing. Pooled leaf samples of poplars exposed to $C$. populi beetles or inoculated with the EMF L. bicolor were used for RNA Sequencing. NC = non inoculated poplars in control cages, $\mathrm{MC}=$ poplars inoculated with L. bicolor in control cages, $\mathrm{NB}=$ non inoculated poplars exposed to $C$. populi, $\mathrm{MB}=$ poplars inoculated with $L$. bicolor exposed to C. populi.

\begin{tabular}{ccc}
\hline Sample & $\begin{array}{c}\text { Number of reads } \\
\text { before processing }\end{array}$ & $\begin{array}{c}\text { Number of reads } \\
\text { after processing }\end{array}$ \\
\hline NC1 & 33010530 & 27408812 \\
NC2 & 30824646 & 25011897 \\
NC3 & 39114117 & 31885593 \\
MC1 & 35644007 & 29669751 \\
MC2 & 31827260 & 24985789 \\
MC3 & 32763223 & 26818472 \\
NB1 & 35369015 & 29600366 \\
NB2 & 31421718 & 26142843 \\
NB3 & 33373616 & 27634844 \\
MB1 & 38276077 & 31604273 \\
MB2 & 35799277 & 29468877 \\
MB3 & 30859414 & 24825667 \\
\hline
\end{tabular}


Table S6.2 (in electronic form)| Genes with significantly increased or decreased transcript abundance in poplar leaves in response to EMF inoculation with $\mathbf{L}$. bicolor or attack by $C$. populi beetles. Results of the comparisons a) $\mathrm{MC} / \mathrm{NC}$, b) $\mathrm{MB} / \mathrm{NB}$, c) $\mathrm{NB} / \mathrm{NC}$ and d) $\mathrm{MB} / \mathrm{MC}$ are givn in seperate Excel sheets. Columns indicate Populus trichocarpa ID, Arabidopsis thaliana gene identifier (AGI ID), P values, the response factor $(\operatorname{logFC})$ of the comparison and the putative gene function. $\mathrm{NC}=$ non-inoculated poplars in control cages, $\mathrm{MC}=$ poplars inoculated with L. bicolor in control cages, $\mathrm{NB}=$ non-inoculated poplars exposed to C. populi, $\mathrm{MB}=$ poplars inoculated with L. bicolor exposed to C. populi. 
Table S6.3 | P-values from multiple comparisons of module eigengene values from WGCNA $($ n.s. $=$ not significant). $\mathrm{NC}=$ non inoculated poplars in control cages, $\mathrm{MC}=$ poplars inoculated with L. bicolor in control cages, $\mathrm{NB}=$ non inoculated poplars exposed to $C$. populi, $\mathrm{MB}=$ poplars inoculated with L. bicolor exposed to C. populi.

\begin{tabular}{|c|c|c|c|c|}
\hline \multirow[t]{2}{*}{ Module } & \multicolumn{2}{|c|}{ EMF effect } & \multicolumn{2}{|c|}{ Beetle effect } \\
\hline & $\begin{array}{l}\mathrm{MC} / \mathrm{NC} \\
\text { (P-value) }\end{array}$ & $\begin{array}{l}\mathrm{MB} / \mathrm{NB} \\
\text { (P-value) }\end{array}$ & $\begin{array}{l}\text { NB/NC } \\
\text { (P-value) }\end{array}$ & $\begin{array}{l}\mathrm{MB} / \mathrm{MC} \\
\text { (P-value) }\end{array}$ \\
\hline \multicolumn{5}{|l|}{ MT1 } \\
\hline darkgrey & 0.037 & n.s. & 0.001 & n.s. \\
\hline skyblue3 & n.s. & n.s. & 0.010 & n.s. \\
\hline darkmagenta & n.s. & n.s. & 0.002 & 0.011 \\
\hline lightcyan1 & n.s. & n.s. & 0.002 & 0.044 \\
\hline \multicolumn{5}{|l|}{ MT2 } \\
\hline midnightblue & n.s. & n.s. & 0.004 & 0.014 \\
\hline darkturquoise & n.s. & n.s. & 0.008 & 0.028 \\
\hline orangered4 & n.s. & n.s. & 0.004 & 0.012 \\
\hline grey & n.s. & n.s. & $<0.001$ & $<0.001$ \\
\hline yellow & n.s. & n.s. & 0.001 & 0.001 \\
\hline greenyellow & n.s. & n.s. & $<0.001$ & 0.001 \\
\hline magenta & n.s. & n.s. & 0.001 & 0.002 \\
\hline \multicolumn{5}{|l|}{ MT3 } \\
\hline grey60 & n.s. & n.s. & $<0.001$ & $<0.001$ \\
\hline royalblue & n.s. & n.s. & 0.006 & 0.006 \\
\hline blue & n.s. & n.s. & 0.045 & 0.005 \\
\hline salmon & n.s. & n.s. & $<0.001$ & $<0.001$ \\
\hline darkgreen & n.s. & n.s. & 0.011 & 0.014 \\
\hline \multicolumn{5}{|l|}{ MT4 } \\
\hline lightsteelblue 1 & n.s. & n.s. & 0.005 & n.s. \\
\hline lightyellow & n.s. & n.s. & 0.005 & n.s. \\
\hline sienna3 & n.s. & n.s. & 0.014 & n.s. \\
\hline plum1 & n.s. & 0.023 & $<0.001$ & $<0.001$ \\
\hline mediumpurple3 & n.s. & 0.025 & $<0.001$ & 0.024 \\
\hline orange & n.s. & n.s. & 0.001 & 0.033 \\
\hline black & n.s. & n.s. & n.s. & n.s. \\
\hline lightcyan & n.s. & n.s. & n.s. & n.s. \\
\hline \multicolumn{5}{|l|}{ MT5 } \\
\hline brown & n.s. & n.s. & 0.020 & 0.008 \\
\hline turquoise & n.s. & n.s. & 0.003 & 0.002 \\
\hline cyan & n.s. & n.s. & 0.011 & 0.014 \\
\hline $\tan$ & n.s. & n.s. & 0.028 & n.s. \\
\hline darkolivegreen & n.s. & n.s. & n.s. & n.s. \\
\hline green & n.s. & n.s. & n.s. & n.s. \\
\hline \multicolumn{5}{|l|}{ MT6 } \\
\hline pink & n.s. & n.s. & n.s. & 0.016 \\
\hline lightgreen & n.s. & n.s. & n.s. & 0.015 \\
\hline violet & n.s. & n.s. & n.s. & 0.040 \\
\hline steelblue & n.s. & n.s. & 0.018 & 0.004 \\
\hline yellowgreen & n.s. & n.s. & 0.003 & 0.001 \\
\hline skyblue & n.s. & n.s. & n.s. & n.s. \\
\hline \multicolumn{5}{|l|}{ MT7 } \\
\hline paleturquoise & n.s. & n.s. & 0.014 & n.s. \\
\hline purple & n.s. & n.s. & 0.003 & n.s. \\
\hline red & n.s. & n.s. & 0.006 & n.s. \\
\hline darkorange & n.s. & n.s. & $<0.001$ & $<0.001$ \\
\hline saddlebrown & n.s. & n.s. & $<0.001$ & 0.006 \\
\hline white & n.s. & n.s. & $<0.001$ & 0.004 \\
\hline \multicolumn{5}{|l|}{ MT8 } \\
\hline darkred & n.s. & n.s. & n.s. & n.s. \\
\hline
\end{tabular}


Table S6.4 | Loading values of variables of principal component (PC) analysis and principal component scores. $\mathrm{NC}=$ non inoculated poplars in control cages, $\mathrm{MC}=$ poplars inoculated with L. bicolor in control cages, $\mathrm{NB}=$ non inoculated poplars exposed to $C$. populi, $\mathrm{MB}=$ poplars inoculated with L. bicolor exposed to C. populi.

\begin{tabular}{|c|c|c|c|}
\hline & & PC1 & $\mathrm{PC} 2$ \\
\hline \multirow[t]{18}{*}{ Loading } & Leaf dry weight (g plant $\left.{ }^{-1}\right)$ & -0.264 & 0.148 \\
\hline & Stem dry weight (g plant ${ }^{-1}$ ) & -0.186 & 0.338 \\
\hline & Coarse roots dry weight $\left(\mathrm{g}_{\text {plant }} \mathrm{t}^{-1}\right)$ & -0.182 & 0.338 \\
\hline & Fine roots dry weight $\left(\mathrm{g}_{\mathrm{plant}}{ }^{-1}\right)$ & -0.061 & 0.481 \\
\hline & Plant height $\left(\mathrm{m}\right.$ plant $\left.^{-1}\right)$ & -0.247 & 0.223 \\
\hline & Number of eggs plant ${ }^{-1}$ & 0.235 & 0.196 \\
\hline & Feeding leaf damage plant $^{-1}$ & 0.266 & 0.131 \\
\hline & Mycorrhization rate $(\%)$ & 0.031 & -0.462 \\
\hline & Leaf area $\left(\mathrm{m}^{2}\right.$ plant $\left.^{-1}\right)$ & -0.264 & 0.015 \\
\hline & C. populi choice $(\%)$ & 0.252 & 0.179 \\
\hline & MT1 (eigengene value) & -0.275 & 0.050 \\
\hline & MT2 (eigengene value) & -0.270 & -0.098 \\
\hline & MT3 (eigengene value) & -0.240 & -0.236 \\
\hline & MT4 (eigengene value) & 0.248 & 0.192 \\
\hline & MT5 (eigengene value) & 0.265 & 0.118 \\
\hline & MT6 (eigengene value) & 0.249 & 0.070 \\
\hline & MT7 (eigengene value) & 0.272 & 0.085 \\
\hline & MT8 (eigengene value) & 0.255 & -0.191 \\
\hline \multirow[t]{4}{*}{ Score } & NC poplars & -4.251 & 1.791 \\
\hline & MC poplars & -1.744 & -2.671 \\
\hline & NB poplars & 3.175 & 1.332 \\
\hline & MB poplars & 2.820 & -0.452 \\
\hline
\end{tabular}


Chapter 6: Influence of EMF inoculation on the behaviour of $C$. populi beetles

\subsection{Declaration}

The following data shown in this chapter have been provided by other authors:

- The bioinformatical analysis of data processing, mapping, annotation and identification of transcripts with significantly increased or decreased transcript abundance was performed by Dennis Janz (Forest Botany and Tree Physiology, Büsgen-Institut, Georg-August Universität Göttingen, Germany). 
Chapter 7

Overall conclusion and outlook 


\section{Overall conclusion and outlook}

Poplars are of high ecological and economic value. However, little information on belowground communication of poplar with root-associated fungi such as EMF and the influence of EMF inoculation of the roots on aboveground herbivores is available. In this work, micropropagation protocols of different poplar species and co-cultivation systems to study the interaction of poplar with EMF are described. These methods enable the production of plant material of homogeneous quality as the prerequisite for reproducible experiments (Müller et al. 2013a).

The present study characterised the VOC emission of EMF and fungi from other lifestyles using a non-invasive method. EMF differed in their VOC patterns from fungal pathogens and saprophytes (Fig. 7.1 A; Müller et al. 2013b). VOCs may be used as biomarkers to distinguish between fungi in a mixture of fungi or to identify fungi under natural conditions such as pathogens in early infection stages of trees. So far, no method exists to detect pathogens in these infection stages. The main differences between the fungal species were the emission pattern of SQTs. In particular, the EMF L. bicolor emitted various SQTs, whereas no SQTs were emitted by the EMF C. geophilum. An intriguing question therefore, was whether plants may be able to recognise and distinguish between EMF by the whole fungal VOC pattern or by specific SQTs. The results of this thesis demonstrated that specific SQTs are important signalling molecules between EMF and plants. VOCs of the EM fungus L. bicolor induced lateral root formation of poplar and Arabidopsis (Fig. 7.1 A). When L. bicolor was cultivated on medium supplemented with the inhibitor lovastatin, the biosynthesis of SQTs was suppressed, and the fungal VOCs no longer affected the root architecture. Of the tested candidate compounds, $\beta$-caryophyllene, which is involved in other biotic interactions such as in the attraction of nematodes to maize roots (Rasmann et al., 2005) or the defence of Arabidopsis against bacterial pathogens (Huang et al., 2012), did not promote lateral root growth, whereas lateral root growth was promoted by the low abundant compound thujopsen. The observation that the root architecture was influenced by thujopsen and not by $\beta$-caryophyllene indicates that plants react to specific fungal compounds.

The VOC valencene was only found in the combinations of plant and fungi, suggesting a function of this VOC in the interaction between the organisms. It is therefore likely that the interaction of the fungus with the plant influenced the fungal VOC blend resulting 


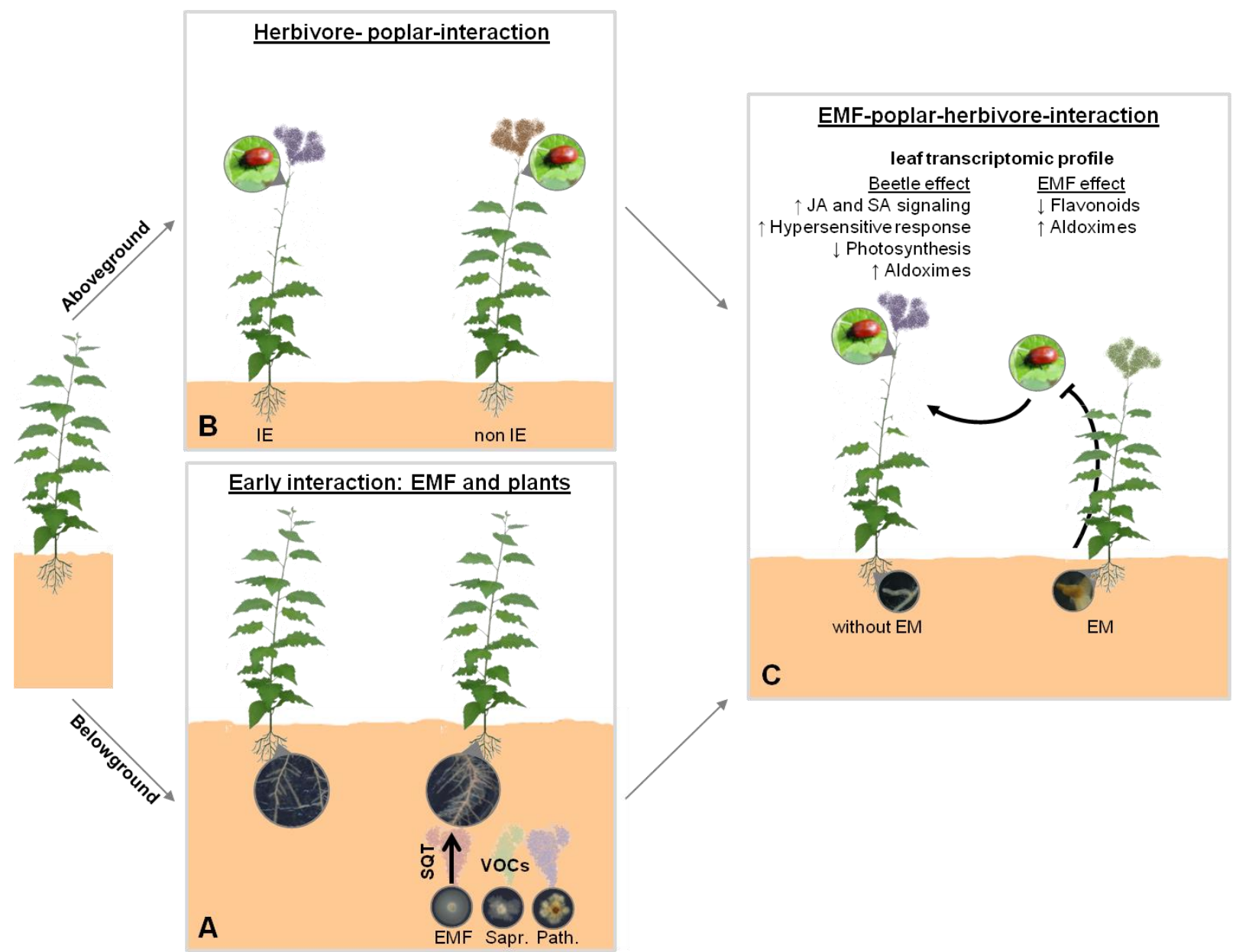

Fig. 7.1| Interaction of poplar and ectomycorrhizal fungi and herbivores. A) Ectomycorhizal fungi (EMF), saprophytes (Sapr.) and pathogens (Path.) strongly differ in the emission of volatile organic compounds (VOCs), mainly sesquiterpenes (SQTs). Arrow indicates that SQTs by EMF induce the formation of lateral roots in poplars. B) C. populi beetles are not able to detect isoprene, but show a preference for isoprene-emitting (IE) over non-emitting poplars (non IE). C) C. populi show a preference for poplars noninoculated than for poplars inoculated with EMF. EMF inoculation and beetle infestation induce changes in the leaf transcriptomic profiles of the poplars (up arrows indicate increased and down arrows decreased transcript abundance). 
in valencene formation. It will be intriguing to investigate whether this compounds has biological functions.

For the VOC experiments with Arabidopsis and EMF an experimental set-up with a low VOC emission was established. Still, more than 40 VOCs had to be removed from the dataset, because they were detected in control plates without fungi and thus originated from the background odor of the plates such as the growth-medium. The measured concentrations of some of these compounds changed under the different treatments. Whether VOC emissions of fungi or plants contributed to increased concentrations of these VOCs was not investigated, because the stir bar sorptive extraction is a semiquantitative method and VOCs produced by the organisms and those present in the background could not be distinguished. Furthermore, very reactive compounds may have not been detected. Therefore, it cannot be excluded that other fungal VOCs than those identified here, may also be important signalling compounds in the interaction with plants. Furthermore, the VOC pattern of fungi can change in different environments and during the fungal lifecycle as was shown for the VOC profile of the fungus Penicillium discolour. This fungus exhibited its highest VOC emissions five days after beginning of the culture (Nilsson et al., 1996). Therefore, under different environmental conditions or cultivation times L. bicolor may emit other fungal SQTs that may also be involved in signalling between plant and fungus.

The finding that the EM fungus C. geophilum does not emit SQTs and was not able to induce lateral root formation in the plants, agrees with its mycorrhizal structure, which has less branches than the mycorrhizas formed by L. bicolor (www.deemy.de). The finding that the non-host Arabidopsis reacts to the L. bicolor VOCs indicates that fungal SQTs have functions that are not related to the mycorrhizal colonisation. Plants release carbohydrates into the rhizosphere through the root system (Kumar et al., 2006). Therefore, the stimulation of lateral roots may be advantageous for L. bicolor by enhancing its access to plant-derived carbohydrates without the necessity of forming a symbiotic structure.

Poplars emit high concentration of isoprene (Kesselmeier and Staudt, 1999). Transgenic non-isoprene emitting poplars did not differ in the number of mycorrhizas formed with L. bicolor compared to isoprene emitting poplars (Habib, personal communication). Aboveground, C. populi beetles were not able to detect isoprene, but showed a preference for isoprene-emitting over transgenic non-isoprene-emitting lines under outdoor conditions (Fig. 7.1 B). The suppression of the isoprene emission influenced metabolic profiles such 
as the MEP pathway of the plants and reduced the emission rate of monoterpenes. The beetles were able to detect other terpenes. Therefore, the terpenes may be important in the communication between poplar and $C$. populi. It is likely that the indirect effects, i.e., the slight changes in the terpene profiles and the metabolome of the non-emitting poplars influenced the behaviour of the beetles. Although isoprene was excluded here to affect host preference of the $C$. populi beetles, it was shown to be involved in the interaction between other plants and insects. The parasitic diadegma wasp (Diadegma semiclausum) was deterred by the isoprene emission of transgenic isoprene-emitting Arabidopsis plants (Loivamäki et al., 2008). Thus, further studies are required to find out whether poplars communicate with other organisms by isoprene.

Mycorrhizal associations of plants can influence insect behaviour (Gange et al., 2005). This led to the question, whether EMF inoculation of poplar influences C. populi infestation. To study the multitrophic interaction of mycorrhizal fungi, poplars and herbivores, poplars were inoculated with L. bicolor and infested with $C$. populi beetles. The direct contact of poplar with the EMF affected the transcript abundance of genes in hormone signalling pathways, flavonoid biosynthesis pathway and aldoxime biosynthesis in the leaves. The plants benefited from the inoculation by a decreased infestation with $C$. populi beetles (Fig. 7.1 C). This is an important finding that enables the development of new strategies of plant protection of poplars against herbivory. For example, inoculating poplars in plantations with the EMF may be desirable to reduce the damage caused by $C$. populi infestations.

The C. populi beetles preferred to feed and oviposit on the non-inoculated compared to the inoculated poplars although the mycorrhization rate was low. This suggests that the intensity of the mycorrhization may not play the essential role in how poplars are affected by EMF. The observation that the inoculation and not the degree of mycorrhization influences plant performance of poplars agrees with recent findings. For example, although in $P$. euphratica inoculated with the EMF $P$. involutus no ectomycorrhizas were formed, Luo et al. (2009b) observed an increased osmolality in leaves under drought conditions and increased stress tolerance and also a reduced plant growth of the inoculated compared to the non-inoculated poplars. Trade-off in growth performance of the inoculated compared with the non-inoculated poplars was also found in the present study. The reasons for this result need to be addressed because the mycorrhization rate was low and thus the direct 
carbon consumption, which can be quite high in functional ectomycorrhizas (Wallander and Nylund, 1991), was expected to be low.

The increased transcript abundance of genes involved in the biosynthesis of aldoximes in response to $C$. populi infestation and EMF inoculation, suggested an enhanced role of aldoximes in the defence of inoculated poplars against the $C$. populi beetles. Irmisch et al. (2013) demonstrated that higher phenyl-acetaldoxime concentrations reduced the survival of gypsy moth caterpillars (Lymantria dispar) and decreased the growth of the larvae. A relationship between aldoximes and $C$. populi behaviour remains speculative until the performance of $C$. populi beetles on plants with modified aldoxime metabolism have been conducted. Changes in the transcript abundance of genes involved in terpene biosynthesis indicated that the beetle attack also affected the biosynthesis of 1,8-cineol and $\beta$ caryophyllene. Both VOCs are involved in defence reactions of plants during biotic stress (Tripathi et al., 2001; Rasmann et al., 2005). Therefore, the influence of the EMF on the VOC pattern may have also affected the beetle behaviour.

Still, open questions about fungal VOCs and the role of VOCs in EMF-plant interactions remain. In the present study it was demonstrated that fungal species and fungal lifestyles differ in their VOC profiles. To use VOCs as biomarkers for the identification of fungi, the VOC emissions of more fungi of different lifestyles should be characterised and compared. We identified SQTs as VOCs that are recognised by plants, but how the VOCs are received by plants such as Arabidopsis and which signalling pathways are triggered in the plants by the VOCs is unknown and needs to be investigated. For this purpose it would be interesting to conduct transcriptional analysis of plants exposed to fungal VOCs and to screen Arabidopsis mutant for changes in their response to fungal VOCs. Also further studies about changes in the fungal VOC emission during different stages of the interaction are needed.

Feeding and oviposition of $C$. populi beetles on inoculated poplars was lower than on noninoculated poplars. To investigate which compounds influenced the beetle behaviour, the effect of aldoximes on the beetles should be investigated. Furthermore, the EMF inoculation of poplars may have changed the aboveground VOC emission of poplars and thereby the attraction of the plants to the leaf feeding beetles. Therefore, aboveground VOC emissions of poplars inoculated with EMF should be measured. Future work about the influence of EMF inoculation of poplar on herbivores should also include other EMF 
and herbivores to determine the specificity of the tritrophic interaction between the fungal, plant and insect species. 


\section{References of introduction and overall conclusion}

Agerer R (2001) Exploration types of ectomycorrhizae. Mycorrhiza 11: 107-114

Agger S, Lopez-Gallego F, Schmidt-Dannert C (2009) Diversity of sesquiterpene synthases in the basidiomycete Coprinus cinereus. Mol Microbiol 72: 1181-1195

Agranoff BW, Eggerer H, Henning U, Lynen F (1960) Biosynthesis of terpenes VII. Isopentenyl pyrophosphate isomerase. J Biol Chem 235: 326-332

Akiyama K, Matsuzaki K, Hayashi H (2005) Plant sesquiterpenes induce hyphal branching in arbuscular mycorrhizal fungi. Nature 435: 824-827

Altincicek B, Kollas A-K, Eberl M, Wiesner J, Sanderbrand S, Hintz M, Beck E, Jomaa H (2001) LytB, a novel gene of the 2-C-methyl-D-erythritol 4-phosphate pathway of isoprenoid biosynthesis in Escherichia coli. FEBS Lett 499: 37-40

Aochi YO, Farmer WJ (2005) Impact of soil microstructure on the molecular transport dynamics of 1,2-dichloroethane. Geoderma 127: 137-153

Arimura G, Huber DPW, Bohlmann J (2004) Forest tent caterpillars (Malacosoma disstria) induce local and systemic diurnal emissions of terpenoid volatiles in hybrid poplar (Populus trichocarpa $\times$ deltoides): cDNA cloning, functional characterization, and patterns of gene expression of (-)-germacr: Insect-induced volatile emission in poplar. Plant J 37: 603-616

Beguiristain T, Cote R, Rubini P, Jay-Allemand C, Lapeyrie F (1995) Hypaphorine accumulation in hyphae of the ectomycorrhizal fungus, Pisolithus tinctorius. Phytochemistry 40: 1089-1091

Behnke K, Ehlting B, Teuber M, Bauerfeind M, Louis S, Hänsch R, Polle A, Bohlmann J, Schnitzler J-P (2007) Transgenic, non-isoprene emitting poplars don't like it hot: Thermotolerance in isoprene emission knock-down mutants of poplar. Plant J 51: 485-499

Behnke K, Grote R, Brüggemann N, Zimmer I, Zhou G, Elobeid M, Janz D, Polle A, Schnitzler J-P (2012) Isoprene emission-free poplars - a chance to reduce the impact from poplar plantations on the atmosphere. New Phytol 194: 70-82

Behnke K, Loivamäki M, Zimmer I, Rennenberg H, Schnitzler J-P, Louis S (2010) Isoprene emission protects photosynthesis in sunfleck exposed Grey poplar. Photosynth Res 104: 5-17 
Bohlmann J, Meyer-Gauen G, Croteau R (1998) Plant terpenoid synthases: molecular biology and phylogenetic analysis. Proc Natl Acad Sci U S A 95: 4126-4133

Byers KJRP, Bradshaw HD, Riffell JA (2014) Three floral volatiles contribute to differential pollinator attraction in monkeyflowers (Mimulus). J Exp Biol 217: 614623

Carr GR, Hinkley MA, Tacon F, Hepper CM, Jones MGK, Thomas E (1985) Improved hyphal growth of two species of vesicular-arbuscular mycorrhizal fungi in the presence of suspension-cultured plant cells. New Phytol 101: 417-426

Chamberlain K, Guerrieri E, Pennacchio F, Pettersson J, Pickett JA, Poppy GM, Powell W, Wadhams LJ, Woodcock CM (2001) Can aphid-induced plant signals be transmitted aerially and through the rhizosphere? Biochem Syst Ecol 29: 10631074

Chen S, Polle A (2009) Salinity tolerance of Populus: Salinity tolerance of Populus. Plant Biol 12: 317-333

Claeys M (2004) Formation of Secondary Organic Aerosols Through Photooxidation of Isoprene. Science 303: 1173-1176

Colpaert JV, Van Assche JA, Luijtens K (1992) The growth of the extramatrical mycelium of ectomycorrhizal fungi and the growth response of Pinus sylvestris L. New Phytol 120: 127-135

Danielsen L, Polle A (2014) Poplar nutrition under drought as affected by ectomycorrhizal colonization. Environ Exp Bot 108: 89-98

Davis EM, Croteau R (2000) Cyclization Enzymes in the Biosynthesis of Monoterpenes, Sesquiterpenes, and Diterpenes. In FJ Leeper, JC Vederas, eds, Biosynthesis. Springer Berlin Heidelberg, Berlin, Heidelberg, 53-95

Degenhardt J, Gershenzon J, Baldwin IT, Kessler A (2003) Attracting friends to feast on foes: engineering terpene emission to make crop plants more attractive to herbivore enemies. Curr Opin Biotechnol 14: 169-176

Dicke M, Loon JJ (2000) Multitrophic effects of herbivore-induced plant volatiles in an evolutionary context. Entomol Exp Appl 97: 237-249

Dicke M, van Loon JJA, Soler R (2009) Chemical complexity of volatiles from plants induced by multiple attack. Nat Chem Biol 5: 317-324 
Dickmann (2001) Poplar culture in North America. NRC Research Press, Ottawa

Dučić T, Berthold D, Langenfeld-Heyser R, Beese F, Polle A (2009) Mycorrhizal communities in relation to biomass production and nutrient use efficiency in two varieties of Douglas fir (Pseudotsuga menziesii var. menziesii and var. glauca) in different forest soils. Soil Biol Biochem 41: 742-753

Farina WM, Grüter C, Acosta L, Mc Cabe S (2007) Honeybees learn floral odors while receiving nectar from foragers within the hive. Naturwissenschaften 94: 55-60

Farmer EE, Ryan CA (1990) Interplant communication: airborne methyl jasmonate induces synthesis of proteinase inhibitors in plant leaves. Proc Natl Acad Sci 87: $7713-7716$

Felten J, Kohler A, Morin E, Bhalerao RP, Palme K, Martin F, Ditengou FA, Legue V (2009) The Ectomycorrhizal Fungus Laccaria bicolor Stimulates Lateral Root Formation in Poplar and Arabidopsis through Auxin Transport and Signaling. PLANT Physiol 151: 1991-2005

Felten J, Legue V, Ditengou FA (2010) Lateral root stimulation in the early interaction between Arabidopsis thaliana and the ectomycorrhizal fungus Laccaria bicolor. Plant Signal Behav 5: 864-867

Finlay RD (2008) Ecological aspects of mycorrhizal symbiosis: with special emphasis on the functional diversity of interactions involving the extraradical mycelium. J Exp Bot 59: 1115-1126

Fontana A, Reichelt M, Hempel S, Gershenzon J, Unsicker SB (2009) The effects of arbuscular mycorrhizal fungi on direct and indirect defense metabolites of Plantago lanceolata L. J Chem Ecol 35: 833-843

Gay G, Normand L, Marmeisse R, Sotta B, Debaud JC (1994) Auxin overproducer mutants of Hebeloma cylindrosporum Romagnesi have increased mycorrhizal activity. New Phytol 128: 645-657

Gehring CA, Whitham TG (2003) Mycorrhizae-herbivore interactions: population and community consequences. Mycorrhizal Ecol. Springer Berlin Heidelberg, Berlin, Heidelberg, 295-320 
Georgi R, Helbig C, Schubert M (2012) The red poplar leaf beetle in short rotation coppice. AFZ/Der Wald, Allgemeine Forst Zeitschrift für Waldwirtschaft und Umweltvorsorge 67: 11-13

Gouinguene SP, Turlings TCJ (2002) The Effects of Abiotic Factors on Induced Volatile Emissions in Corn Plants. Plant Physiol 129: 1296-1307

Guenther A, Hewitt CN, Erickson D, Fall R, Geron C, Graedel T, Harley P, Klinger L, Lerdau M, Mckay WA, et al (1995) A global model of natural volatile organic compound emissions. J Geophys Res 100: 8873

Harley JL, Smith SE (1983) Mycorrhizal symbiosis. Academic, London

Hilker M, Meiners T (2006) Early Herbivore Alert: Insect Eggs Induce Plant Defense. J Chem Ecol 32: 1379-1397

Hobbie EA (2006) Carbon allocation to ectomycorrhizal fungi correlates with belowground allocation in culture studies. Ecology 87: 563-569

Huang M, Sanchez-Moreiras AM, Abel C, Sohrabi R, Lee S, Gershenzon J, Tholl D (2012) The major volatile organic compound emitted from Arabidopsis thaliana flowers, the sesquiterpene (E)- $\beta$-caryophyllene, is a defense against a bacterial pathogen. New Phytol 193: 997-1008

Irmisch S, Clavijo McCormick A, Boeckler GA, Schmidt A, Reichelt M, Schneider B, Block K, Schnitzler J-P, Gershenzon J, Unsicker SB, et al (2013) Two herbivoreinduced cytochrome P450 enzymes CYP79D6 and CYP79D7 catalyze the formation of volatile aldoximes involved in poplar defense. Plant Cell 25: 47374754

Janz D, Lautner S, Wildhagen H, Behnke K, Schnitzler J-P, Rennenberg H, Fromm J, Polle A (2012) Salt stress induces the formation of a novel type of "pressure wood" in two Populus species. New Phytol 194: 129-141

Kesselmeier J, Ciccioli P, Kuhn U, Stefani P, Biesenthal T, Rottenberger S, Wolf A, Vitullo M, Valentini R, Nobre A, et al (2002) Volatile organic compound emissions in relation to plant carbon fixation and the terrestrial carbon budget: Volatile organic compounds. Glob Biogeochem Cycles 16: 73-1-73-9

Kesselmeier J, Staudt M (1999) Biogenic Volatile Organic Compounds (VOC): An Overview on Emission, Physiology and Ecology. J Atmospheric Chem 33: 23-88 
Kessler A, Baldwin IT (2001) Defensive Function of Herbivore-Induced Plant Volatile Emissions in Nature. Science 291: 2141-2144

Kessler A, Baldwin IT (2002) Plant responses to insect herbivory: the emerging molecular analysis. Annu Rev Plant Biol 53: 299-328

Kessler A, Halitschke R, Diezel C, Baldwin IT (2006) Priming of plant defense responses in nature by airborne signaling between Artemisia tridentata and Nicotiana attenuata. Oecologia 148: 280-292

Kessler A, Halitschke R, Poveda K (2011) Herbivory-mediated pollinator limitation: negative impacts of induced volatiles on plant-pollinator interactions. Ecology 92: $1769-1780$

Krupa S, Fries N (1971) Studies on ectomycorrhizae of pine. I. Production of volatile organic compounds. Can J Bot 49: 1425-1431

Kulmala M, Suni T, Lehtinen KEJ, Maso MD, Boy M, Reissell A, Rannik Ü, Aalto P, Keronen P, Hakola H, Back J B, Hoffmann T, Vesala T, Hari P (2004) A new feedback mechanism linking forests, aerosols, and climate. Atmospheric Chem Phys 4: 557-562

Kumar R, Pandey S, Pandey A (2006) Plant roots and carbon sequestration. Curr Sci 91: 885

Langenfeld-Heyser R, Gao J, Ducic T, Tachd P, Lu CF, Fritz E, Gafur A, Polle A (2007) Paxillus involutus mycorrhiza attenuate $\mathrm{NaCl}$-stress responses in the salt-sensitive hybrid poplar Populus $\times$ canescens. Mycorrhiza 17: 121-131

Laothawornkitkul J, Paul ND, Vickers CE, Possell M, Taylor JE, Mullineaux PM, Hewitt CN (2008) Isoprene emissions influence herbivore feeding decisions. Plant Cell Environ 31: 1410-1415

Leitner M, Kaiser R, Hause B, Boland W, Mithöfer A (2010) Does mycorrhization influence herbivore-induced volatile emission in Medicago truncatula? Mycorrhiza 20: $89-101$

Loivamäki M, Louis S, Cinege G, Zimmer I, Fischbach RJ, Schnitzler J-P (2007) Circadian rhythms of isoprene biosynthesis in grey poplar leaves. Plant Physiol 143: $540-551$ 
Loivamäki M, Mumm R, Dicke M, Schnitzler J-P (2008) Isoprene interferes with the attraction of bodyguards by herbaceous plants. Proc Natl Acad Sci 105: 17430 17435

Luo Z-B, Janz D, Jiang X, Gobel C, Wildhagen H, Tan Y, Rennenberg H, Feussner I, Polle A (2009a) Upgrading root physiology for stress tolerance by ectomycorrhizas: insights from metabolite and transcriptional profiling into reprogramming for stress anticipation. Plant Physiol 151: 1902-1917

Luo Z-B, Li K, Jiang X, Polle A (2009b) Ectomycorrhizal fungus (Paxillus involutus) and hydrogels affect performance of Populus euphratica exposed to drought stress. Ann For Sci 66: 106-106

Manninen A-M, Holopainen T, Holopainen JK (1998) Susceptibility of ectomycorrhizal and non-mycorrhizal Scots pine (Pinus sylvestris) seedlings to a generalist insect herbivore, Lygus rugulipennis, at two nitrogen availability levels. New Phytol 140: $55-63$

Mccormick A, Irmisch S, Reinecke A, Boeckler GA, Veit D, Reichelt M, Hansson BS, Gershenzon J, KöLlner TG, Unsicker SB (2014) Herbivore-induced volatile emission in black poplar: regulation and role in attracting herbivore enemies: Herbivore-induced black poplar volatiles. Plant Cell Environ 37: 1909-1923

Menotta M, Gioacchini AM, Amicucci A, Buffalini M, Sisti D, Stocchi V (2004) Headspace solid-phase microextraction with gas chromatography and mass spectrometry in the investigation of volatile organic compounds in an ectomycorrhizae synthesis system. Rapid Commun Mass Spectrom 18: 206-210

Minerdi D, Bossi S, Maffei ME, Gullino ML, Garibaldi A (2011) Fusarium oxysporum and its bacterial consortium promote lettuce growth and expansin A5 gene expression through microbial volatile organic compound (MVOC) emission: Plant growth promotion by antagonistic Fusarium oxysporum. FEMS Microbiol Ecol 76: $342-351$

De Moraes CM, Lewis WJ, Paré PW, Alborn HT, Tumlinson JH (1998) Herbivore-infested plants selectively attract parasitoids. Nature 393: 570-573

Müller A, Volmer K, Mishra-Knyrim M, Polle A (2013a) Growing poplars for research with and without mycorrhizas. Front Plant Sci. 4 
Müller A, Faubert P, Hagen M, zu Castell W, Polle A, Schnitzler JP, Rosenkranz M (2013b) Volatile profiles of fungi - Chemotyping of species and ecological functions. Fungal Genetics and Biology 54: 25-33

Mueller RC, Sthultz CM, Martinez T, Gehring CA, Whitham TG (2005) The relationship between stem-galling wasps and mycorrhizal colonization of Quercus turbinella. Can J Bot 83: 1349-1353

Müller C, Hilker M (2000) The effect of a green leaf volatile on host plant finding by larvae of a herbivorous insect. Naturwissenschaften 87: 216-219

Mumm R, Posthumus MA, Dicke M (2008) Significance of terpenoids in induced indirect plant defence against herbivorous arthropods. Plant Cell Environ 31: 575-585

Nehls U, Göhringer F, Wittulsky S, Dietz S (2010) Fungal carbohydrate support in the ectomycorrhizal symbiosis: a review. Plant Biol 12: 292-301

Nilsson T, Larsen TO, Montanarella L, Madsen J ø. (1996) Application of head-space solid-phase microextraction for the analysis of volatile metabolites emitted by Penicillium species. J Microbiol Methods 25: 245-255

Packer A, Clay K (2000) Soil pathogens and spatial patterns of seedling mortality in a temperate tree. Nature 404: 278-281

Pang PP, Meyerowitz EM (1987) Arabidopsis Thaliana: A Model System for Plant Molecular Biology. Bio/Technology 5: 1177-1181

Peskan-Berghofer T, Shahollari B, Giong PH, Hehl S, Markert C, Blanke V, Kost G, Varma A, Oelmuller R (2004) Association of Piriformospora indica with Arabidopsis thaliana roots represents a novel system to study beneficial plantmicrobe interactions and involves early plant protein modifications in the endoplasmic reticulum and at the plasma membrane. Physiol Plant 122: 465-477

Philippe RN, Bohlmann J (2007) Poplar defense against insect herbivores. Can J Bot 85: $1111-1126$

Phillips MA, Croteau RB (1999) Resin-based defenses in conifers. Trends Plant Sci 4: 184-190

Pichersky E, Gershenzon J (2002) The formation and function of plant volatiles: perfumes for pollinator attraction and defense. Curr Opin Plant Biol 5: 237-243 
Polle A, Douglas C (2010) The molecular physiology of poplars: paving the way for knowledge-based biomass production. Plant Biol 12: 239-241

Polle A, Janz D, Teichmann T, Lipka V (2013) Poplar genetic engineering: promoting desirable wood characteristics and pest resistance. Appl Microbiol Biotechnol 97: $5669-5679$

Raguso RA (2004) Flowers as sensory billboards: progress towards an integrated understanding of floral advertisement. Curr Opin Plant Biol 7: 434-440

Raguso RA (2009) Floral scent in a whole-plant context: moving beyond pollinator attraction. Funct Ecol 23: 837-840

Rasmann S, Köllner TG, Degenhardt J, Hiltpold I, Toepfer S, Kuhlmann U, Gershenzon J, Turlings TCJ (2005) Recruitment of entomopathogenic nematodes by insectdamaged maize roots. Nature 434: 732-737

Reboutier D, Bianchi M, Brault M, Roux C, Dauphin A, Rona J-P, Legué V, Lapeyrie F, Bouteau F (2002) The indolic compound hypaphorine produced by ectomycorrhizal fungus interferes with auxin action and evokes early responses in nonhost Arabidopsis thaliana. Mol Plant Microbe Interact 15: 932-938

Riffell JA, Alarcón R, Abrell L, Davidowitz G, Bronstein JL, Hildebrand JG (2008) Behavioral consequences of innate preferences and olfactory learning in hawkmoth-flower interactions. Proc Natl Acad Sci 105: 3404-3409

Rodriguez-Concepcion M (2004) Distinct light-mediated pathways regulate the biosynthesis and exchange of isoprenoid precursors during Arabidopsis seedling development. Plant Cell Online 16: 144-156

Rohmer M, Knani M, Simonin P, Sutter B, Sahm H (1993) Isoprenoid biosynthesis in bacteria: a novel pathway for the early steps leading to isopentenyl diphosphate. Biochem J 295: 517-524

Sacchettini JC, Poulter CD (1997) Biochemistry: Creating isoprenoid diversity. Science 277: $1788-1789$

Sallaud C, Rontein D, Onillon S, Jabes F, Duffe P, Giacalone C, Thoraval S, Escoffier C, Herbette G, Leonhardt N, et al (2009) A novel pathway for sesquiterpene biosynthesis from Z,Z-Farnesyl pyrophosphate in the wild tomato solanum habrochaites. Plant Cell Online 21: 301-317 
Scagel CF, Linderman RG (1998) Relationships between in vitro indole acetic acid or ethylene production capacity by ectomycorrhizal fungi and conifer seedling responses in symbiosis. Symbiosis 24: 13-34

Scalcinati G, Knuf C, Partow S, Chen Y, Maury J, Schalk M, Daviet L, Nielsen J, Siewers V (2012) Dynamic control of gene expression in Saccharomyces cerevisiae engineered for the production of plant sesquitepene $\alpha$-santalene in a fed-batch mode. Metab Eng 14: 91-103

Schiestl FP, Dötterl S (2012) The evolution of floral scent and olfactory preferences in pollinators: coevolution or pre-existing bias? Evolution 66: 2042-2055

Schnee C, Kollner TG, Held M, Turlings TCJ, Gershenzon J, Degenhardt J (2006) The products of a single maize sesquiterpene synthase form a volatile defense signal that attracts natural enemies of maize herbivores. Proc Natl Acad Sci 103: 11291134

Schützendübel A, Polle A (2002) Plant responses to abiotic stresses: heavy metal-induced oxidative stress and protection by mycorrhization. J Exp Bot 53: 1351-1365

Sharkey TD, Singsaas EL, Vanderveer PJ, Geron C (1996) Field measurements of isoprene emission from trees in response to temperature and light. Tree Physiol 16: 649-654

Smith SE, Read D (2008) Mycorrhizal Symbiosis Third Ed. Academic Press, London

Söderström B, Finlay RD, Read DJ (1988) The structure and function of the vegetative mycelium of ectomycorrhizal plants IV. Qualitative analysis of carbohydrate contents of mycelium interconnecting host plants. New Phytol 109: 163-166

Soler E, Feron G, Clastre M, Dargent R, Gleizes M, Ambid C (1992) Evidence for a geranyl-diphosphate synthase located within the plastids of Vitis vinifera L. cultivated in vitro. Planta 187:171-5

Splivallo R, Bossi S, Maffei M, Bonfante P (2007a) Discrimination of truffle fruiting body versus mycelial aromas by stir bar sorptive extraction. Phytochemistry 68: 25842598

Splivallo R, Novero M, Bertea CM, Bossi S, Bonfante P (2007b) Truffle volatiles inhibit growth and induce an oxidative burst in Arabidopsis thaliana. New Phytol 175: 417-424 
Steele CL, Crock J, Bohlmann J, Croteau R (1998) Sesquiterpene synthases from grand fir (Abies grandis). Comparison of constitutive and wound-induced activities, and cDNA isolation, characterization, and bacterial expression of delta-selinene synthase and gamma-humulene synthase. J Biol Chem 273: 2078-2089

Thompson AM (1992) The oxidizing capacity of the earth's atmosphere: Probable past and future changes. Science 256: 1157-1165

Tribak M, Ocampo JA, García-Romera I (2002) Production of xyloglucanolytic enzymes by Trichoderma viride, Paecilomyces farinosus, Wardomyces inflatus, and Pleurotus ostreatus. Mycologia 94: 404-410

Tripathi AK, Prajapati V, Aggarwal KK, Kumar S (2001) Toxicity, feeding deterrence, and effect of activity of 1,8-cineole from artemisia annuaon progeny production of tribolium castanaeum (Coleoptera: Tenebrionidae). J Econ Entomol 94: 979-983

Turlings TC, Tumlinson JH (1992) Systemic release of chemical signals by herbivoreinjured corn. Proc Natl Acad Sci USA 89: 8399-8402

Tuskan GA, DiFazio S, Jansson S, Bohlmann J, Grigoriev I, Hellsten U, Putnam N, Ralph S, Rombauts S, Salamov A, et al (2006) The Genome of Black Cottonwood, Populus trichocarpa (Torr. \&amp; Gray). Science 313: 1596-1604

Velikova V, Loreto F (2005) On the relationship between isoprene emission and thermotolerance in Phragmites australis leaves exposed to high temperatures and during the recovery from a heat stress. Plant Cell Environ 28: 318-327

Vespermann A, Kai M, Piechulla B (2007) Rhizobacterial volatiles affect the growth of fungi and Arabidopsis thaliana. Appl Environ Microbiol 73: 5639-5641

Vickers CE, Gershenzon J, Lerdau MT, Loreto F (2009) A unified mechanism of action for volatile isoprenoids in plant abiotic stress. Nat Chem Biol 5: 283-291

Vozzo JA, Hacskaylo E (1974) Endo- and ectomycorrhizal associations in five Populus species. Bull Torrey Bot Club 101: 182

Vuorinen T, Nerg A-M, Syrjälä L, Peltonen P, Holopainen JK (2007) Epirrita autumnata induced VOC emission of silver birch differ from emission induced by leaf fungal pathogen. Arthropod-Plant Interact 1: 159-165

Wenke K, Kai M, Piechulla B (2010) Belowground volatiles facilitate interactions between plant roots and soil organisms. Planta 231: 499-506 
Williams J, Roberts JM, Fehsenfeld FC, Bertman SB, Buhr MP, Goldan PD, Hübler G, Kuster WC, Ryerson TB, Trainer M, et al (1997) Regional ozone from biogenic hydrocarbons deduced from airborne measurements of PAN, PPN, and MPAN. Geophys Res Lett 24: 1099-1102

Wright GA, Schiestl FP (2009) The evolution of floral scent: the influence of olfactory learning by insect pollinators on the honest signalling of floral rewards. Funct Ecol 23: $841-851$ 


\section{Acknowledgements}

This work would not have been possible without the support and help of a large number of people.

I am grateful to my supervisor Prof. Dr. Andrea Polle for giving me the chance to work on this interesting and complex topic, for her continuous support and guidance during the time of research and writing.

I am sincerely thankful to the following people of the Helmholtz Zentrum München: I express my deepest thanks to my second supervisor Prof. Dr. Jörg-Peter Schnitzler, who has supported me with his enthusiasm for research and creative ideas. I wish to thank Dr. Maaria Rosenkranz for her help and advice in VOC measurements. I express my thanks to Dr. Patrick Faubert, who kindly introduced me in GC-MS analysis. I am thankful to Maja Miloradovic van Doorn and Moritz Kaling, for their contribution to the project. I thank Dr. Andrea Ghirardo for help with GC-MS analysis.

I also thank all co-authors of the papers and manuscripts for their contributions.

I express my special thanks to Merle Fastenrath, who has constantly helped and supported me in the last years with her excellent technical assistance in the Arabidopsis and beetle experiments.

I would like to thank the team of the Department of Forest Botany and Tree Physiology: Christine Kettner, for providing me with the poplar plantlets and for her creativity in the development of new growth systems; Gisbert Langer-Kettner, for constructing the cages of the beetle experiments and for his technical support; Dennis Janz, for conducting and explaining me the bioinformatical analyses; Marianne Smiatacz, for her help with the harvests and plant care; Gabriele Lehmann, for her guidance in the work with fungal cultures; Monika Franke-Klein, for conducting lovastatin experiments with fungi; Bernd Kopka, for helping me with computer problems; Thomas Klein, for advising and helping me with molecular work.

I thank the German Science Foundation (DFG Po362/20-1 and SCHN653/5-1) for financial support. The thesis project was part of a collaboration between the Department of Forest Botany and Tree Physiology of the University of Göttingen and the Research Unit Environmental Simulation of the Helmholtz Zentrum München.

Furthermore, I thank my colleagues for the nice working atmosphere and support whenever needed: Mareike Kavka, Dr. Bettina Otto, Katharina Volmer, Dr. Henning 
Wildhagen, Michaela Rath, Josephine Sahner, Dr. Rodica Pena, Dr. Lara Danielsen, Dr. Kerrtu Valtanen and Dr. Martin Leberecht. I express my deepest thanks for my office mates Shanty Paul, for her help and feedback, and Kristina Schröter, for the inspiring discussions, advice and support during work and social hours.

I am thankful to Prof. Dr. Reiner Finkeldey for being part of my thesis committee and to Prof. Dr. Ivo Feußner, PD Dr. Thomas Teichmann and Prof. Dr. Petr Karlovsky for participating in the committee of my oral examination.

This work would not have been possible without the support of my family and friends. I want to thank my parents, my sister, my niece and especially Malthe for their encouragement, love and patience throughout the work and without whom this thesis would not have been finished. 


\section{Curriculum vitae}

\section{Persönliche Daten}

$\begin{array}{ll}\text { Name } & \text { Anna Müller } \\ \text { Geburtsdatum } & \text { 03. März 1986 } \\ \text { Geburtsort } & \text { Frankfurt/Oder } \\ \text { Nationalität } & \text { Deutsch }\end{array}$

\section{Ausbildungsweg und wissenschaftlicher Werdegang}

03/2011 - 06/2014 Wissenschaftliche Mitarbeiterin zur Promotion

Georg-August-Universität Göttingen, Abt. Forstbotanik und Baumphysiologie

Dissertation: "Communication between mycorrhizal fungi and poplar"

10/2008 - 02/2011 Master of Science-Studium in Pflanzenbiotechnologie

Leibniz Universität Hannover

Masterarbeit: „Gene Stacking mit transgenen Erbsen"

10/2005 - 10/2008 Bachelor of Science-Studium in Pflanzenbiotechnologie

Leibniz Universität Hannover

Bachelorarbeit: „Optimierung der in vitro Regeneration von

Brassica oleracea var. botrytis"

1998 - $2005 \quad$ Gymnasium Theodor-Heuss-Schule, Pinneberg

1996 - $1998 \quad$ Gymnasium Lerchenfeld, Hamburg

1992 - 1996 Grundschule Humboldt-Schule, Hamburg 